DISCOURSE STRUCTURE AS THE SCAFFOLDING OF STANCE STRUCTURE:

DEVELOPMENTS OF A CENTRAL CONCEPT IN A CENTRAL SITE

OF DISCURSIVE INTERACTION IN BIOETHICS

\begin{tabular}{c} 
A Dissertation \\
presented to \\
the Faculty of the Graduate School \\
at the University of Missouri-Columbia \\
In Partial Fulfillment \\
of the Requirements for the Degree \\
Doctor of Philosophy \\
\hline DAVID L ELLIOTT \\
MAY 2019 \\
Dard E. Brent, Dissertation Supervisor \\
MAY
\end{tabular}


(C) Copyright by David L. Elliott 2019

All Rights Reserved 
The undersigned, appointed by the dean of the Graduate School, have examined the dissertation entitled

\section{Discourse Structure as the Scaffolding of Stance Structure Developments in a Central Concept in a Central Site of Discursive Interaction in Bioethics}

presented by David Elliott, a candidate for the degree of doctor of philosophy, and hereby certify that, in their opinion, it is worthy of acceptance.

Professor Ed Brent

Professor Amit Prasad

Professor Richard Hessler

Professor Doug Steinley 
This dissertation is dedicated to my son, Alexander Elliott, my daughter, Margaret Elliott, my mother, Sandra Carman, and my partner, Elizabeth Moore, for their patience, support, and love through this long process. 


\section{ACKNOWLEDGEMENTS}

I should like to express my deep appreciation to my adviser and dissertation chair, Dr. Ed Brent, for his encouragement, incisive comments, sound advice, patience, and needed nudges. I am also grateful to committee members Amit Prasad and Richard Hessler for their helpful questions, critical comments, and support. A special thanks goes to my committee member from Psychological Sciences, Doug Steinley, a much valued teacher and adviser on all matters related to statistics and social network analysis. My thanks also go to Victoria Johnson, my former adviser, who helped guide me through the writing of the proposal for this dissertation. I owe a special thanks as well to Lydia Mai Ho-Dac, associate professor of linguistics at the University of Toulouse, for her directions, clarifications, and encouragement in our correspondence. 
TABLE OF CONTENTS

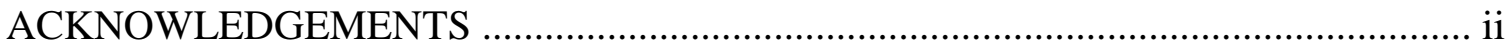

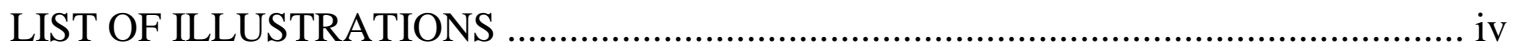

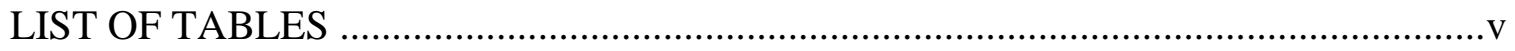

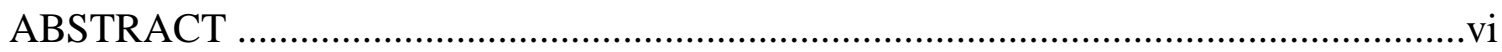

Chapter

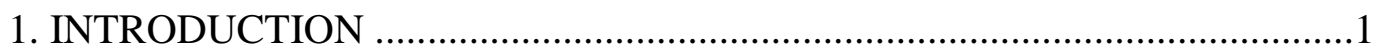

2. LITERATURE REVIEW .................................................. 8

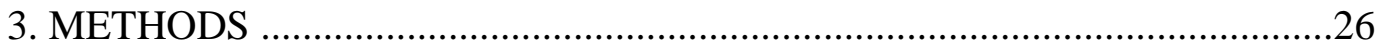

4. RESULTS I: MULTILEVEL AND STANCE STRUCTURE AND DISCIPLINARY PROMINENCE.......................................................... 41

5. RESULTS II: STANCES, INTERACTIONS, AND DISCIPLINES IN

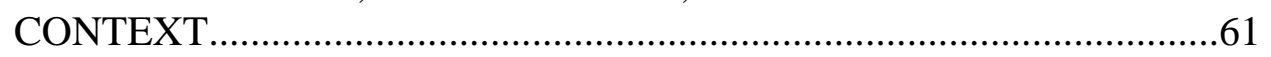

6. CONCLUSIONS AND FUTURE WORK ………………………................95

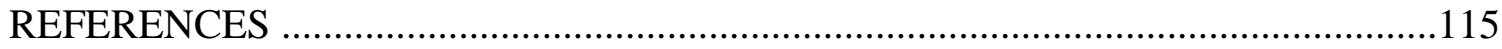

APPENDICES

A. ANNOTATED CHAPTER 3, "THE PRINCIPLE OF AUTONOMY," FROM BEAUCHAMP AND CHILDRESS, 1ST EDITION (1979) ......121

B. ANNOTATED CHAPTER 4, "RESPECT FOR AUTONOMY," FROM BEAUCHAMP AND CHILDRESS, 7TH EDITION (2012)...................153

VITA 187 


\section{LIST OF ILLUSTRATIONS}

Figure

3-1. Example of Display and Multi-level Annotations in Glozz

(Ho-Dac et al. 2010)............................................. 29

4-1. All Text and Stance Text by Level and Year.............................50

4-2. Prominence of All Cited Work by Discipline and Year.......................56

4-3. Prominence of Empirical Cited Work by Discipline and Year.................60 


\section{LIST OF TABLES}

Table $\quad$ Page

3-1. Legend for Text Structure Representation..................................

4-1. Chapter Text Measurements by Level (1979)............................45

4-2. Chapter Text Measurements by Level (2012) $\ldots \ldots \ldots \ldots \ldots \ldots \ldots \ldots \ldots \ldots \ldots \ldots \ldots$

4-3. Number and Length of Stances by Level (1979)............................48

4-4. Number and Length of Stances by Level (2012).........................49

4-5. Position of Stance Appearances by Text Segment (1979)....................52

4-6. Position of Stance Appearances by Text Segment (2012)....................53

4-7. Prominence Scores of All Cited Work by Discipline and Year....................55

4-8. Prominence Scores of Empirical Cited Work by Discipline and Year.............59 


\title{
DISCOURSE STRUCTURE AS THE SCAFFOLDING OF STANCE STRUCTURE: DEVELOPMENTS OF A CENTRAL CONCEPT IN A CENTRAL SITE OF DISCURSIVE INTERACTION IN BIOETHICS
}

\author{
David L. Elliott \\ Dr. Edward E. Brent, Dissertation Supervisor
}

\begin{abstract}
This study explored how a major concept and principle in the interdisciplinary area of bioethics, respect for autonomy, changed across the first and the seventh editions of the textbook Principles of Biomedical Ethics by Beauchamp and Childress, a period covering 33 formative years in the institutionalization and growth of bioethics. The question explored by the study was: what can the structure of the stance interactions between authors reveal about institutional changes and the relative position of different academic disciplines in bioethics over this period? A new, relational method of content analysis that draws on methods developed in applied linguistics, concerning evaluative or stance-taking language and on the discourse or rhetorical structure of expository texts, was used in pursuing an answer to the question.

Between the first and seventh editions, the core of Beauchamp and Childress's concepts of respect for autonomy and informed consent did not change significantly, though additions and refinements were added in the seventh edition. Philosophy retained a prominent place in the discussion across editions, but medicine, combined with other biomedical sciences and professions, slightly overtook philosophy's place of prominence. The interactions between these disciplines were, on balance, cooperative, and some division of labor was evident in the seventh edition, with philosophers used mostly for conceptual analysis and biomedical disciplines used mostly for technical and empirical support of the concepts. The overall number of disciplines represented in the bioethics discourse on autonomy grew exponentially.
\end{abstract}




\section{Chapter 1}

\section{Introduction}

Over the course of the 1970s, bioethics emerged in the United States with claims of being a profession and an academic discipline. Sociologist Andrew Abbott (1998, 2001, 2005) has theorized professions and academic disciplines as emerging, changing, and disappearing through interactions within ecologies of competition with other professions or disciplines for the legitimation of their control over certain areas of work. He argues (1998) that one key process through which such legitimation takes place is through the development of a system of abstract academic knowledge that is institutionalized in leading textbooks.

According to Abbott (1998), the professional knowledge of immediate importance to practitioners is organized around the efficacy of its use. In contrast, the academic knowledge embodied in textbooks is abstracted from practice and reorganized along more logical and rational lines. A profession's abstract knowledge system has three main tasks: 1) to legitimate the profession's jurisdiction by aligning it with major cultural values, such as rationality, logic, and science; 2) to generate new knowledge through research that will benefit professional knowledge in use, and 3) to instruct professional students. Abbott argues that all three of these tasks can affect the profession's competitive position within the ecology of professions. 
Thus, textbooks, while not the only data source for institutional research into professions and disciplines, nevertheless are a key one to analyze. In the case of bioethics, a clear consensus of sociological researchers of bioethics (e.g., Evans, 2012; Fox and Swazey, 2008; Orfali and De Vries, 2010; De Vries, Dingwall, and Orfali, 2009) identifies Principles of Biomedical Ethics by Tom L. Beauchamp and James Childress as the dominant textbook institutionally and in terms of influence from its first publication in 1979 through its seventh edition in 2012. As such, this textbook not only serves as a presentation of the abstract academic knowledge that served to legitimate bioethics and to educate its practitioners, it also provides some documentation of the periodic changes that knowledge has undergone over the course of the seven successive editions, covering 23 years.

However, a problem arises when considering how to analyze this text and how to conceptualize written academic discourse in general. Is it to be viewed as merely a monoglossic statement listing and elaborating upon a body of abstract academic knowledge, or is it constructed through authors' claim-makings and stance-takings vis-àvis other authors and its reading audience? Does it reflect the pronouncements of an institutional actor writing from a preestablished position of accepted dominance, or is it an interactional turn by an author seeking to establish such a position through carefully constructed rational (and rationalized) argument?

Abbott, in line with other relational sociological theorists such as Harrison White (2008), Charles Tilly (2008), Paul McLean (2007, 2017), and Ann Mische (2007, 2011), 
theorizes social structures as emerging and changing through the interactions of social actors, whether individual or collective, and in different social settings. Applying this theoretical approach to the case of the system of professions, Abbott argues that actors make jurisdictional claims over areas of work, with actors from other professions making possible counter-claims and with governmental or public actors involved in the interactions as jurisdiction-granting audiences. From this perspective, a textbook is not merely a logical statement of a system of knowledge, although it is that. It is also a body of knowledge claims, argument claims, and presumably, in the case of a professional textbook, some of its jurisdictional claims. In other words, a textbook has interactional aspects.

However, existing social scientific methods of text analysis such as content analysis, whether in its more traditional or its more contemporary approaches, do not adequately map and analyze written academic discourse such as a textbook or chapter in terms of its interactional features in combination with its content, which in this study I attempt to examine primarily through the texts' claim-making moves. For the purposes of this study, claim-making is understood here to be synonymous with and to be achieved through stance-taking or evaluative statements.

Also, current methods do not account for one of the most distinctive characteristics of written academic discourse, as opposed to the verbal discourse of faceto-face interaction, which is its hierarchical discursive or coherence structure. It is arguably this structure which makes written discourse the premier vehicle for presenting 
a system of academic knowledge and for making arguments for why it should have legitimate jurisdiction over particular areas of professional work.

In line with Benarama, Tobaoda, and Mathieu's (2017) recent argument and supporting evidence, the hierarchical discourse structure of a text assists readers and analysts in identifying which authorial stances are more central and which are more peripheral to its overall argument, the assumption of this study is that the hierarchical discourse structure of a text provides the contextual scaffolding for examining the structure of the stance-taking and claim-making moves its authors make. With a view toward studying professional and academic interaction in the text, it follows that this discourse structure can also help to identify the degree of centrality of the attributions (i.e., citations and references) of a text.

I distill these considerations into the study's research questions, one principal and one subsidiary.

\section{Research Question:}

What do the stance structures of successive editions of the "Autonomy" chapter in Principles of Biomedical Ethics reveal about the discursive interactions through which its authors constructed and maintained a key principle within the body of abstract academic knowledge they used to legitimate the bioethics profession?

Each individual stance identified in the chapters, which may be as short as an independent clause or at least as long as a paragraph, is expected to be a prime site of 
interactions with previous authors and their textual statements. The qualitative text analysis reported in Chapter 5 will interpret the contextual meaning of each stance and identify any citations related to it. These are the ingredients of a stance interaction through which the textbook authors, Beauchamp and Childress, position themselves visà-vis other authors. In other words, the interactants typical will be aligned or disaligned, and Chapter 5 will note these aspects of the interactions.

However, the focus of the analysis of stance interactions will not be on individual cited authors, whose names will usually not even be noted in the analysis. Instead, the focus will be on the academic disciplines of the cited authors as measured by their discipline(s) of training. In other words, the interactions will be viewed more as interactions between disciplines.

Once the multi-level discourse structure of a chapter has been identified, individual stances can be analyzed in terms of their place in the context of the discursive structuring of the overall argument. The working assumption is that the structure of the stance-making moves follows from the multi-level discourse structure, and the main research question asks what this stance structure reveals about the institutional work done by the interactional moves through which the authors establish their conception of autonomy.

\section{Subsidiary Research Question:}


What can a formal graphical analysis reveal about the stance and discourse structures of the "Autonomy" chapter of Principles of Biomedical Ethics across successive editions?

By a formal graphical analysis, as will be explained in Chapter 3, I mean that the multi-level discourse structure and individual stance sentences or clauses will be identified through a text analysis and annotation and represented in Word documents through the use of a color-coding scheme. In this graphical scheme, adjacent or overlapping zones of multilevel structure are mapped out and measured in characters, with stances falling within the zones. Statistics describing aspects of the discourse and stance structures of the chapter texts as graphs will be analyzed and presented in Chapter 4.

\section{Chapter Overview}

In Chapter 2, I will motivate these research questions by presenting background literature on the interdisciplinary academic field of bioethics and on the Principles of Biomedical Ethics. Harrison White's relational theory of identities, their strategic interactions, and the social networks that form from them are discussed next. I then relate White's sociological theory to research by linguists on stance-taking and evaluative language.

The limits of traditional and more contemporary approaches to formal content analysis are discussed, followed by a presentation of alternatives developed by linguists 
through their development of conceptual and analytic tools for understanding the cohesion, coherence, and structure of discourse at different levels of granularity.

In Chapter 3, I describe how and why I chose the sample of "autonomy" chapters from Principles and the software I used to annotate and analyze these sample chapters, including Microsoft R Open 3.51, RStudio 1.1.463, Microsoft Word 365, and Microsoft Excel 365. Then, I list the procedures used in the analysis, from cleaning and otherwise preparing the data through developing the annotation and graphical model used. This is followed by my procedural approach for the qualitative analysis.

In Chapter 4, I report the results of the multi-level annotation, measurement, and analysis of the discourse structure, stance structure, the prominence of the disciplines of the authors by of cited works by chapter, and the prominence of the disciplines of the authors of empirical cited works by chapter.

In Chapter 5, I report and analyze the stances and interactions of each chapter in their context within the textual structures.

In Chapter 6, I draw conclusions, identify limitations, and suggest future research. 


\section{Chapter 2}

\section{Literature Review}

\section{Bioethics and Principles of Biomedical Ethics}

Significant events in the institutionalization of bioethics as an interdisciplinary area of study included the founding of the Hastings Center in 1969 and the Kennedy Institute of Ethics at Georgetown University in 1971, the issuing of the Belmont Report in 1976, and the publication of the textbook Principles of Biomedical Ethics in 1979. Many other ethics centers, ${ }^{1}$ mostly affiliated with universities across the U.S., were to follow (Fox and Swazey 2008, Jonsen 1998).

Congress passed the National Research Act of 1974, which established the National Commission for the Protection of Human Subjects in Biomedical and Behavioral Research. The Act also mandated a study to identify ethical principles that should guide research practice. With commissioned background papers in ethical principles in hand, the Commissioners, along with their staff and advisers, met in Belmont House in Maryland for four days in 1976 to synthesize and report its findings. The product of the meeting was the Belmont Report, which guided federal regulations of research practice.

\footnotetext{
${ }^{1}$ Elliott (2011) counted 54 ethics centers in the U.S. granting graduate degrees.
} 
The author of one of the background papers, theologist James Childress, and the staff philosopher who wrote the polished final version of the Belmont Report, Tom L. Beauchamp, began during the Belmont meeting to write a textbook together centered on the principles developed in the Report. Their textbook, Principles of Biomedical Ethics, was published three years later in 1979.

The arguments of theologians held the most sway in the early years of the 1960s and early 1970s, but philosophers came to dominate the field, and the philosophical backgrounds they drew upon came principally from the analytic philosophy dominant in Anglo-American philosophy departments for much of the latter half of the Twentieth Century. Analytic philosophers tended to practice a rigorous method of logical and rational analysis, and their approach to ethics tended toward universal rules and principles of conduct that were ahistorical, acultural, and asocial. Any other approach was expected to lead down a slippery slope to moral relativism (Fox and Swazey 2008, Evans 2012).

This approach of analytic philosophy led to an influential conception in bioethics of a common morality assumed to be followed by any competent moral person at any time and in any place. Liberal theologians favored the common morality approach since it was thought to bridge the divides concerning ethical questions in the public and secular spheres between people of otherwise differing religious and moral views. For example, the natural law tradition in Roman Catholic theology was considered to be consistent with the common morality concept.

Chiefly through the Belmont Report and Beauchamp and Childress's textbook, common morality took the form of "principlism," an approach to ethical decision making 
guided by principles. The Belmont Report discussed three central principles, 1) Respect for Persons, 2) Beneficence, and 3) Justice. The Principles textbook considers four principles (with Beneficence divided into Beneficence and Nonmaleficence): 1) Respect for Persons, or the Principle of Autonomy, 2) Beneficence, 3) Nonmaleficence, and 4) Justice (Fox and Swazey 2008, Evans 2012).

Beauchamp and Childress (1979) argued that ethical principles were sufficient to guide ethical decision making in actual cases without resort to ethical theories. Evans (2012) argued that the principles served as metrics of commensuration for bioethics regulators and practitioners, simplifying ethical decision making and making it more calculable through the ability to ignore any details of an ethical case that do not pertain to the principles.

Although the Belmont Report and the Principles textbook present the different principles as equally important, in Beauchamp and Childress's hands, and in much subsequent bioethical practice, autonomy came across to some other prominent bioethics researchers as the most central of the principles (e.g., Jonsen, 1998). It is for this reason that the autonomy chapter is an obvious candidate for a chapter from the textbook to select as a sample for analysis.

\section{A Relational Theoretic Approach to Identities, Strategic Interaction, and Social Network Formation}

Like George Herbert Mead (1934, 1938), Charles Tilly (2008) considers ontological questions and assumptions to be more important than epistemological ones. Differentiating his ontological perspective from those that focus on individuals or holistic systems as the principal social entities for study, Tilly's relational realism places 
transactions or interactions among social settings at the center of efforts to explain social processes, structures, and the communicative, cultural accompaniments of interaction. Harrison White was another relational sociologist whose major theoretical work, Identity and Control: How Social Formations Emerge (2008), recommended a closer attention to language and social networks in social explanation. In this work, White theorizes uncertainty as central to the human and social condition. He uses economist Frank Knight's (1921) definition of uncertainty as distinct from risk insofar as risk is to some degree predictable, therefore allowing a degree of planning, whereas uncertainty is completely unpredictable.

An identity, which can be defined at different levels such as the individual or the organizational, emerges when faced with a situation of uncertainty in which it seeks footing through an effort at control. Footing, a term adapted from Goffman $(1974,2001)$ in a context in which it is largely synonymous with the concept of stance that is central to this study of stance and discourse structures in written academic discourse, is used by White to signify a social and semiotic position taken in a control effort by an identity to overcome uncertainty. Identities seek footing that is reliable and somewhat durable, and the control efforts of identities in seeking secure footing lead to the emergence of larger social formations.

In the context of this study, the identity is the authors'. Stances are taken vis-à-vis the claims of cited authors, in the authors' claims toward knowledge and professional jurisdiction in which they and their professional are positioned, and toward expected readers. Through their stance-taking, the authors seek control in terms of some secured 
footing in ongoing discursive interactions which simultaneously reflect an important site of professional competition for jurisdiction.

\section{Language in White's Theory}

White views language as a site of power and unequal resources, similar to theories of the political economy of language theorized by Bourdieu as well as by linguistic anthropologists Judith Irvine and Susan Gal. Drawing largely from sociolinguistics, specifically from anthropologists of language and folklore and from systemic functional linguists and corpus linguists, White (Fontdevila and White, 2013; White and Godart, 2010; Godart and White, 2010; see also Fontdevila, 2010) emphasizes the reflexive and indexical aspects of language as key to understanding social action and social formations. Language is reflexive when used to refer to itself, a prime example of which is what applied linguist Ken Hyland (2000) calls metadiscourse in his studies of written academic discourse as social interaction. Language is indexical when it points beyond its semantic reference to aspects of its context.

Linguistic indexing is central to the concept of register in systemic functional linguistics, and attempts by identities to secure footing in contexts of uncertainty through attempts at relational control is the indexical object of most importance in terms of White's theory.

However, the sociolinguistic studies central to the discussion in Fontdevila and White (2013, Fontdevila 2010) have more to do with conversation and face-to-face interaction which, while an important part of academic interactions, have some but less significance for written academic discourse. The linguistic theories and research that 
have the most relevance for written academic discourse are those by the systemic functional, cognitive (or discourse) functional, and computational linguists whose concepts and theories are outlined below.

This study aspires to contribute to relational theories such as White's by exploring the strategic and other interactions embodied in the stance structures of written academic discourse.

Some similarity of purpose and theoretical approach can be found in McLean (2007), who studied patronage letters in Renaissance Florence in terms of strategic interaction, culture, identities, and social networks. While McLean's patronage letters represent a genre with many differences from textbooks, including its much briefer length, and though he does not take into account discourse structure in his study, his is the prime example of analyzing written texts as sites of strategic interaction.

\section{Linguistic Approaches to Stance-Taking and Evaluation}

Most linguists studying academic discourse in its reflexivity, indexicality, and pragmatics, focus on stance-taking and evaluative language, different terms for studying roughly the same linguistic phenomena. Also, in the linguistics literature on stance-taking and evaluative language in written discourse, these terms are often used as roughly synonymous with Goffman's term footing. Previous studies have found that most of the evaluative stances taken in written academic discourse concern epistemic claims, while a minority are usually termed "affective," or expressing the subjective perspective of the writer toward a discursive object (e.g., Hyland 2004 [2000]).

The systemic functional linguistics associated with Michael Halliday and colleagues offers a complete linguistic theory from the lexical level through the clausal 
level of the theory's functional grammar, to analysis at the level of entire texts (and their coherence and cohesiveness) and beyond texts to the analysis of genres and registers. Systemic functional linguistics focus on semantics and on language's social semiotic functions. At every level of language, the choices made by language users in the context of all possible linguistic choices in that context are central, as are the subsequent possibilities of choice based on previous choices.

J. R. Martin and P. R. R. White's (2005; see also Hood 2010) appraisal theory is the systemic functional approach to stance-taking or evaluative language. Martin and White's approach is dialogistic, drawing heavily from Bakhtin, and is designed to focus on the in-depth analysis of single texts. According to Hunston (2011), Martin and White's theory in part supersedes and replaces aspects of her own corpus linguistic approach to evaluative language. However, Hunston (2011) also points out that Martin and White's appraisal theory is based more on empirical studies of conversation or verbal discourse, whereas her corpus linguistic theory of evaluation is based on empirical studies of written academic discourse in samples of research articles.

Discourse functional linguist John Du Bois (2007, 2011), like Martin and White (2005), 1) approaches stance-taking in a dialogistic manner à la Bahktin and 2) focuses on conversation or verbal discourse. Du Bois (2007) formalized the notion of the stance triangle for studying stance as it develops dialogistically in conversations as a speaker takes a stance toward an evaluative object and, in the process, both positions him- or herself vis-à-vis the object and aligns or disaligns him- or herself from an interaction partner. 
Susan Hunston (2011) takes a mixed methods approach to evaluative language in written academic discourse, with the qualitative part of her analyses studying concordance lines that allow comparisons of particular words in their various contexts of use within a corpus. Hunston also notes that the more implicit nature of evaluation in written academic discourse makes qualitative analysis necessary if a researcher seeks to catch as many instances of evaluation as possible. Even the corpus stance-taking (or evaluative) studies of Biber and colleagues and of Hyland and colleagues, which Hunston categorizes as quantitative, require at least a fair amount of qualitative work to supplement the semi-automated portions of their analysis.

Biber and colleagues, in their approach to stance taking, identify words and phrases that consistently serve as stance markers, and they perform descriptive and statistical analyses of the types of stances taken in a type of text in comparison with another type of text. Biber has developed what he calls a multidimensional approach to register analysis based on a factor analysis on a set of seven different polarities defining the contextual features key to any linguistic register, which he uses in comparative studies of different registers, such as written vs. spoken academic registers (Biber and Conrad, 2009).

Biber, in association with his student Bethany Gray, has identified the largest collection of stance markers, including those identified by Hyland in his studies, and including new markers only recently discovered. The stance markers of Gray and Biber (2015) will be used in this study as part of the premarking of the sample chapters to be annotated. However, like other linguistic markers, stance markers can be no more than 
suggestive aids to qualitative analysis since evaluation and stance-taking can be implicit and can occur explicitly without common markers.

Computational linguists Benemara, Toboada, and Mathieu (2017) discussed the need for analyzing evaluative language in texts within its contexts of discourse structure as opposed to the more common "bag-of-words" approaches such as in sentiment analysis and the opinion mining of texts and present some empirical evidence backing up the hypothesis behind the pursuit of this study that discourse structure provides the scaffolding for evaluating the different levels of a text's stance structure.

The work of applied linguist Ken Hyland $(2000,2012)$ unites to a large degree the relational theories of interaction above with the linguistic studies of evaluation and stance-taking in texts. He also uses Goffmanian concepts of stance and footing in interaction so central to White's (2008) and McLean's $(2007,2017)$ theories. Hyland's approach is also similar to Martin and White's (2005) in their Appraisal framework in attending to the degree of dialogism or mulivocality present in written academic discourse.

Hyland (2000) analyzed a sample of textbooks across disciplines from the natural to the social sciences to the humanities. Of particular interest to this study were his findings for philosophy, since Principles of Biomedical Ethics is written by authors trained in philosophy and theology. Hyland used markers of metadiscourse in his study of textbooks. Metadiscourse is discourse distinct from a text's propositional content. In combination with layout features, some types of metadiscourse serve to organize a text and to guide readers through it. Hyland identifies other types of metadiscourse as interactional, including language that indicates an author's stance or attitudes toward her 
or his propositions, toward the propositions of cited authors, or toward her or his relationship to readers. Hyland's concepts of metadiscourse and markers for identifying it overlap with those of other linguists of evaluation such as Martin and White (2005), Hunston (2011), Gray and Biber (2015), and Du Bois (2007).

Of particular interest for this study, Hyland (2000) found that philosophy textbooks are more like the other paperback monographs in the humanities or social sciences. While science textbooks are often monoglossic discourses that collect the accepted or canonized knowledge of a discipline, philosophy textbooks commonly are heteroglossic and sites for new theoretical arguments.

Philosophy textbooks and philosophy articles use much more personalized and openly disputational engagement with other authors and more use of personal pronouns and stance language, the relative opposite of the conventional detached and neutral scientific author writing in a passive voice.

These characteristics of philosophical discourse as can be expected to be found in the Principles of Biomedical Ethics textbook indicate a sample of discourse to study that is likely to have a rich interactional and stance structure expected to be fairly readily discernable.

However, though Hyland's theory informs this proposed study, his method does not take account of discourse structure and stance structure. Like traditional content analysis, he does not go beyond comparative descriptive statistics of the counts of stance and metadiscursive markers in texts in his sample corpus. 


\section{Content Analysis}

Social scientists typically turn to content analysis for the analysis of written documents such as a textbook. Traditional content analysis concentrated mostly on counts of key topic words or counts of events, as in the work of Kriesi and colleagues on counts of protests and other contentious political events that Charles Tilly (2008), like Popping, discusses in terms of being an earlier approach to text analysis.

Semantic text analysis was developed by a former colleague of Tilly's, Robert Franzosi, who drew from structuralist theories of narrative form (e.g., Propp). Franzosi coded Italian contentious events from newspaper accounts in terms of S-V-O (subjectverb-object) triples. Tilly (1995, 1997, 2008, Tilly and Wood 2003) adopted this approach in his coding of contentious events, mainly in Great Britain, recorded in newspaper accounts. Tilly coded these semantic triplets in terms of groups of disgruntled citizens (the Subject) making a type of claim (the Verb) against a target of the claim (the Object), sometimes capitalist owners but usually governments. Tilly conceptualized these triplets in terms of network relations between collective actors and not merely narratives. He also conceptualized them in terms of repertoires of contention, which are cultural rituals or frameworks widely shared within a time and place but that allow for flexibility and improvisation in their use.

According to Popping, text analysis reached a new level of sophistication in the network text analysis of Kathleen Carley, which she also called map analysis in its earlier form. Carley used interview data in her early work, and drew semantic networks from this data to construct what she termed "mental maps" of teams or other groups. Diesner and Carley (2005) eventually developed a multi-matrix approach to text analysis, which 
represented, in simple terms, the who, what, where, when, and how represented in a text's content.

In theory, Popping is correct in considering network text analysis such as Carley's to be an advance over semantic triples. In practice, however, the verbs drop out in Carley's map analyses. Popping explains that the verbs tend not to recur regularly enough to be included. However, Tilly and colleagues have shown that verbs can be retained in the analysis by reducing them to broader, more encompassing verb categories of significance with the assistance of statistical methods such as multidimensional scaling or blockmodeling.

Mohr and Bagdanov (2013) also reviewed the development of content analysis in their introduction to a special issue of Poetics devoted to the use of topic modeling in the social sciences, a technique they declare to point to the future of content analysis. A number of leading relational and cultural sociologists, such as Paul DiMaggio, Ron Breiger, and Daniel McFarland, contributed empirical demonstrations of the technique in the special issue. Topic modeling is a "bag-of-words" statistical technique which clusters similar words into topics that are ranked by their proportion of occurrence in a text. The technique can be used to identify texts with similar semantic patterns as similar in content, as determined by clusters of individual words. Like Carley's map analysis and meta-matrix analysis, topic modeling is a computationally efficient way of finding semantic patterns in vast quantities of text. However, the hypothesis underlying this study is that the hierarchical discourse structure (also called coherence or rhetorical structure) of a text matters, especially for a text analysis examining the interactions and stancetakings in written academic discourse. 


\section{Discourse Structure: Cohesion, Coherence, and Bottom-up Approaches to Discourse}

\section{Structure}

The study of coherence in discourse was first approached by linguists of the Prague functionalist and systemic functionalist schools in terms of surface markers of cohesion. By 1980, texts were seen as cohesive either a) through topic continuity through referential links, or, when referential links end, through an explicit semantic connecter. In her early psycholinguistic experiments of coherence, however, Giora found that neither type of explicit cohesion marker is necessary for the coherent organization of texts. In other words, cohesion is not necessary for coherence in language (Giora 2014).

Giora later posited a Relevance Requirement for a coherent discourse, which states that all of a discourse's propositions must be relevant to a DT (discourse topic), which is prototypical or general proposition which subsumes all subsidiary or similar propositions. A discourse with a proposition that digresses from relevance is still coherent if it is explicitly marked as connected to the discourse. Giora's Graded Informativeness Requirement states that a discourse is organized such that each new or more specific proposition following a general DT must be more informative concerning the DT or at least as informative as preceding propositions. Again, the exception are digressive propositions, which must be explicitly marked as connected to the discourse (Giora 2014).

Giora's experiments found that coherent texts are processed more quickly than incoherent ones or ones that include digressions. Giora's experiments used short texts, and her theory of discourse coherence relates most clearly to discourse at the level of the paragraph. However, her theory is related to the concept of topical chains (TC) that will 
be used in the top-down analysis to be employed in this study, and TCs are found at different levels of granularity in a text.

In functional linguistics, the term "discourse" refers to the level of a text beyond single clauses or propositions, and functional linguists collaborated with computational linguists to develop the first bottom-up approach to discourse structure, RST (Rhetorical Structure Theory). RST is a descriptive theory of coherent discourse structure that posits rhetorical relations that connect different EDUs (elementary discourse units, which generally are identified at the level of the clause) into discourse. ${ }^{2}$ These are relations between EDUs that an annotator (or reader) can plausibly interpret as capturing the author's rhetorical intentions.

Most RST relations are assumed to connect a nucleus EDU to one or more satellite EDUs, and graphically an RST mapping of the rhetorical structure of a text is represented as a hierarchical tree, with relations as edges connecting higher nuclear EDUs with lower satellite EDUs. If the satellite EDUs are removed from an RST tree structure of a text, the remaining nuclear EDUs still make a mostly coherent, understandable text that also is a rough summarization of the text.

Originally, about 30 relations were identified based on empirical studies (Mann and Thompson 1987, 1988; Toboada and Mann 2006a), and one way of categorizing the relations suggested was into "subject matter" and "presentational" relations. In annotating a corpus of Wall Street Journal articles, Marcu and colleagues (2000) expanded the number of rhetorical relations to 85, and it was the expanded set which Elliott (2017)

\footnotetext{
${ }^{2}$ The terms rhetorical relation (as used in RST), discourse relation (as used in SDRT, or segmented discourse representation theory), and coherence relation (which can apply to both theories) are roughly synonymous and interchangeable.
} 
used to annotate a section of the 1979 chapter of the autonomy chapter from Principles using RSTTool software ${ }^{3}$.

Critics of RST point out that the requirement that relations connect only adjacent EDUs does not account for long-distance discourse relations or for crossed dependencies between relations (Asher and Lascarides 2003; Wolf and Gibson 2005). In their own theories and accompanying annotation schemes, these same critics use a graph (or network) representation, with EDUs as nodes and discourse relations as edges.

Building from the theoretical perspective of dynamic formal semantics, which uses formal logical models to evaluate meaning relationships, Asher and Lascarides (2003) developed SDRT (Segmented Discourse Representation Theory). In contrast to RST's conceptualization of rhetorical relations as author intentions, discourse relations are based on semantic relations between EDUs. Semantic criteria for discourse relations results in SDRT positing a smaller number of distinct types as compared to RST, where rhetorical relations are descriptive and empirically derived. As Asher and colleagues put it $(2017,5)$, "SDRT insists on a semantic characterization of relations, which provides a method of verifying whether two relations are the same, one entails the other, are independent, or are incompatible."

An advanced knowledge of formal logic is not required to annotate texts using SDRT. Asher and colleagues (2017) have found that even naïve annotators in their recent ANNODIS project chose the correct semantic scope of discourse relations $95 \%$ of the time. Nevertheless, the bottom-up approaches of both RST and SDRT are much more time-consuming for the annotation of longer spans of text like the chapters to be

\footnotetext{
${ }^{3}$ http://www.wagsoft.com/RSTTool/
} 
examined in this study, so a top-down approach to discourse structure is preferred.

[However, the top-down approach to be employed here also represents discourse structure as graphical (or network) structures as are those used in SDRT. Drop?]

\section{A Top-Down Approach to Discourse Structure}

Dijk (1980) is among the few who have theorized discourse structure at a more global or macro level. His theory of macrostructures and superstructures focused on the topical contents of propositions and how they connected into macrostructures at higher levels. He posited several "derivation or inference rules" for relating propositions to macropropositions. These included DELETION for propositions irrelevant to a macroproposition's interpretation and which cannot be inferentially subsumed under it, SELECTION for propositions that are relevant and subsumable, GENERALIZATION for connections to conceptually more general macropropositions that abstract from the semantic detail of its supporting propositions, and CONSTRUCTION for a sequence of propositions that together define or make up the steps involved in a macroproposition (e.g., the more detailed steps involved in driving to the post office). Propositions at higher levels of macrostructure were mostly more general than those at lower levels, recalling the Graded Informativeness Requirement of Giora's theory and the theories behind bottom-up annotations like RST and SDRT, where such relations as ELABORATION are among the most frequent ones found in expository discourse.

Dijk conceptualized superstructures as conventional and functional containers for macrostructures. Some examples of superstructures include the highly standardized sections of journal articles in the natural sciences, the informal argument structure first described by Stephen Toulmin (1958), and Propp's narrative structure. 
Despite aspiring to be a theory of global text structure, the annotation procedures for macrostructure identification in Dijk (1980) are just as time-intensive for annotators as the bottom-up approaches of RST and SDRT, and Dijk used them for shorter texts, mostly newspaper articles or magazine advertising texts.

A more promising approach to top-down analysis, and the one to be used for this study, is the one employed recently in the ANNODIS project and described in Ho-Dac et al. (2010, 2011, 2012), Péry-Woodley et al. (2017), and Asher et al. (2017). This topdown approach to discourse structure focuses on the identification and annotation of ESs (enumerative structures) and TCs (topical chains), which have been found to be very common in expository texts such as Principles.

An enumerative structure consists of a listing (or enumeration) of two or more EDUs, with an optional trigger, which introduces the ES and which may refer to what is to follow in it, and a closure, which often summarizes what has preceded in the ES. An ES can structure topical, temporal, or rhetorical connections between a set of enumerated EDUs.

A topical chain is identified by a continuity of topical referential links, similar to the links of cohesion described by Giora (2014). According to Ho-Dac et al. $(2010,98)$, these referential links include “...proper names, definite NPs [noun phrases], demonstrative NPs, etc. and anaphoric reference via pronouns."

ESs and TCs are recursive. In other words, an ES or a TC can be nested within a larger ES or within a larger TC. ESs and TCs also occur at multiple levels of granularity. In other words, an ES or a TC could be contained within one paragraph or could structure an entire section of a chapter or an entire chapter. This points to the possible complexity 
as well as multilevel structure of the network representation resulting from this type of top-down analysis. It also points to the promised value of this top-down annotation for mapping key aspects of both the global and more local levels of a text's discourse structure. Some of these discourse structures may be entirely embedded within higherlevel ones that span more of the text, or else the structures may only partially overlap.

The multi-level approach using top-down annotation procedures of Ho-Dac and colleagues (Ho-Dac et al., 2010, 2011, 2012; Asher et al., 2017; see also Power, Scott, and Agha, 2003) has been successfully applied to the annotation of longer texts in the ANNODIS corpus, including linguistics articles from the proceedings of a conference and full Wikipedia entries, using the Glozz annotation software tool developed by Widöcher and Mathet (2012) for use with both the bottom-up SDRT annotations and the top-down annotations for the ANNODIS corpus project.

\section{Research Question:}

What do the stance structures of successive editions of the "Autonomy" chapter in Principles of Biomedical Ethics reveal about the discursive interactions through which its authors constructed and maintained a key principle within the body of abstract academic knowledge they used to legitimate the bioethics profession?

\section{Subsidiary Research Question:}

What can a formal graphical analysis reveal about the stance and discourse structures of the "Autonomy" chapter of Principles of Biomedical Ethics across successive editions? 


\section{Chapter 3}

\section{Methods}

Introduction. This study seeks to answer its research questions largely through the exploratory use of a new approach to text or content analysis that attends to text and stance structures. It follows the mixed-method logic presented in Spillman (2014) and Bail (2014). The traditional view among quantitative researchers was that qualitative methods had value for exploring newer areas of study and in developing concepts and categories to be more scientifically studied using the statistical inference of hypotheticodeductive methods. Bail (2014), and especially Spillman (2014), reverse this order, arguing that formal, quantitative methods are useful in the digital age for using data reduction and pattern recognition techniques in identifying samples for a closer qualitative analysis. In place of hypothesis testing through statistical inference, the ultimate explanatory logic is one of qualitative inference.

Adequate data is collected for this study to permit some statistical modeling and inference. However, that is left for possible future work, and only descriptive statistics will be used to summarize aspects of the data. Other aspects of the data, such as of the stance structure and pattern of interactions, are left to qualitative analysis.

Sample. The sample consists of the principle of autonomy chapters of Principles

of Biomedical Ethics by Beauchamp and Childress from the first and most recent editions of the text. This will include Ch. 3 of the first edition, "The Principle of Autonomy" 
(1979, 38 pages including footnotes) and Chapter 4 of the seventh edition, "Respect for Autonomy" (2012, 49 pages). The chapters from these two editions allow a view of the development of the principle over a period of 33 years. The sample is chosen to be of a manageable size for a dissertation, especially one using newer and more exploratory methods.

Software. The software used in the data analysis included Adobe Acrobat Pro DC for the optical character recognition (OCR) of scanned texts and for converting .pdf files to accessible .txt files. Microsoft Word 365 was used for cleaning the data, for identifying and marking stance and topical chain markers, for annotating the text for stance clauses and sentences, for annotating the multilevel text structures (macro topical chain and enumerative structure), and for measuring the lengths of these stances and structures.

Microsoft Excel 365 was used for matching the list of stance and structural markers to the words in the sample chapters, for storing data on text and stance measurements, on the disciplines of cited authors and works in their textual context, on the interactions of the textbook authors through their stances, and for calculating the descriptive statistics reported in the tables and figures in Chapter 4. Microsoft R Open 3.5.1 ${ }^{4}$ statistical software through the RStudio $1.1 .463^{5}$ integrated development environment (IDE) was used for parsing the sample text into word lists and for constructing the bar plots of results in Chapter 4 .

The original plan was to follow the ANNODIS project researchers in using Glozz, version $2.0 .1^{6}$ (2014) for visually navigating the chapters at both the global and local

\footnotetext{
${ }^{4}$ https://mran.microsoft.com/open

5 https://www.rstudio.com/

${ }^{6}$ www.glozz.org
} 
levels, for finding and annotating the stance and structural markers, and for annotating the multilevel discourse structures of the chapters. Figure 3.1 illustrates a working display of top-down annotation in Glozz as given in Ho-Dac et al. (2010, 103, Figure 1).

In preparation for annotating the chapters, Microsoft Visual Studio 2017 was used to compose, edit, and debug the annotation models for Glozz in extensible markup language (.xml) files, following Ho-Dac and colleagues' use of the TEI-P5 guidelines. ${ }^{7}$

\section{Text Annotation Procedures.}

Scanning and Data Cleaning. The two sample chapters were scanned into .pdf files using Adobe Acrobat Pro's optical character recognition (OCR) tool to make the data machine readable as characters for analysis. The files were then saved as plain text (.txt), the format needed for loading the data into the Glozz annotation software. However, the files needed to be saved as accessible text files, which also have the .txt extension, rather than as plain text, so that all of the pages of the chapters could be captured.

Although Adobe Acrobat Pro's OCR tool correctly recognized most of the characters from the scanned pages, manual corrections had to be made to the data by carefully checking it against the original book chapters. The chapter, section, subsection, paragraph, and sentence format of the text was relevant to the analysis and was retained in the cleaning process, as were citations and chapter references. However, the original page headers, page numbers, page breaks, and line breaks were not relevant. Therefore, they are removed from the data during the cleaning process. The .txt files were loaded into Glozz to make the small formatting adjustments necessary for the data to be

\footnotetext{
${ }^{7}$ http://www.tei-c.org/guidelines/p5/
} 
Figure 3.1. Example of Display and Multi-level Annotations in Glozz

\section{(Ho-Dac et al. 2010)}

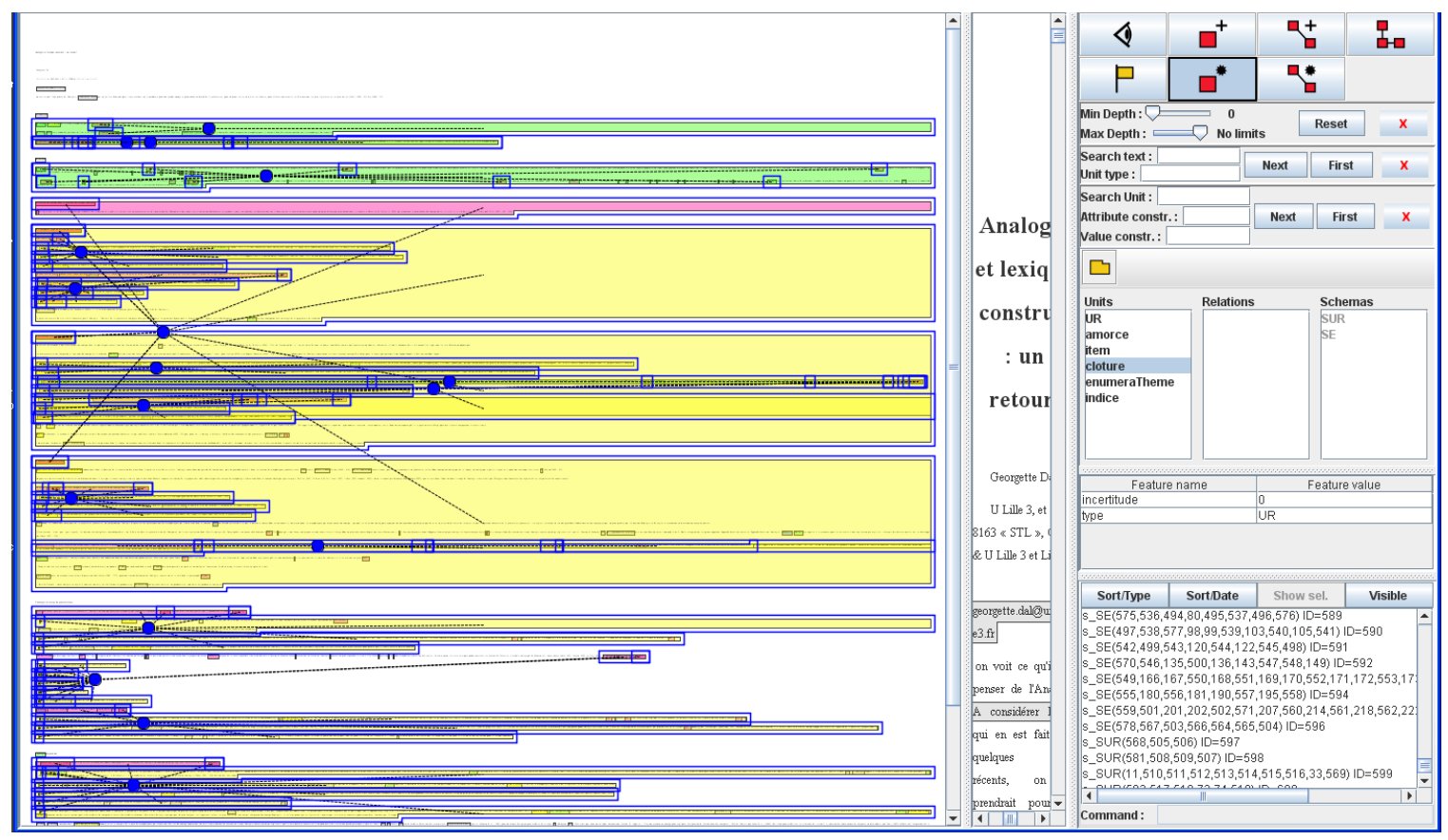


displayed in the format appropriate for annotation.

Premarking of data with stance and multilevel structural markers. Ho-Dac and colleagues (e.g., 2010, 2012), prior to the annotation of multi-level textual structures in Glozz, premarked the files with part-of-speech (POS) and grammatical dependencies tags. They used Treetagger ${ }^{8}$ software for the POS tagging and Syntex ${ }^{9}$ software for grammatical dependency tagging. However, TreeTagger and alternative tools for POS tagging such as the Stanford Natural Language Group tools cannot yet process entire texts efficiently. Most such software packages to date are designed to tag only one sentence at a time. Furthermore, Syntex software has been sold to a private company and is no longer available at no cost to researchers. Therefore, the cost of following the procedure of Ho-Dac and colleagues was judged to be much greater than its benefit for this study, a benefit also judged to be unnecessary.

The tagging of the text of direct interest here are of those words and phrases that have been found in prior research (Gray and Biber 2015; Hyland 2000, 2012) to signal the stance and macro-structures to be identified in the sample chapters. The approach to the premarking of the text utilized here was to construct a separate annotation model for the purpose. This is in addition to the annotation model already developed by Ho-Dac and colleagues for the multilevel text structures, i.e., enumerative structures and topical chains, ${ }^{10}$ and the one for chapter/section/subsection/paragraph structure available in Glozz.

Annotation of multi-level text structure and stances. A number of steps were

\footnotetext{
${ }^{8}$ http://www.cis.uni-muenchen.de/ schmid/tools/TreeTagger/

${ }^{9} \mathrm{http} / / / \mathrm{www}-\mathrm{etud}$.iro.umontreal.ca/ demorali/syntex/

${ }^{10} \mathrm{http}: / /$ redac.univ-tlse2.fr/corpus/annodis/me_download/index_en.html
} 
involved in developing and using the Glozz annotation model for stance and structural markers. First, the stance markers identified by Gray and Biber (2015) and by Hyland (2000) and the markers associated with enumerative structures and topical chains identified by Ho-Dac and colleagues were collected in a spreadsheet with a column for each word or phrase and columns for all the categories of properties and functions to which they belonged, such as source authors, usual placement within sentence structure, functional types such as epistemic, attitude/emotion, evaluation, boosters, hedges, relational indicators, code glosses, etc.

Second, R Open was used to parse each of the chapters into a vector of the unique words occurring in them. These vectors were exported into an Excel spreadsheet with a column containing the list of stance and structural markers, a column of the unique words in the first edition chapter, and a column of the unique words in the seventh edition chapter. Matches between each of the chapter lists and the stance/structural list were made using the conditional formatting rule for duplicates in Excel. Matches for phrases and punctuation in the stance/structural marker list were found individually through searching the chapters in Word.

Third, the list of markers used in either of the sample chapters was compared to the full list in the original spreadsheet with their categories of function and placement. Those markers in the full list not used in either chapter were deleted, and duplicate markers of different categories of function and placement were combined. An analysis of the patterns in the multiple categories of the markers found in the sample was used to arrive at the categories for the stance/structural annotation model. 
As the sole annotator for the study, I read the detailed guidelines provided in Colléter et al. (2012) for annotating multilevel structures in Glozz and the Glozz User's Manual (Mathet and Widlocher, 2011) three or more times each as necessary familiarization and training. Once the first sample text and the annotations models were successfully loaded in Glozz, I began the annotation process for three to four hours. However, this experience led to the realization that the stance and topical chain markings and the multilevel structure and stance annotations could be accomplished more efficiently in Word. An additional reason for annotating in Word documents was that this was to be the format for representing the finished annotations (see Appendices A and B). The training in Glozz was not wasted since the multilevel structural concepts and the analytic framework embodied in the Glozz software were still in effect but simply transferred to the annotation in the word processing software.

Each word or phrase in the list of stance and topical markers was searched in each of the Word documents of the sample chapters using the Replace function, therefore annotating each instance of the lists of markers in succession. False positives and false negatives marked in this process were manually corrected.

With the markers found in the text indicated by their annotation, the chapters were then annotated according to their multilevel structures (i.e., macro topical chain and enumerative structures). Then, stance sentences and clauses were identified and annotated. Several iterations of annotation were performed in order to refine and correct the annotations.

Macro topical chains. Many of the topical chains as discussed by Ho-Dac (2010, 2012) and colleagues and the co-reference chains discussed by Mathet and Widlöcher 
(2011) are more micro in extent, often encompassed within a paragraph. In this study, these topical chains are considered micro and are not annotated. Instead, macro topical chains are here defined and annotated at the chapter, section, subsection, and subsubsection levels. These are levels designated by the text layout, and they qualify as topical chains mostly through the lexical repetition between these levels (i.e., between a section title and its subsection titles and between subsection titles and sub-subsection titles).

\section{Formal, graphical definitions, measurement, and representation of the text.}

A crucial question for the analysis of multilevel rhetorical structures in a discourse is how the structure is to be measured and represented graphically. Does it have a structure like a network, with relational lines connecting nodes, or is it different? A key for answering the question can be found in Mathet and Widlocher's (2011) definition of an annotation meta-model and its entities of unit, relation, and schema. Units and relations are analogous to the nodes and ties of a network. For example, a topical chain consists of the ties between a referential unit and each of its co-referential occurrences. The links between each of the units of the topical chain are relations, and the overall pattern of units and relations form a topical chain schema. In terms of the multilevel structure of a text, the overall schemas, whether for topical chains or enumerative structures, are the relevant measurement, not units and relations as in a network. These schemas are segments, blocks, or zones ${ }^{11}$ of the text.

The size of a schema was measured by the number of characters from starting to ending position. As the unit of measurement is increased to words, sentences, or

\footnotetext{
${ }^{11}$ Computational linguist Teufel (2010) developed a model for the semi-automated text annotation of expository texts into what she calls argumentative zones.
} 
paragraphs, the precision of the measurement decreases. No relation types are defined to connect schemas as relation types connect discrete nodes in a social network. Instead, schemas are related to each other in terms of the degree to which they abut or overlap with each other (i.e, are nested or encompassed within each other).

Given the definition of the multilevel schemas as blocks of textual units rather than as a network, the resulting structure can be represented adequately in a Word document with the blocks of text represented with color coding and shades to represent the nesting of the macro schemas. The Glozz display, with its main view of text large enough to be readable for annotation and its macro view of the same text reduced too small to be read but displaying more of the overall structure at a glance, suggests two ways for the texts' multilevel schema structure to be represented, with version of the text with its multilevel schema structure large enough to be read and another too small to read but better able to display the overall structural pattern. A reduced representation is reserved for future work, but the larger representations with readable text are presented in the appendices.

Appendix A presents the results of the multi-level annotation of the "Autonomy" chapter of the first edition of Beauchamp and Childress (1979), and Appendix B presents the annotation of the "Respect for Autonomy" chapter of the seventh edition (2012). Table 1 presents a legend of the color coding used in the annotations to represent the enumerative structures (ESs) and topical chains (TCs). Words that are candidate markers for topical chains are shown in green font in the appendices. Words that are candidate markers for stance (i.e., evaluative and interpersonal words), useful for identifying stance 
statements, are shown in blue font. Blocks of stance text are shown in blue font, and the stance markers within them are shown in purple font.

Level 1, represented as having no shading, is text at the chapter level. Level 2 is text at the section level, Level 3 at the subsection level, and Level 4 is at the subsubsection level, with darker background shading representing each lower level. Blocks of text with just macro topical chains are represented in background shades of blue, blocks of text with just enumerative structures are represented in background shades of gray, and blocks of text with overlapping enumerative structures and topical chains are represented in background shades of blue-gray.

An enumerative structure within a topical chain is defined as being at the level of the topical chain, but two nested enumerative structures within a topical chain are defined as being at the next lower level, and a nesting of three enumerative structures within a topical chain is defined as being at two levels lower than the topical chain alone would be.

Thus, a text with a chapter/section/subsection/sub-subsection layout structure with lexical repetition between the different levels of titles, as found in the sample chapters, will have four levels from the macro topical chain structure alone. The addition of nested enumerative structures can result in even lower levels, depending on the layers of nesting. In this graphical scheme, Level 1 is considered the highest and is assumed to be the most general level of text. Part of the question of the study is whether stances appearing at higher levels are also more central or important to the argument. Each lower level is assumed to delve into more specific and detailed topical material in the text's argument, with enumerative structures assumed to be signs of more specific discussion. 
Table 3.1.

Legend for Text Structure Representation

\begin{tabular}{|c|c|c|c|}
\hline $\begin{array}{c}\text { Level } \\
\text { (Depth) }\end{array}$ & $\begin{array}{c}\text { Enumerative Structures } \\
(\mathrm{ESs})\end{array}$ & $\begin{array}{l}\text { Overlapping } \\
\text { ES \& TC }\end{array}$ & $\begin{array}{c}\text { Topical Chains } \\
\text { (TCs) } \\
\end{array}$ \\
\hline 1 & No Shading & No Shading & No Shading \\
\hline 2 & $\begin{array}{c}\text { Light Gray, Background 2, } \\
\text { Darker } 10 \%\end{array}$ & $\begin{array}{l}\text { Blue-Gray, Text } 2, \\
\text { Lighter } 80 \%\end{array}$ & $\begin{array}{l}\text { Blue, Accent } 1 \text {, } \\
\text { Lighter } 80 \%\end{array}$ \\
\hline 3 & $\begin{array}{c}\text { Light Gray, Background 2, } \\
\text { Darker } 25 \%\end{array}$ & $\begin{array}{c}\text { Blue-Gray, Text 2, } \\
\text { Lighter } 60 \%\end{array}$ & $\begin{array}{c}\text { Blue, Accent 1, } \\
\text { Lighter } 60 \%\end{array}$ \\
\hline 4 & $\begin{array}{c}\text { Light Gray, Background 2, } \\
\text { Darker } 50 \%\end{array}$ & $\begin{array}{l}\text { Blue-Gray, Text } 2, \\
\text { Lighter } 40 \%\end{array}$ & $\begin{array}{l}\text { Blue, Accent } 1 \text {, } \\
\text { Lighter } 40 \%\end{array}$ \\
\hline 5 & $\begin{array}{c}\text { Light Gray, Background 2, } \\
\text { Darker } 75 \%\end{array}$ & $\begin{array}{c}\text { Blue-Gray, Text 2, } \\
\text { Darker } 25 \%\end{array}$ & $\begin{array}{c}\text { Blue, Accent 1, } \\
\text { Darker } 25 \%\end{array}$ \\
\hline 6 & $\begin{array}{c}\text { Light Gray, Background 2, } \\
\text { Darker } 90 \%\end{array}$ & $\begin{array}{c}\text { Blue-Gray, Text 2, } \\
\text { Darker } 50 \%\end{array}$ & $\begin{array}{l}\text { Blue, Accent } 1 \text {, } \\
\text { Darker } 50 \%\end{array}$ \\
\hline
\end{tabular}


Definition, identification, and measurement of cited authors and works. All works and authors cited in the sample chapters were collected in a spreadsheet. A Google search was made of the cited works, with links to their online versions collected in the spreadsheet. Works with numerous co-authors, beyond the first three included in APA references and in the chapter footnotes, were identified and included in the spreadsheet. Then, a Google search was made to identify the full names and discipline of training of each cited author. For authors with doctoral-level degrees, this highest-level degree was recorded as the discipline of training. For authors with multiple doctoral-level degrees, each of these disciplines of training was recorded for them. A link to this author information was also recorded for each of them.

A separate spreadsheet was used to record the citations within the context of the chapter/section/subsection/sub-subsection structure. Variables measured were:

1. cited work titles (with links to online access to the work),

2. authors of the work,

3. discipline(s) of training of each author,

4. whether or not the work was an empirical study,

5. whether the main text had a block quote from the work,

6. whether it had any other direct quote from the work,

7. whether the title was mentioned in the main text,

8. whether the full name of an author was mentioned in the main text,

9. whether the last name of an author was mentioned in the main text,

10. whether a personal pronoun referred to an author in the main text,

11. whether a demonstrative pronoun or phrase referred to an author in the main text, 
12. whether another type of co-reference referred to an author in the main text. In addition, variables 5 through 12 above were repeated as variables 13-20 for respective mentions in the footnotes. The first edition (1979) edition of the textbook included an appendix of ethical cases and another appendix of relevant codes of ethics. Variables 5 through 12 were repeated in variables $21-28$ for chapter references to works and authors in these appendices.

A measure of discipline prominence. A measure was needed that would weigh the importance of the citations according to their appearance in the main text, in the footnotes, or in the appendices. The assumption was made that citations in the body of the text should carry more weight than those appearing in the footnotes, which should in turn carry more weight than those in the appendices. At each of these levels, a further assumption was that direct quotations (including block quotes), title mentions, and author full name or last name should carry more weight than personal pronouns, demonstrative pronouns and phrases, and other co-references.

Further, these measures needed to be weighed by the number of co-authors since a count of all cited authors would overweigh the authors of co-authored works and since some disciplines such as the natural and biomedical sciences tend to have more coauthored works, often amounting to a large number of co-authors.

I call the weighted measure used in this study a prominence score. In it, direct quotations, cited work titles, and cited author full or last names given in the body of the main text received a score of 3 each. Each personal pronoun, demonstrative pronoun or phrase, or other types of co-reference to a cited work or author in the body received a score of 2. Direct quotations, cited title mentions, cited author full or last name mentions 
in the footnotes also each received a score of 2, and occurrences of all other of the variables at the footnote or appendix level received a score of 1 .

These scores were equally apportioned between co-authors by the number of coauthors of a cited work. Also, the scores for authors with two disciplines of training were equally apportioned between those disciplines.

These prominence scores were summarized by each discipline within a section, subsection, or sub-subsection, and prominence scores for each discipline were summarized according to the level of the text structure in which they appeared.

Stance, interaction, and text measurement. A separate spreadsheet was constructed to record the measurements of the text. Each row or case was a successive paragraph of a chapter, with measurements of the paragraph in words, characters without spacing, and characters with spacing. Each stance was counted and measured in words and characters by the paragraph in which they appeared. Each enumerative structure was also recorded over the paragraphs or paragraph segments in which they occurred. Lastly, the level of text structure as well as the specific chapter, section, subsection, or subsubsection in which the paragraph or paragraph segment occurred was recorded.

Evaluation and interpretation of results. The resulting set of major stances sentences and multilevel textual structure, in both their "graphic" representation and in their descriptive statistics, are evaluated and interpreted for what they can tell us about the argument about the autonomy principle in its first and latest editions and about how the principle has developed over three decades from the perspective of this textbook chapter. A comparative analysis of the two chapters is undertaken, as well as qualitative 
analysis based on a close reading of the chapters. The results of this analysis are given in Chapter 4 . 


\section{Chapter 4}

\section{Results I: Multi-Level and Stance Structure and Disciplinary Prominence}

Introduction. This chapter presents the results of a descriptive analysis by chapter of the macro-level topical structures, multi-level structures, stances within those structures, and the prominence of disciplines, both overall and for the empirical work cited. The focus is on overall patterns rather than on stance interactions, which are described in Chapter 5.

To review the two types of multi-level structure identified and measured, topical chains can vary in length from entire sections or chapters at the macro level to paragraphs or portions of paragraphs at the micro level. Macro topical chains are controlled by lexical repetition within the titles of chapters, sections, subsections, and sub-subsections. Only topical chains at this macro level are annotated and presented in the appendices, and these coincided with the layout organization of the chapters into sections.

Enumerative structures (ESs) can also vary in length, from macro ESs extended over sections to ones extending over several paragraphs, and on down to those contained within one or two sentences. All ESs are marked in the appendices.

Macro topical organization of the chapters. The first edition (1979) chapter is organized into four sections. The first extends from the beginning of the chapter through 
the sections and subsections dealing with the conceptualization and properties of autonomy. The second and longest one covers the section on informed consent, the third covers the section on the informed refusal of treatment, and the fourth extends over the section on autonomous suicide. The "Conclusion" section is connected with the autonomous suicide section and is not conclusion of the entire chapter. The one major enumerative structure in the first edition chapter concerns the elements of informed consent and extends over most of the informed consent topical chain.

The seventh edition (2012) chapter has seven sections, four of which are devoted to elements from the authors' list of seven elements of informed consent. As in the first edition chapter, the longest enumerative structure concerns these elements. However, in the seventh edition, this ES begins with the section on competence (or the capacity for autonomous choice), which, as an element of informed consent, belongs to that enumerative structure. However, it is presented at an earlier stage of the chapter, before those elements are listed, and is thus textually separated from the rest of the ES. This is an example of what Asher and Lascarides (2003) call discourse popping in their microoriented segmented discourse representation theory.

Stances. Stances were identified qualitatively according to their evaluative language and usually claim-making and interactional contexts. Most sentences in the text had some candidate stance markers of evaluative words and phrases, but only some of these were designated as stance statements. Here is an example from the annotated seventh edition chapter of a sentence with stance markers (in blue font) that was not identified as a stance statement: 
Sometimes a competent person who can usually select appropriate means to reach his or

her goals will act incompetently in some circumstances $(2012,116)$.

Stances of one sentence or even one independent clause are not uncommon, as in this example from the first edition:

“...the very notions of autonomy and authority employed in this theory are eccentric and indefensible” (1979, p. 60).

However, even more usual were stances that extended over more than one sentence to comprise several sentences and sometimes all or almost all of a paragraph, as in this example from the seventh edition:

We welcome this approach as a way of interpreting our second sense of institutional informed consent, but the Miller-Wertheimer theory moves into unacceptably dangerous territory by altogether, and by design, abandoning the first sense of autonomous authorization and substituting the "fair transaction" model. Their model would be more suitable if it were presented as an explication of our second sense of "informed consent" and as a fairness-based analysis of requirements for various practical contexts in which informed consent is obtained. However, as their theory stands, these authors give a priority to fairness to all parties that loses sight of the central role of respect for the subject's or patient's autonomy. We see no justification for their claims that their model merits adoption "in place of the autonomous authorization model" and that "consent is a bilateral transaction," rather than the "one-sided focus on the quality of the subject's consent" to which the autonomous authorization model is committed. We earlier argued, in treating the "shared decision-making" conception, that informed consent is misconceived as bilateral. Bilateral transactions of informational exchange often appropriately occur in consent contexts, but genuine informed consent is not reducible to a bilateral transaction. ${ }^{48}$ (2012, pp. 123-124)

The first edition chapter, not counting notes, is 15,110 words long, compared to the seventh edition's 17,763 words. So, the latest edition chapter is about $18 \%$ longer. A total of 31 stances were identified in the first edition chapter, while 56 were identified in the seventh edition, a $80 \%$ increase. In terms of interactions with other authors, the first edition chapter cites 53 scholars, while the seventh edition cites 300, a 466\% increase. 
Multi-level discourse structure. Both chapters had text at 6 different levels. Table 4.1 (for the 1979 chapter) and Table 4.2 (for 2012) show the measurements at each level in units of paragraphs, sentences, words, and characters (including spaces). The measurements were proportionally similar at each level of granularity, becoming more similar at the more precise levels of words and characters. Using characters as the unit of measurement, over two-thirds (69.2\%) of the 1979 chapter is at Level 3, the level of subsections. Only the first paragraph is at the chapter level (Level 1), or .7\% of the text.

In both chapters, all instances of text at Level 1 is at the chapter level, the first paragraph of the 1979 chapter (.7\% of the text) and the two introductory paragraphs and three conclusion paragraphs of the 2012 chapter (9.9\% of the text). Also, in both chapters, all instances of text at Level 2 are at the section level. All instances of text at Level 3 in the 1979 chapter are at the subsection level (69.2\% of the text), and all instances of the 2012 chapter are also at the subsection level save for one section-level paragraph with a nesting of an enumerative structure within another one. The 1979 chapter has only 4.5 paragraphs at Level 4, 2 at the sub-subsection level and 3 are nested enumerative structures at the subsection level. On the other hand, the 2012 chapter has 56 paragraphs at Level 4, with most (49.5) paragraphs at the sub-subsection level, and 6.5 paragraphs nested enumerative structures at the subsection level. In both chapters, text at Levels 5 and 6 are at the sub-subsection level plus two nested enumerative structures at Level 5 and three nested enumerative structures at Level 6.

Stances and multi-level structure. Tables 4.3 (for the 1979 chapter) and Table 4.4 (for the 2012 chapter) summarize, for each level of text structure, the number and percent of stances and the length and length percent of stances measured in sentences, 
Table 4.1. Chapter Text Measurements by Level (1979)

\begin{tabular}{|c|c|c|c|c|c|c|c|c|}
\hline & \multicolumn{2}{|c|}{ Paragraphs } & \multicolumn{2}{|c|}{ Sentences } & \multicolumn{2}{|l|}{ Words } & \multicolumn{2}{|c|}{ Characters* } \\
\hline Level & $\mathrm{n}$ & $\%$ & $\mathrm{n}$ & $\%$ & $\mathrm{n}$ & $\%$ & $\mathrm{n}$ & $\%$ \\
\hline 1 & 1 & 1.1 & 3 & 0.5 & 90 & 0.6 & 621 & 0.7 \\
\hline 2 & 12 & 13.5 & 67 & 11.4 & 1648 & 10.9 & 10553 & 11.0 \\
\hline 3 & 60.5 & 68.0 & 413 & 70.1 & 10547 & 69.8 & 66137 & 69.2 \\
\hline 4 & 4.5 & 5.0 & 21 & 3.6 & 607 & 4.0 & 3886 & 4.1 \\
\hline 5 & 5.5 & 6.2 & 38 & 6.4 & 1106 & 7.3 & 7142 & 7.5 \\
\hline 6 & 5.5 & 6.2 & 47 & 8.0 & 1112 & 7.4 & 7207 & 7.5 \\
\hline Total & 89 & 100.0 & 589 & 100.0 & 15110 & 100.0 & 95546 & 100.0 \\
\hline
\end{tabular}

*(includes spacing) 
Table 4.2. Chapter Text Measurements by Level (2012)

\begin{tabular}{|r|r|r|r|r|r|r|r|r|}
\multicolumn{1}{c|}{ Paragraphs } & \multicolumn{1}{l}{ Sentences } & \multicolumn{1}{l}{ Words } & \multicolumn{3}{l}{ Characters* } \\
\hline Level & $\mathrm{n}$ & $\%$ & $\mathrm{n}$ & $\%$ & $\mathrm{n}$ & $\%$ & $\mathrm{n}$ & $\%$ \\
\hline 1 & 5 & 3.6 & 11 & 1.5 & 372 & 2.1 & 1810 & 9.9 \\
\hline 2 & 9.5 & 6.8 & 50 & 7.0 & 1065 & 6.0 & 1384 & 7.5 \\
\hline 3 & 56 & 40.0 & 302 & 41.9 & 7452 & 41.9 & 5678 & 30.9 \\
\hline 4 & 56 & 40.0 & 284 & 39.5 & 7301 & 41.1 & 7497 & 40.9 \\
\hline 5 & 12 & 8.2 & 60 & 8.3 & 1326 & 7.5 & 854 & 4.7 \\
\hline 6 & 2 & 1.4 & 13 & 1.8 & 247 & 1.4 & 1117 & 6.1 \\
\hline Total & 140 & 100.0 & 720 & 100.0 & 17763 & 100.0 & 18340 & 100.0 \\
\hline
\end{tabular}

*(includes spacing) 
words, and characters (with spaces included). In 1979, 24 of the 31 stances (74.2\%) appeared at Level 3, the subsection level, and four (12.9\%) appeared at Level 5. None appeared at Level 1, the chapter level, one appeared at both Level 2, the section level, and Level 4, the sub-subsection level, and two appeared at Level 6.In 2012, stances were almost equally divided between Level 3, the subsection level, and Level 4, the subsubsection level, with $23(41.1 \%)$ at Level 3 and $22(39.3 \%)$ at Level 4 . An equal number (2, or 5.35\%) appeared at Level 2, the section level, and Level 5. Four (7.1\%) appeared at Level 1, the chapter level, and one (1.8\%) appeared at Level 6.

The bar chart in Figure 1 makes these proportions easier to grasp. In the 1979 chapter, most of the text is at Level 3. Only a tiny proportion is at Level 1, little is at Level 4, and fairly similar amounts are at Levels 2, 5, and 6. The proportion of 1979 stance text is about what would be expected by chance according to the proportion of all text at Levels 1, 3, and 6. Less stance text than would be expected by chance appears at Levels 2 and 4, and much more than would be expected by chance appears at Level 5 . The overall distribution of all text and of stance text in 1979 can be seen to be uneven.

In the 2012 chapter, most of the text appears at the middle levels, but it is more evenly distributed between Level 3 (30.9\%) and Level 4 (40.9\%). So, $71.8 \%$ of the text appears at the subsection or sub-subsection level. The distributions are also more even at the other levels, with $9.9 \%$ at Level $1,7.5 \%$ at Level 2, $4.7 \%$ at Level 5 , and $6.1 \%$ at Level 6. Remarkably, the length of the stance text at each of these levels is very close to what would be expected by chance according to the length of all text at this level.

Position of stances within each level of text segment. Table 4.5 for the first edition chapter (1979) and Table 4.6 for the seventh edition chapter summarizes at what 
Table 4.3. Number and Length of Stances by Level (1979)

\begin{tabular}{|r|r|r|r|r|r|r|r|r|}
\multicolumn{4}{c}{ Stances } & \multicolumn{3}{c}{ Sentences } & \multicolumn{1}{c|}{ Words } & \multicolumn{2}{c|}{ Characters* } \\
\hline Level & $\mathrm{n}$ & $\%$ & $\mathrm{n}$ & $\%$ & $\mathrm{n}$ & $\%$ & $\mathrm{n}$ & $\%$ \\
\hline 1 & 0 & 0 & 0 & 0 & 0 & 0 & 0 & 0 \\
\hline 2 & 1 & 3.2 & 4 & 5 & 91 & 4.4 & 579 & 4.4 \\
\hline 3 & 23 & 74.2 & 57 & 70.4 & 1391 & 67.1 & 8767 & 66.4 \\
\hline 4 & 1 & 3.2 & 1 & 1.2 & 16 & 0.8 & 123 & 0.9 \\
\hline 5 & 4 & 12.9 & 15 & 18.5 & 466 & 22.5 & 3016 & 22.8 \\
\hline 6 & 2 & 6.5 & 4 & 4.9 & 109 & 5.2 & 726 & 5.5 \\
\hline Total & 31 & 100 & 81 & 100 & 2073 & 100 & 13211 & 100 \\
\hline
\end{tabular}

*(includes spacing) 
Table 4.4. Number and Length of Stances by Level (2012)

\begin{tabular}{|r|r|r|r|r|r|r|r|r|}
\multicolumn{4}{c|}{ Stances } & \multicolumn{3}{c}{ Sentences } & \multicolumn{1}{c|}{ Cords } & \multicolumn{2}{c|}{ Characters* } \\
\hline Level & $\mathrm{n}$ & $\%$ & $\mathrm{n}$ & $\%$ & $\mathrm{n}$ & $\%$ & $\mathrm{n}$ & $\%$ \\
\hline 1 & 4 & 7.1 & 8 & 7.2 & 282 & 10.1 & 1810 & 9.7 \\
\hline 2 & 3 & 5.4 & 9 & 8.1 & 208 & 7.5 & 1384 & 7.5 \\
\hline 3 & 23 & 41.1 & 38 & 34.2 & 894 & 32.1 & 5922 & 31.9 \\
\hline 4 & 22 & 39.3 & 43 & 38.8 & 1114 & 40.0 & 7498 & 40.3 \\
\hline 5 & 3 & 5.3 & 5 & 4.5 & 124 & 4.5 & 854 & 4.6 \\
\hline 6 & 1 & 1.8 & 8 & 7.2 & 162 & 5.8 & 1117 & 6.0 \\
\hline Totals & 56 & 100.0 & 111 & 100.0 & 2784 & 100.0 & 18585 & 100.0 \\
\hline
\end{tabular}

*(includes spacing) 
Figure 4.1. All Text and Stance Text by Level and Year

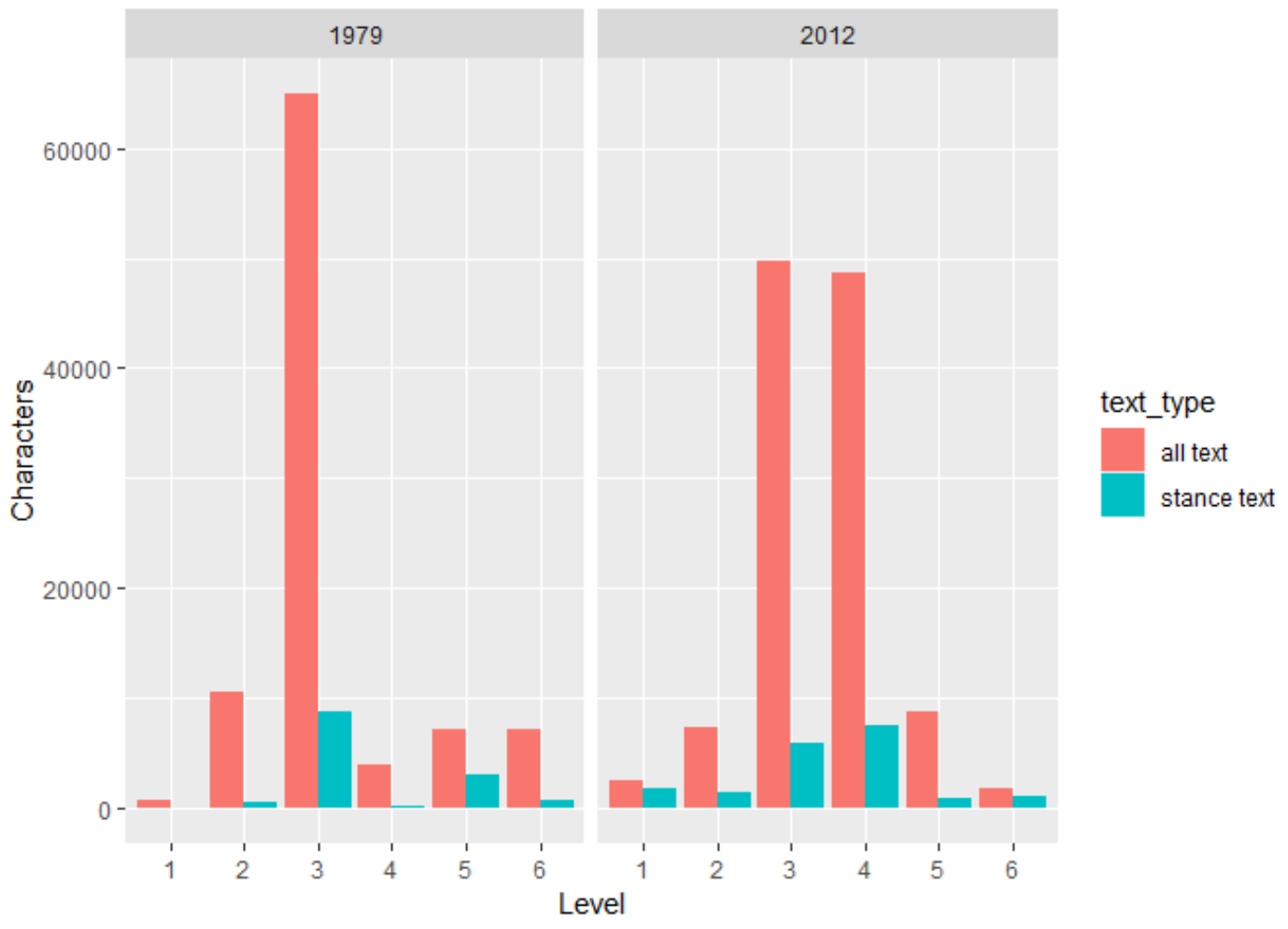


position in the different levels of text structure, from paragraph to sub-subsection to subsection to section to chapter, stances appeared. At the paragraph level, over half of the stances (17) in 1979 appeared at the close of a paragraph, and an almost equal number appeared at the beginning of a paragraph (5) as appeared in middle (6). Three stances comprised the entirety of a paragraph. In 2012, stances were again more likely to appear at the close of a paragraph (23), though the likelihood of a stance appearing at the beginning of a paragraph or to comprise the entirety of a paragraph increased.

At the sub-subsection level, stances were more likely to appear in the middle of a paragraph in both 1979 and 2012, though the likelihood of a stance closing a subsubsection had increased in 2012. A stance was more likely to appear in the middle or at the close of a subsection in both editions, and one was about equally likely to open as to close a section. No stances appeared at the chapter level in 1979, but in 2012, a stance closed the introduction and roughly comprised the entirety of the conclusion.

The prominence of disciplines. Table 4.7 and Figure 4.2 summarize the prominence scores of all cited work in the chapters by discipline and year. ${ }^{12}$ Philosophy was most prominent in the first edition chapter (1979) with $46.2 \%$ of the total prominence score, followed by law (both court decisions and legal scholars) at $22.7 \%$. Citations to the behavioral and social sciences, primarily psychology and sociology, were next in prominence with $14.5 \%$, then ethical codes and commission reports at $6.2 \%$, medicine at $5.5 \%$, and bioethics and medical humanities at $4.3 \%$. Citations missing reference information accounted for .6\% of the total 1979 prominence score.

\footnotetext{
${ }^{12}$ See Chapter 3 for how prominence scores were conceived and calculated and how scores were distributed between co-authors and their disciplines of training.
} 
Table 4.5. Position of Stance Appearances by Text Segment (1979)

\begin{tabular}{|l|r|r|r|r|r|r|}
\hline Stance position & Opening & Middle & Closing & Entirety & Footnote & Totals \\
\hline Chapter introduction & 0 & 0 & 0 & 0 & 0 & 0 \\
\hline Section & 0 & 0 & 1 & 0 & 0 & 1 \\
\hline Subsection introduction & 0 & 0 & 0 & 0 & 0 & 0 \\
\hline Subsection & 3 & 10 & 10 & 0 & 0 & 23 \\
\hline Sub-subsection & 1 & 5 & 1 & 0 & 0 & 7 \\
\hline Paragraph & 5 & 6 & 17 & 3 & 0 & 31 \\
\hline
\end{tabular}


Table 4.6. Position of Stance Appearances by Text Segment (2012)

\begin{tabular}{|l|r|r|r|r|r|r|}
\hline Stance position & Opening & Middle & Closing & Entirety & Footnote & Totals \\
\hline Chapter introduction & 0 & 0 & 1 & 0 & 0 & 1 \\
\hline Chapter conclusion & 0 & 0 & 0 & 1 & 0 & 3 \\
\hline Section & 2 & 0 & 1 & 0 & 0 & 3 \\
\hline Subsection & 3 & 10 & 10 & 0 & 0 & 23 \\
\hline Sub-subsection & 2 & 14 & 9 & 0 & 1 & 26 \\
\hline Paragraph & 14 & 8 & 23 & 10 & 1 & 56 \\
\hline
\end{tabular}


Philosophy continued to be most prominent in the seventh edition chapter (2012) with a numerically increased prominence score (from 236 to 293.4), though its share of prominence shrank to $33.6 \%$. The growth in the prominence of medicine was dramatic with an almost eight-fold increase in prominence score (from 28 to 213.2) and a more than four-fold increase in its share of prominence (from $5.5 \%$ to $24.5 \%$ ). The prominence of the behavioral and social sciences ${ }^{13}$ saw a substantial numerical increase in prominence (from 74 to 137.6 ), which amounted to only a slight proportional increase (from $14.5 \%$ to $15.8 \%$ ). Law declined significantly both numerically (from 116 to 89.2 ) and proportionally (from $22.7 \%$ to $10.2 \%$ ). Other biomedical sciences and professions ${ }^{14}$ were not cited in 1979, but had a prominence score of 62.7 in 2012 (a $7.2 \%$ share). Ethical codes and ethics commission reports increased its prominence score in 2012 from 32 to 39 , but their proportion prominence declined from $6.2 \%$ to $4.5 \%$. Bioethics and the medical humanities declined significantly in prominence both numerically (from 22 to 11.2 ) and proportionally (from $4.3 \%$ to $1.3 \%$ ). Theology and religious studies were not cited in 1979, but had a 2012 prominence score of 11.5 (a $1.3 \%$ share). Other miscellaneous disciplines ${ }^{15}$ were not cited at all in 1979 , but had a prominence score of

\footnotetext{
${ }^{13}$ Under "behavioral and social sciences" are included psychology, sociology, anthropology, political science, economics, and history.

${ }^{14}$ The category of "other biomedical sciences and professions" cited in the seventh edition chapter includes a large number of disciplines. These include public health, epidemiology, biostatistics, physiology, neuroscience, nursing, pharmacology, neurology, biochemistry, biophysics, dentistry, health sciences, health systems management, medical information sciences, veterinary science, speech pathology, audiology, cancer biology, medical decision making, and research assistants of unspecified discipline.

${ }^{15}$ The "other disciplines" cited included American studies, linguistics, business administration, journalism, engineering and public policy, education, and social work.
} 
Table 4.7. Prominence Scores of All Cited Work by Discipline and Year

\begin{tabular}{|l|r|r|r|r|}
\multicolumn{2}{c}{1979} & \multicolumn{3}{c}{2012} \\
\hline Discipline & $\mathrm{n}$ & $\%$ & $\mathrm{n}$ & $\%$ \\
\hline philosophy & 236.0 & 46.2 & 293.4 & 33.6 \\
\hline law & 116.0 & 22.7 & 89.2 & 10.2 \\
\hline behavioral and social sciences & 74.0 & 14.5 & 137.6 & 15.8 \\
\hline ethical codes & 32.0 & 6.2 & 39.0 & 4.5 \\
\hline medicine & 28.0 & 5.5 & 213.2 & 24.5 \\
\hline bioethics \& medical humanities & 22.0 & 4.3 & 11.2 & 1.3 \\
\hline theology \& religious studies & 0.0 & 0.0 & 11.5 & 1.3 \\
\hline other biomedical sciences \& professions & 0.0 & 0.0 & 62.7 & 7.2 \\
\hline other disciplines & 0.0 & 0.0 & 12.3 & 1.4 \\
\hline [missing data] & 3.0 & 0.6 & 1.9 & 0.2 \\
\hline Totals & 511.0 & 100.0 & 872.0 & 100.0 \\
\hline
\end{tabular}


Figure 4.2. Prominence of All

Cited Work by Discipline and Year

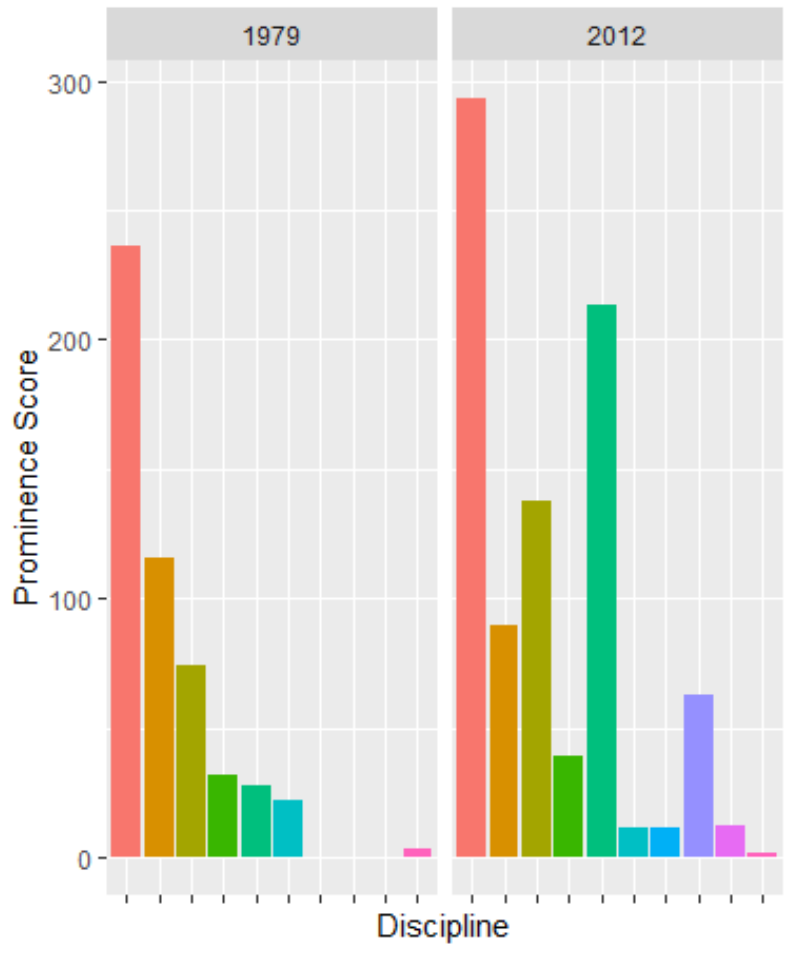

discipline

philosophy

law

behavioral and social sciences

ethical codes

medicine

bioethics \& medical humanities

theology \& religious studies

other biomedical sciences \& professions

other disciplines

[missing data] 
12.3 in 2012 (a 1.4\% share of total prominence). Citations with missing references declined in prominence score from 3 to 1.9, a decline in their share of prominence from $.6 \%$ to $.2 \%$.

Prominence of disciplines in empirical work. Table 4.8 and Figure 4.3 summarize the prominence of empirical cited work by discipline and year. The first edition chapter (1979) did not cite many empirical studies. Those it did cite had a total prominence score of 12. Two-thirds of these citations were to the behavioral and social sciences, with most of those being to examples of deception in research. A quarter of the prominence was to a citation to an empirical study with a missing reference, and philosophy had an $8.3 \%$ share of 1979 empirical prominence.

There was an almost three-fold increase in citations to empirical studies by 2012, from a prominence score of 12 to 32. Empirical studies from medicine, not cited at all in the first edition (1979), were the most prominent in the seventh edition (2012) with a prominence score of 14.9, a 46.6\% share. Empirical studies from other biomedical sciences and professions besides medicine were not cited in 1979, but had a prominence score of 8.1 in 2012, a $25.3 \%$ share. Next in prominence in citations to empirical work were the behavioral and social sciences, with a decline in prominence score from 8 to 6 , and a decline in share of prominence from $66.7 \%$ to $18.8 \%$. However, these citations were not to examples of deceptive research but to empirical research related to bioethical questions.

No citations to empirical work by theology and religious studies were made in 1979, but they had a prominence score of 1 in 2012, a 3.1\% share. Philosophy's prominence in empirical cited work declined in 2012 from a score of 1 to .8 , a decline in 
share of prominence from $8.3 \%$ to $2.5 \%$. No citations were made to empirical cited work by legal scholars in 1979, but they had a prominence score of .6 in 2012, a $1.9 \%$ share of prominence. Other miscellaneous disciplines, not cited for empirical work in 1979, had a prominence score of .3 in 2012 (a .9\% share). Citations to empirical work with missing references declined from a prominence score of 3 to .3 , which amounts to a proportional decline from $25 \%$ to $.9 \%$. 
Table 4.8. Prominence Scores of Empirical Cited Work by Discipline and Year

\begin{tabular}{|l|r|r|r|r|}
\hline & 1979 & & 2012 & \\
\hline Discipline & $\mathrm{n}$ & $\%$ & $\mathrm{n}$ & $\%$ \\
\hline philosophy & 1.0 & 8.3 & 0.8 & 2.5 \\
\hline law & 0.0 & 0.0 & 0.6 & 1.9 \\
\hline behavioral and social sciences & 8.0 & 66.7 & 6.0 & 18.8 \\
\hline ethical codes & 0.0 & 0.0 & 0.0 & 0.0 \\
\hline medicine & 0.0 & 0.0 & 14.9 & 46.6 \\
\hline bioethics \& medical humanities & 0.0 & 0.0 & 0.0 & 0.0 \\
\hline theology \& religious studies & 0.0 & 0.0 & 1.0 & 3.1 \\
\hline other biomedical sciences \& professions & 0.0 & 0.0 & 8.1 & 25.3 \\
\hline other disciplines & 0.0 & 0.0 & 0.3 & 0.9 \\
\hline [missing data] & 3.0 & 25.0 & 0.3 & 0.9 \\
\hline Totals & 12.0 & 100.0 & 32.0 & 100.0 \\
\hline
\end{tabular}




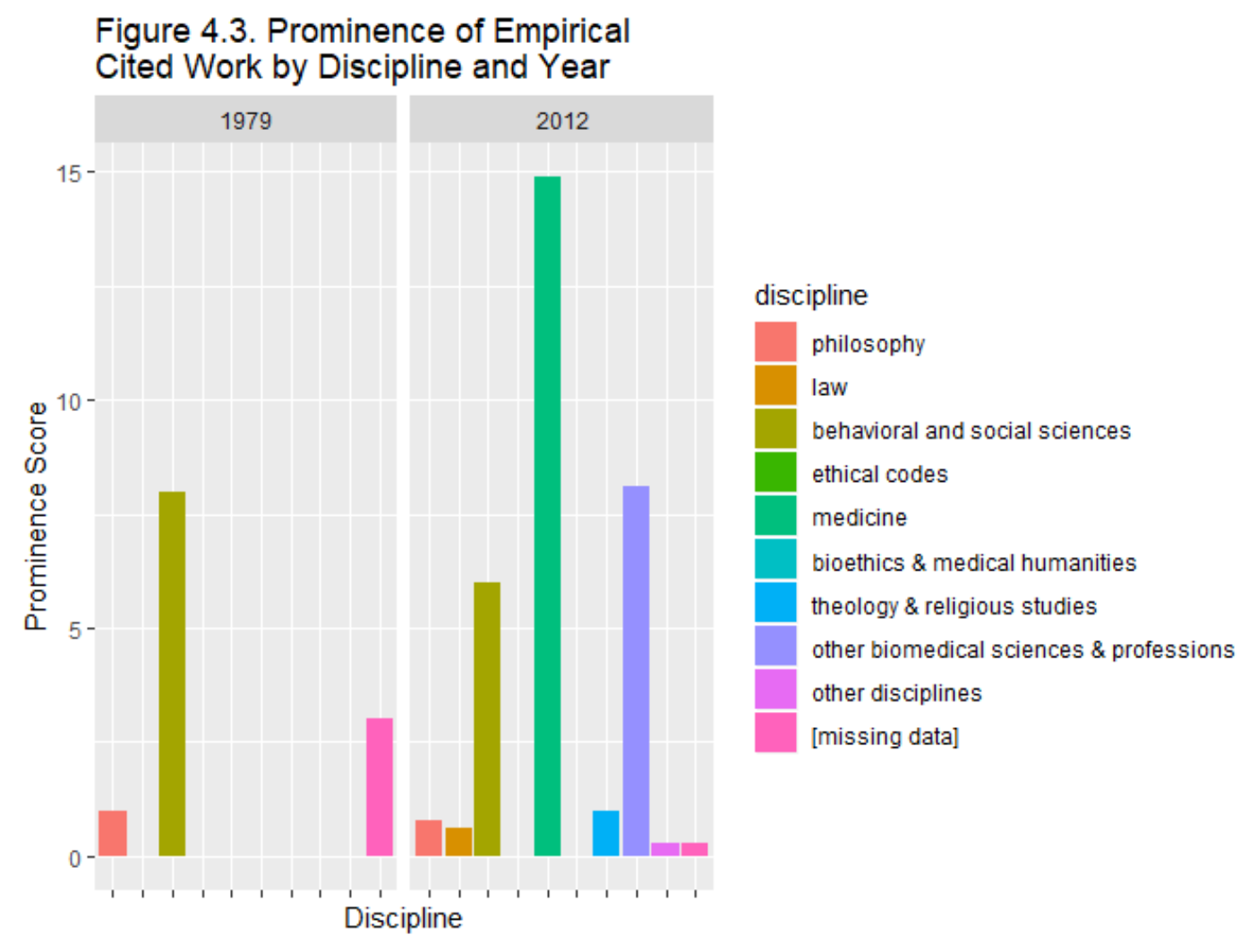




\section{Chapter 5}

\section{Results II: Stances, Interactions, and Cited Disciplines in Context}

\section{The Principle of Autonomy (First Edition, 1979)}

The Concept of Autonomy. In the 1979 chapter, "3 The Principle of Autonomy," the chapter-level introductory paragraph and the first section on "The Concept of Autonomy" cites only philosophers, none of whose work was empirical. The first subsection, "The autonomous person," is all at the subsection level (3). Of the four paragraphs, the second through the fourth are organized as an enumerative structure that contrasts how Immanuel Kant (representing deontological theory) and John Stuart Mill (representing utilitarian theory) conceived of autonomy. The second and third paragraphs summarize respectively the theories of Kant and of Mill. The fourth paragraph consists of a paragraph-long stance to close the subsection in which the authors conclude what they take from Kant and Mill in constructing their principle of autonomy for bioethics. The authors' alignment with Kant and Mill is all positive except for some qualification to Mill which they defer to their chapter on "Paternalism."

The next subsection on "Respect for autonomy and the principle of autonomy" consists of four paragraphs at the subsection level (3). The second and third paragraphs comprise an enumerative structure around the two aspects of the authors' principle. Each of the four subsection paragraphs ends with a stance. The first paragraph ends with a 
positive alignment with Kant on persons' relations of mutual respect of each other's autonomy, the second with a positive alignment with Mill on how each person should have the maximum possible liberty in self-regarding action, and the third with a claim that the views on autonomy of the two philosophers are acceptable and compatible with each other. The stance ending the fourth paragraph and the subsection, without reference to other authors, stipulates that the principle of autonomy applies only to those with the capacity for autonomous choice.

The third and closing subsection on "Autonomy and authority" consists of five paragraphs, all at the subsection level (3). The subsection casts philosopher Robert Paul Wolff's anarchistic conception of autonomy, which treats autonomy as inconsistent with any form of social authority, as an example of a more general perspective that is "radical," with "eccentric and indefensible" views of both autonomy and authority that are inconsistent with correct interpretations of Kant and Mill. The first two paragraphs each contain a stance that rejects the view exemplified by Wolff, and the fourth paragraph closes with a stance consisting of the positive delineation of the authors' view on authority as consistent with autonomy so long as the authority is autonomously accepted. This last stance called upon Kant again as authoritative support.

Informed Consent. The chapter's second section on "Informed Consent" opens with a two-paragraph introduction at the section level (2) that is without a stance. Citations are all to ethical codes, primarily the Nuremberg Code, but also the Declaration of Helsinki. In an enumerative structure that closes the introduction, these codes are cited as the main source for standards in research ethics, with legal decisions said to be the main source of standards of medical practice. The first subsection on "The functions of 
informed consent" consists of two paragraphs at the subsection level (3) that cite legal scholar Alexander Capron and philosopher Mill. Capron's list of the functions of informed consent is given and is followed by a stance that approves of his list but claims that the first function on the list, the protection of autonomy, is the primary function of informed consent. The stance is preceded by and followed by two short enumerative structures.

The five-paragraph subsection on "The justification of informed consent," is all at the subsection level (3), and all but the last paragraph consists of an enumerative structure of the justifications. The authors present Capron's functions of informed consent as also justifications for it. Justifications related to the principles of nonmaleficence and utility are discussed in the first two paragraphs and are followed by a stance within the third paragraph claiming that the principle of autonomy is the primary justification for informed consent. Bioethicist Robert Veatch is quoted in this connection, as is Justice Cardozo in a Supreme Court decision. Legal scholars and court decisions are the primary sources for this subsection, with the addition of the bioethicist Veatch, and all the citations are offered in support of this stance. The final paragraph includes another stance recommending that medical treatment should not be withheld when the secondary consent for a nonautonomous patient is of uncertain validity.

The two-paragraph subsection on "The elements of informed consent" is all at the subsection level (3), and the first paragraph presents a list of the author's elements of informed consent that commences an enumerative structure that covers a little over half of the topical content of the chapter as the elements are discussed in more detail. The subsection contains no stances and no citations. 
The following seven-paragraph subsection on "Competence" is all at the subsection level (3) except for a three-sentence nested enumerative structure in the fifth paragraph. The subsection contains only one stance, the opening sentence of the third paragraph, in which a conclusion is drawn from the discussion of the previous two paragraphs that each class of subjects who are incompetent in some area of their lives should be evaluated separately concerning their competence for informed consent. The subsection's citations are mostly to philosophers, followed by physicians, and including in small measure law and behavioral and social sciences. All are used as sources for examples of difficult cases in judging competence, supporting the subsection's stance and textually subsequent to it.

The one-paragraph introduction to the subsection on "Disclosure of information," is at the subsection level (3) and contains a stance on why it is more important to specify the standards of disclosure with the highest moral priority than to give a long list of conditions for standards as in many ethical codes. No specific codes are cited or mentioned.

The first sub-subsection under "Disclosure of information," on "Standards of disclosure," consists of six paragraphs, the first at the sub-subsection level (4) and all the others at Level 5, with the nesting of an enumerative structure on the standards within the widespread one on the elements of informed consent, or at Level 6 for the three paragraphs containing enumerative structures nested three deep. This is the chapter's first sub-subsection to contain Levels 5 and 6 text. The first stance comes at the end of the first paragraph and at Level 5, agreeing with what the authors characterize as a 
widespread view, that the standard that follows the prevailing professional practice of disclosure is insufficient to ensure patient autonomy. No citations accompany the stance.

The second stance of the sub-subsection opens the third paragraph (at Level 5) and evaluates the reasonable-person standard of disclosure to be a definite improvement over the professional practice standard. This is followed, in the remainder the third paragraph and the following two, by the sub-subsection's citations to what case law says about the reasonable-person standard, about its relation to a subjective standard, and to two empirical studies by behavioral and social scientists, with a philosopher co-author in one, on how patients or research participants often are guided by their prior decisional commitments without regard to the disclosure of additional information. The authors use this work in drawing their paragraph-long stance closing the sub-subsection. They conclude that morality requires that persons be supplied with all the information judged to be consistent with the reasonable-person standard plus, along the lines of the subjective standard, asking patients/participants what additional information they would like in their particular cases.

The sub-subsection on "Intentional nondisclosure" consists in six paragraphs, the first at the sub-subsection level (4), the next two at Level 5, and the final three at Level 6. The first of four stances closes the first paragraph, concluding that the legal doctrine of therapeutic privilege, which allows physicans to withhold information when disclosure would be impractical or when judged harmful to their patients, is not intrinsically unethical when practiced judiciously in the appropriate circumstances. This stance is not accompanied by citations. 
The second stance closes the third paragraph, giving a long delineation of the conditions under which nondisclosure in randomized clinical trials is acceptable. In short, they argue that disclosure of the general procedures involved in such trials and disclosure that the results will be shared with the participants following the trial can be adequate. In leading to this stance, and in connection with it, an article by a physician and a book by a legal scholar are cited as giving further information regarding clinical trials. Also, in a negative stance alignment, the specifications given in the American Psychological Association's ethical code are judged to be inadequate.

The third stance closes the fourth paragraph and follows the delineation of a list of conditions under which the nondisclosure of randomized clinical trials is acceptable. The conditions are restated in the stance in terms of how violations of the principles of nonmaleficence, beneficence, and autonomy can be avoided. The fourth stance closes the sub-subsection and follows examples of intentional nondisclosure in empirical research in psychology (e.g., Stanley Milgram's) and in sociology (e.g., Laud Humphreys'). The stance restates the conditions for acceptable nondisclosure given in the previous three stances in summary fashion: "Generally, deception should be permitted only if essential, to obtain important information, when there is insubstantial risk, and when no other moral principles are violated" $(1979,77)$.

The preceding two sub-subsections under "Disclosure of information" and the following nine-paragraph subsection on "Comprehension of information" are the main parts of the 1979 chapter to cite empirical work, though two empirical studies are cited in the "Autonomous Suicide" section that closes the chapter. Of these, the empirical work cited under "Intentional nondisclosure" are all examples of intentional nondisclosure in 
behavioral and social science research rather than empirical work undertaken in answering bioethical questions. Thus, citations to behavioral and social scientists are most prominent in the sub-subsection, along with ones to a physician, a legal scholar, and a journalist.

The nine-paragraph subsection on "Comprehension of information" is all at the subsection level (3) save for the fourth and fifth paragraphs, for which two nested enumerative structures put them at Level 4 . The first of four stances is given in the second paragraph and in opposition to a physician and a legal scholar who argue that patients and participants are never fully informed because they never fully comprehend the information given to them. In contrast, the authors argue that under the reasonableperson standard, patients/participants can be said to be adequately informed even if not meeting an ideal of full comprehension.

Paragraphs 3-5 discuss the question of whether waivers of informed consent should be permitted, and the authors take a stance on the question in paragraph six. In this second stance, they propose a procedural solution in which a general rule against waivers of consent can be relaxed if an institutional review committee or a hospital ethics committee deems it appropriate in particular cases. The cited authors in this interaction include, in order of prominence, a physician, a behavioral/social scientist, a bioethicist, and a philosopher. All this cited work, with the exception of that by the bioethicist, is of empirical research on the extent to which patients/participants desire or use disclosable information.

The third stance is given in the eighth paragraph. In contrast to the arguments against the forced disclosure of information by cited authors representing bioethics, 
philosophy, and medicine, the authors maintain that in cases of false belief or irrationality, the attempted forcing of disclosure of information can be necessary to promote autonomous choice. They see a procedural solution as appropriate here as in the case of waivers of informed consent.

The fourth and final stance comes in the ninth and final paragraph. This stance denies an hypothetical argument that the stances they took about inadequate comprehension of information by patients do not apply to the case of adequate comprehension by research participants. No citations are connected with this stance.

The four-paragraph subsection on "Voluntariness" is all at the subsection level (3). The only reference in the subsection comes in the final paragraph and is to Case \#26 in Appendix I, which reports on a case study of alleged coercion in recruiting research participants. The paragraph closes with the only stance in the subsection, which draws the distinction between generally coercive environments like prisons, wherein informed consent is possible, and individual cases of coercion, as in the cited case, where informed consent is impossible. The cited case study was written by a philosopher.

Refusal of Treatment. The six-paragraph section on "Refusal of treatment" is all at the section level (2) and includes an enumerative structure of cited legal cases in the third through sixth paragraphs. The only stance of the section closes it. Positions taken in stances on informed consent are applied in this stance to the case of informed refusal, for which the authors' modified reasonable-person standard is recommended. Also recommended is to err on the side of treatment in cases of doubtful competence or in cases where the refusal also affects another patient, such as a child. The stance is taken in interaction with previously given citations to, in order of prominence, legal decisions and 
legal scholars, a quoted ethical code ("The Patient's Bill of Rights"), a philosopher, and a journalist.

Autonomous Suicide. The three-paragraph introduction to the section on "Autonomous Suicide" is all at the section level (2), with most of the introduction part of an enumerative structure of contemporary events renewing interest in the topic.

Reference to two sources are given in the introduction with unnamed, missing references. One is an estimate on suicides per day by the World Health Organization, and the other is a quotation from an unnamed empirical study. No stance is taken in the introduction.

The five-paragraph subsection on "The definition of suicide" is all at the subsection level (3). No citations are given, but the subsection closes with a paragraphlong stance which argues that common definitions of suicide are not objective and precise enough for a proper moral analysis. In the authors' definition, suicide only occurs when one intentionally ends one's life, regardless of the means used or the nature of the intention.

The eight-paragraph subsection on "The morality of suicide" is all at the subsection level (3), with all but the concluding paragraph part of an enumerative structure listing and discussing the moral principles relevant to acts of suicide. The first paragraph closes with a stance, unconnected to any citations, that claims that three such principles are relevant to suicide. The enumerative structure closes with another stance at the end of paragraph seven that concludes that autonomous suicide, when principles of utility and of human dignity and worth are not violated, is morally acceptable and should not be hindered. The authors emphasize that the facts of a particular concrete case must be considered. The third stance comes at the end of the eighth and final paragraph and 
largely restates the second stance. It also clarifies that encouraging or assisting another person with suicide is morally problematic, but that suicide under the conditions laid out in the second stance is not immoral. The stance is connected to the only reference in the subsection, in the same paragraph, to philosopher David Hume's essay on suicide, which presents a similar argument.

The four-paragraph subsection on "Problems of suicide interventions" is all at the subsection level (3), with the second through fourth paragraphs encompassed in an enumerative structure giving points of disagreement with the view by legal scholar Glanville Williams, given in a block quote, that mental health professionals are apt to see all suicides as signs of mental illness. This, and a general reference to "Freudians," are the only citations in the subsection. The only stance is at the beginning of the final paragraph, which approves of interventions to prevent the suicides of nonautonomous persons.

The three-paragraph subsection on "Conclusions" to the section on autonomous suicide is all at the subsection level (3). The last paragraph coincides with an enumerative structure. Points from the section are restated, but no new stances or conclusions are drawn. The one citation is to a philosopher's essay on the subject.

\section{Respect for Autonomy (Seventh Edition, 2012)}

The companion chapter in the latest (2012) edition of the textbook, "4 Respect for Autonomy," begins with two introductory paragraphs at chapter-level (1). The first paragraph includes the only citation, which is to a ethics commission paper that covers the fact that research "subjects" are sometimes called "participants." This is not part of a 
stance interaction. However, the second paragraph consists of a stance interaction in which the authors seek to answer previous criticisms without at this point citing anyone, but referring to "some of our critics" and "some of our commentators" $(2012,101)$. They deny that (1) the principle of autonomy takes priority over the other three principles in their framework, (2) the principle of autonomy is too individualistic, (3) is too focused on cognition over affect, and (4) is too legalistic.

\section{THE CONCEPT OF AUTONOMY AND THE PRINCIPLE OF RESPECT}

FOR AUTONOMY. The two introductory paragraphs of the section on "THE

\section{CONCEPT OF AUTONOMY AND THE PRINCIPLE OF RESPECT FOR}

AUTONOMY" are at the section level (2) and contain no stances. The one citation is to philosophers. This is followed by two introductory paragraphs of a subsection on "Theories of Autonomy" which is all at the subsection level (3). The first paragraph begins with a stance that declares that the authors will focus on autonomous choice and decision making rather than on the approach taken by others that focuses on the general capacities of an autonomous person. The only citation is to a philosopher who takes the kind of broader conception of autonomy the authors reject.

The five-paragraph sub-subsection on "Split-level theories of autonomy" is all at the sub-subsection level (4). The three stances are interrelated in arguing against the theory of autonomy most prominently identified with philosopher Gerald Dworkin, which distinguishes between more basic first-order desires and more reflective and critical second-order desires. According to this theory, autonomy is only present if second-order desires are followed. The first stance, a sentence opening the second paragraph, critiques the "split-level" theory by arguing that a second-order desire could 
be caused by a first-order desire. The second stance, a sentence opening the fourth paragraph, cites philosopher Agnieszka Jaworska's argument that choosing contrary to one's stable, reflectively-accepted values can still be autonomous. The third, paragraphlong stance to close the sub-subsection concludes that a theory of autonomy should not be so ideal and aspirational that it does not cover many ordinary autonomous choices. All of the sub-subsection's citations are to philosophers.

The next seven-paragraph sub-subsection on "Our three-condition theory" is all at the sub-subsection level (4) and is all organized as an enumerative structure. The subsubsection contains no stance, and one citation to a philosopher whose work provides supportive background information on plans and intentionality, is given. The three conditions for the authors' theory of autonomy are intentionality, understanding, and lack of undue influence.

These two sub-subsections provide an interesting example of (1) interrelated stances and (2) the relationship between stances and claims. The three stances in "Splitlevel theories of autonomy" can be seen as comprising different aspects of one overall stance taken against these theories and covering the topic of the sub-subsection. The companion sub-subsection on "Our three-condition theory," in which the authors present their theory of autonomy, could be considered a major claim of the chapter even though it contains no stance interaction. This raises questions about the relationship between stance interactions, which can often be interpreted as major claims of the chapter, and a set of expository propositions that could be considered claims. In this example, the stance interactions in "Split-level theories of autonomy" can be interpreted as partially setting up the conditions for autonomy listed in "Our three-condition theory." 
The four-paragraph subsection on "Autonomy, Authority, Community, and Relationships" is all at the subsection level (3) and contains two stances. The first two paragraphs are about the compatibility of autonomy and authority. "Some theorists argue" $(2012,105)$ that accepting the prescriptions of institutions is incompatible with autonomy, as if individuals must be the authors of their own values and choices in order to be autonomous. The authors reject this view in a stance sentence that closes the second paragraph.

The next two paragraphs discuss the views of "some critics" of a conception of autonomy as too rational and individual (106). These cited theorists (almost all philosophers, but also including a physician/lawyer and a philosopher/lawyer) present a feminist critique that argues for a more relational understanding of autonomy (i.e., what they call "relational autonomy") or alternatively seeks to lessen the influence of autonomy in bioethics. Beauchamp and Childress consider that relational autonomy is more relevant to their principle of justice and, in a stance sentence that closes the last paragraph, they say that relational autonomy is defensible so long as the main conditions of their conception of autonomy are maintained. In these two paragraphs, the concept of relational autonomy is defined in terms that sound very sociological. Yet, almost all the references are to philosophers and none to sociological theorists.

The five-paragraph subsection on "The Principle of Respect for Autonomy" is all at the subsection level except for a nesting of two enumerative structures in the fourth paragraph at Level 4 . The first stance is taken at the close of paragraph three, the second of three paragraphs on negative and positive obligations implied in the principle. Contemporary Kantian philosophers are cited as support for the authors' view that respect 
for autonomy includes a positive obligation to aid others in achieving their autonomous ends and to enhance their capacity for autonomous choice. The subsection closes with a stance that says that nonautonomous persons are due moral respect and status and that biomedical professionals are obligated to provide them with benefits and protection from harm. This is in interaction with a theologian who they claim misunderstood their position on this point (see Footnote 12).

The seven-paragraph subsection on "The Triumph or Failure of Respect for Autonomy?" is all at the subsection level (3) and all but the first paragraph is part of an enumerative structure of two empirical studies that the authors claim misunderstand their principle of autonomy. The first stance appears in the middle of the second paragraph in interaction with legal scholar Carl Schneider, who criticized those like the authors who insist on the importance of the principle of respect for autonomy. The authors respond that Schneider misunderstands how their principle works. Then, across the next four paragraphs, two of the empirical works cited by Schneider are summarized. One compared by ethnicity the attitudes of elderly patients about disclosure of information and end-of-life decision making, while the second focused on the effects of the disclosure of medical information to Navajo patients.

The sixth paragraph opens with the second stance, which praises the contributions to our cultural understanding of these two studies while claiming that some such studies misunderstand what is required by the principle of respect for autonomy, by the law, and by institutional and professional policies. A stance later in the paragraph questions the soundness of the conclusion of the Navajo study, which the authors interpret as saying that to even inform patients of their right to decide risks harming them. The seventh and 
final paragraph consists of a paragraph-long stance that claims that patients should almost always be asked what information they want to receive and what decisions they want to make. To do so is a profession obligation. Also, patients should be treated as individuals whose choice may not match what would be expected for a mainstream member of their culture.

The citations of the subsection are primarily to lawyers and philosophers, but this is the first section of the chapter to cite empirical work, which is by co-authors from a variety of disciplines. The citations in the subsection represent more disciplines than any section in the 1979 chapter. Also, this subsection provides another example of how several stances can all be directed related to each other, with a longer, closing stance acting as an overall summary and conclusion.

The subsection on "Complexities of Respecting Autonomy" has no introduction, but rather begins with the thirteen-paragraph sub-subsection on "Varieties of autonomous consent." Only the first paragraph is at the sub-subsection level (4). The remainder of the paragraph is organized as an enumerative structure of the varieties of autonomous constent at Level 5, with one paragraph and one sentence of another paragraph containing smaller enumerative structures, making this text Level 6.

The first stance occurs in Footnote 16, given at the end of the first paragraph, which seeks to clarify that the authors do not view consent as necessary and sufficient for all subsequent treatments. A book by philosophers is cited as example of critics who misunderstand the authors' view on this point. The second stance occurs in a discussion of presumed consent. It cautions against presuming what an ideal of rationality or of the common good should be rather than what an individual patient or participant chooses or 
is known to prefer, and it is not stated in the context of any explicit interaction with other authors.

The third stance occurs in the sixth paragraph in the context of reports that a general consent to treatment has been used to allow medical students to practice pelvic exams on anesthetized patients without the patients' specific consent to serve as volunteer teaching subjects. The authors approve of a physician's statement that patients should be treated as teachers of medical students rather than as their tools. The fourth stance, which occurs in the next paragraph, is closely related to the third in claiming that better alternatives in such circumstances are to seek specific consent for the exams or to recruit volunteers for them. The fifth and final stance occurs in the next-to-last paragraph in the context of discussions of presumed consent associated with a change in policy by the CDC to the use of opt-out options for HIV testing and, more directly, of proposals to increase U.S. organ donations by similarly shifting from an opt-in to an opt-out system. This is in interaction mostly with physicians, other biomedical professionals, social scientists, and lawyers, including, as in the last subsection, empirical works with multiple co-authors.

The two-paragraph sub-subsection on "Consents and refusals over time" is all that the sub-subsection level (4). The one stance occurs at the end of the first paragraph in interaction with an ethical case developed by a physician. The case involved whether a patient's previous request for the termination of chronic dialysis treatment should be overridden by his later choice, and the authors suggest that the patient should have been returned to dialysis at least long enough for his choice to be more reliably known. 
THE CAPACITY FOR AUTONOMOUS CHOICE. The one-paragraph introduction to the section on "THE CAPACITY FOR AUTONOMOUS CHOICE" is at the section level (2) and commences the most extensive enumerative structure of the chapter in both editions on the elements of informed consent. The paragraph closes with a stance that rejects a distinction drawn by cited co-authors, a physician and a psychologist, between judgments of decision-making capacity and judgments of competence. The distinction was drawn because the former judgments are made by health professionals and the latter by courts, but the authors maintain that these judgments result in similar practical effects.

The two-paragraph subsection on "The Gatekeeping Function of Competence Judgments" is all at the subsection level (3). A stance occuring at the beginning of the second paragraph states that health professionals who make competence judgments sometimes incorrectly report them as empirical when, even if empirical tests are used, the judgment itself is a normative one. No citation is given in support or in opposition to this stance.

The seven-paragraph subsection on "The Concept of Competence" is all at the subsection level (3). The first stance comes in the middle of the second paragraph, building from a definition of competence given by a cited philosopher and a physician/behavioral scientist as "the ability to accomplish a task" (Culver and Gert, 1982 , quoted in 2012,115). The authors maintain that competence is contextual, relative to the type of decision to be made. Someone incompetent in many areas may be competent to give informed consent for a treatment or for research participation. The second and final stance comes near the beginning of the fourth paragraph, claiming that 
courts have traditionally judged incompetence to apply to a person across different types and occasions of decision making. A citation to a legal decision is given as an example. The two stances of this subsection are closely interrelated. Philosophers are the prominent cited authors overall in the subsection.

The two-paragraph subsection on "Standards of Competence" is all at the subsection level (3) and closes with a stance that comments on a cited case, developed by a physician, of a person judged to be incompetent because he had taken out one of his eyes and cut off one of his hands. The authors consider this a difficult borderline ethical case since the patient's actions were consistent with his extreme religious beliefs and argue that judgments of incompetence in such cases must be carefully reasoned and explained in documentation.

The two-paragraph sub-subsection on "Rival standards of incompetence" begins at the sub-subsection level (4), but a second enumerative structure nested within the larger one on elements of informed consent puts most of it at Level 5. No stances are taken. The most prominent of the citations are to physicians, including an empirical study, but the behavioral and social sciences, law, and philosophy are also represented.

The three-paragraph sub-subsection on "Testing for incompetence" is at Levels 4 and 5 and, like the previous sub-subsection, contains no stances. Again, physicians are most prominent, including an empirical study, with the behavioral sciences, law, and philosophy also represented.

The six-paragraph sub-subsection on "The sliding-scale strategy" is mostly at the sub-subsection level (4), but part of the second paragraph is at Level 5. The first stance occurs at the beginning of the third paragraph, primarily in response to the "competence 
balance scale" of clinical psychologist Thomas Grisso and physician Paul Applebaum, but also citing works by other physicians, philosophers, and another psychologist. The basic idea of this and other sliding scale strategies is that making riskier and otherwise more consequential decisions should require higher levels of decision-making competence. The first stance acknowledges that such a strategy is attractive and recognizes that an interest in good outcomes legitimately influences how standards are set.

The second stance occurs at the beginning of the fourth paragraph, claiming conceptual and moral problems with the sliding-scale strategy. Specifically, the idea that riskier and more consequential decisions require more competence is rejected as unsound. The third stance, covering all of the fifth paragraph, is closely related to the second stance, being basically a restatement of it.

The fourth and final stance, which closes the sub-subsection, is taken in interaction against the views of philosophers defending sliding-scale strategies and in alignment with recommendations from the National Bioethics Advisory Commission that standards of evidence for competence should be on the sliding scale. Risker decisions should require higher standards of evidence for competence. Philosophers are most prominent is this sub-subsection, followed by physicians, psychologists, and the National Bioethics Advisory Commission, and all these disciplines contributed empirical studies save for the Commission.

THE MEANING AND JUSTIFICATION OF INFORMED CONSENT. The section on "THE MEANING AND JUSTIFICATION OF INFORMED CONSENT" opens with a one-paragraph introduction at the section level (2) and has no stances or 
citations. The two-paragraph subsection on "The Justification of Informed Consent requirements" is all at the subsection level (3). The first paragraph closes with a stance on how the justification for the requirement of all medical and research codes for informed consent shifted in the mid-1970s from the avoidance of harm to autonomy. No citations are given in support of the claim.

The second and third stances occur in the middle and close of the second paragraph, both in disaligned interaction with philosopher Onora O’Neill. O'Neill argues against autonomy as the justification for informed consent since she sees the concept as too variable, vague, and otherwise a difficult fit with informed consent. In the second stance, the authors concede that the concept needs clarification, but maintain that autonomy is still the primary justification. O'Neill is further represented as arguing that the primary reasons for informed consent are to avoid deception and coercion. In the third and closing stance, the authors argue that this view needs to be expanded to include attempts to promote patient/participant understanding, to avoid manipulation, and to respect the rights of the patient or participant.

The subsection on "The Meaning and Elements of Informed Consent" opens with a one-paragraph introduction at the subsection level (3), and most of the paragraph consists in a stance against shared decision making as the defining form of or as a substitute for informed consent. The authors argue that improved communication with patients or participants is good, but that a sharing of the decision to undergo treatment or to participate in research would not be autonomous consent and would risk paternalistic behaviors and relationships. The cited authors cited argue for shared decision making are most prominently physicians and the Presidents Commission on the Study of Ethical 
Problems in Medicine and in Biomedical and Behavioral Research, with philosophy, law, and medical humanities also represented. No empirical work is cited.

The five-paragraph sub-subsection on "Two meanings of "informed consent" is all at the sub-subsection level (4) and is all organized as an enumerative structure laying out those two meanings. According to the authors' reading of the bioethics literature, he first meaning is informed consent as genuine autonomous authorization, and the second meaning is legal and institutional. So, consent in the first sense is not necessarily legal, for example, and consent in the second sense might not qualify as autonomous authorization. The first stance is taken at the close of the fourth paragraph, using the work of a philosopher, a psychologist, and a legal decision as background support. The stance claims that rigorous autonomy requirements should be the standard for informed consent, but that in some circumstances in which these standards are too burdensome for institutions and professionals, the rigor can be relaxed.

The sub-subsection closes with a stance that responds to the "fair-transaction model" of informed consent of the philosophers Franklin G. Miller and Alan Wertheimer. These authors conceive of informed consent as a bilateral transaction between the biomedical or research professional and the patient or participant. In their stance, the chapter authors maintain that the fair-transaction model is fine for the second sense of informed consent but, like shared decision making, is not an adequate model for the autonomous authorization of consent. Autonomous consent is seen as belonging to an individual, not as a bilateral transaction. Philosophers are most prominent in this subsubsection, with law and psychology also represented. This fits a pattern in both editions of the chapter of philosophers being cited for conceptual issues. 
The four-paragraph sub-subsection on "The elements of informed consent" begins at the sub-subsection level (4), but switches to Level 5 within the first paragraph with a prior list of elements that becomes the authors' expanded list in the remaining three paragraphs, with the third paragraph at Level 6 with enumerative clarifications concerning the list, and the final paragraph back to Level 4 . The only stance claims that the five-element list of informed consent found in the literature is preferable to the oneelement (disclosure) list that had previously guided courts and the medical literature. However, the authors expand this to a seven-element list. ${ }^{16}$ The elements are divided into threshold elements or preconditions (competence and voluntariness), informational elements (disclosure, recommendation, and understanding), and consent elements (decision and authorization). Most of the citations of the sub-subsection, most prominently to the Belmont Report, a report from the President's Commission, and a work by a physician and a legal scholar, are used as support. However, one legal case is cited as using the disclosure-only definition of informed consent judged by the authors to be inadequate. The commission reports (or ethical codes) are the most prominent.

DISCLOSURE. The three-paragraph introduction to the section on "DISCLOSURE" is all at the section level (2) except for a nested enumerative structure in the second paragraph at Level 3. The first paragraph closes with a stance that claims that informed consent is about autonomous authorization, not about professional obligations of disclosure as in legal decisions. The only citation in the introduction is to a legal decision which is not connected to the stance.

\footnotetext{
${ }^{16}$ The list, which can be considered a major claim of the chapter, could be considered a part of the stance. However, I judged that the stance does not include the list itself.
} 
The one-paragraph introduction to the subsection on "Standards of Disclosure" is all a nested enumerative structure and hence at Level 4. It does not contain a stance or any citations. The sub-subsection on "The professional practice standard" consists of two paragraphs, the first with two nested enumerative structures (Level 5) and the second with three nested structures (Level 6). The first paragraph provides a summary description of the standard, which rests on the established standards of a professional community of practice, whether or not these are adequate to satisfy the principle of respect for autonomy. Also, with this standard, only the expert judgment of the professionals counts as evidence. The entirety of the second paragraph is a stance outlining the reasons for the inadequacy of the professional practice standard: (1) not all communities of professional practice have such a standard, (2) the community standard may be inadequate yet perpetuated, (3) the professionals don't always understand patients'/participants' best interests, and (4) patients'/participants' autonomy may be ignored. The only citation is to two empirical studies on which the third point above is based, among which physicians and other biomedical professions are most prominent and religious studies is included.

The two-paragraph sub-subsection on "The reasonable person standard is all at Level 5. As in the last sub-subsection, the first paragraph provides a summary description of the standard, while the entirety of the second paragraph is a stance that claims that aspects of the concept are underdeveloped and that the standard is too abstract to be used in practice as biomedical professionals must project what would be adequate disclosure to a reasonable person. No citations are made in the sub-subsection. 
The two-paragraph sub-subsection on "The subjective standard" is all at Level 5. Again, the first paragraph provides a summary description of the standard, while the closing sentence of the second paragraph contains a stance. Under the subjective standard, information to be disclosed is tailored to the needs of the individual patient or participant. In the only citation in the sub-subsection, a legal decision is used as an example of support for the subjective standard. However, this standard is not entirely feasible to implement, so in their stance, the authors recommend that the reasonable person standard be supplemented with as much information tailored to the individual patient/participant as they desire and as is feasible for the professionals to provide.

The one-paragraph introduction to the subsection on "Intentional Nondisclosure" is at the subsection level (3) and contains no stances nor citations. The three-paragraph sub-subsection on "The therapeutic privilege" is all at the sub-subsection level (4). The authors report that the therapeutic privilege, differently defined and protected in different legal jurisdictions, is the only controversial exception to informed consent requirements. It allows professionals to withhold the disclosure of information in cases where, for medical reasons, it could cause a patient or participant harm or prevent a good. In the stance near the end of the final paragraph, the authors maintain that the reason for withholding information should not be because it might lead to the patient declining treatment. The most prominent citations, none of which are in interaction with the stance, are to legal decisions and legal scholarship. Others are to physicians, other biomedical professionals, and a psychologist.

The three-paragraph sub-subsection on "The therapeutic use of placebos" is all at the sub-subsection level (4) and cites the most works of any single section in the chapter. 
The limited evidence of the benefits of placebos and patterns in their use are discussed. The deception that frequently accompanies their use is said to diminish patient trust in biomedical professionals. Two empirical studies by physicians, psychologists, other biomedical professionals, and a philosopher, are cited in this discussion, but are not connected to the sub-subsection's two stances. The first stance, which closes the second paragraph, endorses a position taken by the American Medical Association to require informed consent for placebo use. This is in interaction with citations to the work of physicians, philosophers, and psychologists on the ethical aspects of the undisclosed use of placebos, none of which are empirical. The second stance, closing the third paragraph and the sub-subsection, claims that the undisclosed use of placebos misses opportunities for better doctor-patient communication. The stance is taken in interaction most prominently with physicians, but also with other biomedical professionals, psychologists, and a philosopher. These are not empirical works, and all are in support of the stance. Overall, physicians and philosophers are most prominent in this sub-subsection, followed by other biomedical professionals and psychologists, with a marginal representation from law.

The four-paragraph sub-subsection on "Withholding information from research subjects" is all at the sub-subsection level (4). A first stance closes the first paragraph: “...disclosures, warnings, and opportunities to decline involvement are sometimes legitimately substituted for informed consent" $(2012,130)$. This is in the context of a discussion, without any citations of cases, such as in epidemiology, where a failure to get informed consent is sometimes justifiable. The second stance is in the context of a discussion of a particular medical study in which participants were informed that their 
drawn blood would be tested for HIV, but failed to disclose that it would also be tested for cocaine use. This empirical study and a reaction to it by a philosopher are the citations in interaction with the stance, which argues that the researchers should have developed an alternative research design that did not require a failure to get completely informed consent for its success. The third stance, closing the sub-subsection and comprises the entire final paragraph, summarizes the conditions under which deception by researchers is justified: "only if it is essential to obtain vital information, it involves no substantial risk, they inform subjects that deception or incomplete disclosure is part of the study, and subjects consent to participate under these conditions" (131). These three stances are all connected, especially the first and third. Physicians are most prominent in the citations, with a philosophers also cited.

UNDERSTANDING. The two-paragraph introduction to the section on "UNDERSTANDING" is all at the section level (2) and contains no stances. The two citations are to co-authored empirical studies in which physicians are most prominent, followed by other biomedical professionals and behavioral and social scientists.

The seven-pararaph subsection on "The Nature of Understanding" is all at the subsection level (3), save for a portion of a paragraph at Level 4. Most of the citations in the subsection are to empirical works, with physicians being most prominent, followed by behavioral and other social scientists and other biomedical professionals, with a linguist also represented. However, the two stances are in more specific interaction. The first stance is argued against unspecified authors who are skeptical that the full disclosure and full understanding necessary for informed consent is possible. The stance responds, with support from a cited philosopher, that "From the fact that actions are never fully 
informed, voluntary, or autonomous, it does not follow that they are never adequately informed, voluntary, or autonomous" $(2012,132)$. The second stance opens the final paragraph. It concerns the notion of the therapeutic misconception, which suggests that informed consent is not achieved if research participants believe they are receiving therapy rather than volunteering for research. In the stance, the authors endorse the distinction drawn by philosopher and bioethicist Christine Grady and her co-author, physician/neurologist Sam Hrong, between therapeutic misconception, therapeutic misestimation, and therapeutic optimism. It is argued, that while a therapeutic misconception invalidates informed consent, these latter two types of misconception do not. The stance is in interaction only with Hrong and Grady.

The five-paragraph subsection on "Problems of Information Processing" is all at the subsection level (3). The only stance opens the subsection with the claim that with a few exceptions in studies of comprehension, information processing has not received enough attention in understanding patient/participant decision making. All of the subsequent citations to studies on the topic are given in support of the stance, and so are in interaction with it. These citations are primarily to empirical work, and behavioral and social scientists are most prominent, followed by physicians and other biomedical professionals, with law and education having marginal representation.

The three-paragraph subsection on "Problems of Nonacceptance and False Belief" is all at the subsection level (3). The only stance opens the second paragraph and claims that, in cases in which ignorance prevents informed consent or refusal, the imposition of undesired information may be justifiable and even necessary. This is in interaction with 
the only citation in the subsection, which is to an illustrative case study authored by a physician and a psychologist.

The three-paragraph subsection on "Problems of Waivers" is all at the subsection level (3), and the only stance closes the second paragraph. The stance warns against the moral dangers of waivers of informed consent, such as the fact that too many patients/participants put too much trust in biomedical and behavioral science professionals and the possibility of waivers being used for the mere convenience of professionals. Two citations are given in support of the stance, one by a philosopher and one a legal decision. Overall, philosophers are much more prominent in the subsection, with law represented in the one citation.

VOLUNTARINESS. The one-paragraph introduction to the section on "VOLUNTARINESS" is all at the section level (2). The Nuremberg Code is cited as an early document demanding a greater emphasis on voluntariness. In their stance in the latter half of the paragraph, the authors take a position for a conception of voluntariness more narrow than that of the scholars cited on the issue. In this other, broader view, they claim, voluntariness is not clearly differentiated from autonomy. Instead, they will use voluntariness to mean to will an action without controlling influence from outside forces, whether from other persons or from medical conditions. The citations in the introduction are all part of the stance interaction, mostly prominently the ethical code, followed by physicians, behavioral and social sciences, and a marginal representation by business administration and theology. One of the citations is to an empirical work by physicians and a sociologist. 
The five-paragraph subsection on "Forms of Influence," after an introductory paragraph at the subsection level (3), consists of a nested enumerative structure on the forms of influence at Level 4. The forms discussed are coercion, persuasion, and manipulation. The only stance occurs at the end of paragraph two on coercion, staking out a narrow definition of coercion as involving intentional and credible threats to control a patient or subject. The four citations are all within the stance interaction, and all are to philosophers. They all appear to be in support of the authors' position, but the context is not clear for the alignment of the fourth of these. This is another instance of conceptual work treated as the province of philosophy.

The four-paragraph subsection on "The Obligation to Abstain from Undue Influence" is all at the subsection level (3) and contains no stances. Though no positions are taken, a number of issues pertaining to undue influence are discussed. The citations are most prominently to behavioral and social scientists, then to historians and American Studies scholars on the Tuskegee case, and further to philosophers, physicians, and other biomedical professionals. Law, business administration, and theology were also slightly represented. Two of the citations were to co-authored empirical studies related to nursing homes.

CONCLUSION. The three-paragraph chapter "CONCLUSION" is all at the chapter level (1) and contains no citations. Each paragraph is a stance, save for the conclusion's opening sentence. The first stance concedes that the principle of respect for autonomy is still under development and will undergo further specification. The second stance continues with the concession that conceptual and practical issues with informed consent and with the place of respect for autonomy remain under development. Finally, 
the third stance reiterates a point made in the chapter introduction that the principle of respect for autonomy does not take a priority over the other bioethical principles in the authors' framework, beneficence, nonmaleficence, and justice. Now that the stance interactions of each chapter have been described, the focus turns to a comparison of the chapters by their major topics.

\section{Chapter Comparisons by Major Topics}

Now that the stance interactions of each chapter have been described, the focus turns to a comparison of the chapters by their major topics. The textbook's autonomy chapters center on two interrelated concepts, respect for autonomy and informed consent. In the first edition chapter, as already stated, autonomy is discussed only in interaction with other philosophers, principally the classic philosophers Kant and Mill.

In the seventh edition chapter, the definition and discussion of autonomy and of the principle of respect for autonomy is the authors' principles framework is refined and extended. In this chapter, the interactions in the sections on autonomy are still principally with philosophers $(69.1 \%$ prominence $)$, though researchers from all the other disciplines represented in the chapter are cited. Most prominent among these are legal scholars (11.5\%), behavioral and social scientists $(7.9 \%)$, and physicians $(4.3 \%)$.

However, these citations are mostly in the final autonomy subsection, "The Triumph or Failure of Respect for Autonomy?", after the concept and principle have been worked out among philosophers. Challenges to the principle, including in two empirical studies, are reported, but Beauchamp and Childress treat such challenges as misinterpreting how the principle meant to be applied. 
Challenges to their conception of autonomy from feminist philosophers who argued for a relational conception of autonomy in the earlier subsection on "Autonomy, Authority, Community, and Relationships." Beauchamp and Childress did not reject this relational conception per se, but claimed it applied more to their principle of justice.

The discussion of informed consent in the first edition (1979) chapter was in interaction most prominently with law and with the behavioral and social sciences, with philosophy, ethical codes and commission reports, medicine, and bioethics also being represented. In the seventh edition (2012), medicine and other biomedical sciences and professions, considered together, were most prominent (35.6\%) in the discussion of informed consent, with philosophy not far behind (28\%). The behavioral and social sciences and law, also less prominent, still made a significant contribution.

Focusing more closely on those elements of informed consent discussed at some length in the chapters, namely competence (to understand and decide), voluntariness (in deciding), disclosure (of material information), and understanding (of information), can increase our grasp on the contexts of interaction.

Philosophers were mostly prominently $(83.3 \%)$ cited in the first edition discussion on competence, with law and the behavioral and social sciences also represented. A major shift in prominence is seen in the seventh edition chapter, however, with medicine overtaking philosophy (40\% to $31.4 \%$ ). The behavioral and social sciences were also better represented (19.8\%), and law's minor presence remained. No empirical research is cited in this discussion in the first edition, and only a single empirical study of small prominence, from medicine, is cited in the seventh edition. 
The authors' basic views on competence do not change between the first and seventh editions, but the seventh edition chapter seems to reflect more contributions by physicians to the literature on competence and incompetence, including standards and tests used as part of clinical assessments of incompetence. The authors draw upon these contributions in refining and elaborating on this element of informed consent.

The more limited discussion on voluntariness in the first edition chapter has only one citation, which is to philosophy. The discussion is expanded in the seventh edition, with philosophy still most prominent $(43.6 \%)$, followed by the behavioral and social sciences (26.5\%), ethical codes and commission reports (10.1\%) and other disciplines $(15.1 \%)$. As with the treatment of competence, the discussion of voluntariness makes no citation to empirical work in the first edition and only a limited number in the seventh edition. As with competence, the authors' basic position on voluntariness does not change substantially between editions but again, the position is expanded and refined. More attention is given in the seventh edition to the distinction between coercion, persuasion, and manipulation (or undue influence), whereas persuasion was not explicitly discussed in the first edition.

Even in the first edition chapter, the discussion on the disclosure of information included barely any interaction with philosophy. Over half (58\%) of the interactional prominence was to the behavioral and social sciences, primarily as examples of the use of deception in research. Law was next in prominence (32\%), with a minor amount of attention going to medicine and other disciplines. A large shift in prominence occurred by the seventh edition chapter, with most (56.7\%) going to medicine and other biomedical 
sciences and professions. Philosophy increased in prominence to $19 \%$, while law (18.5\%) and the behavioral and social sciences $(5.3 \%)$ drew a smaller proportion of attention.

In both editions, a significant proportion of the chapters' citations to empirical studies occur in the context of disclosure. Whereas the most prominent of these are almost all (92.9\%) to behavioral and social science in the first edition, however, most prominent of the citations (60.4\%) in the seventh edition were to medicine and other biomedical sciences and professions. Behavioral and social sciences were still wellrepresented with $33.7 \%$ of citation prominence.

The authors' basic focus on the distinction between the professional practice standard, the reasonable person standard, and the subjective standard of disclosure persists between editions. So does their recommendation of the reasonable person standard supplemented with the disclosure of as much information as both feasible and desired by each individual patient, intended as a more practical application of the subjective standard.

Nevertheless, there is a shift in content concerning the disclosure of information between editions that helps to explain the shift in the prominence of disciplines. Whereas the first edition focused on examples of deception in research in the behavioral and social sciences, the example discussed in the seventh edition concerned a medical study. Discussions of the concept of therapeutic privilege and of the therapeutic use of placebos were more concerned with medicine, which was reflected in its citational prominence both overall and in empirical studies.

Finally, the discussion of patients' and subject/participants' understanding of disclosed information was most prominently to medicine (32.1\%) and the behavioral and 
social sciences (21.4\%) in the first edition, with law (17.9\%), bioethics (17.9\%), and philosophy also having substantially prominence in the citations. In the seventh edition, medicine, if combined with other biomedical sciences and professions, was still most prominent (41.5\%). The behavioral and social sciences and philosophy grew in prominence to $31.9 \%$ and $14.4 \%$, respectively.

Citations to empirical studies in the first edition discussion of understanding were few, but they grew to a proportionally substantial degree in the seventh edition. In the latter edition, $77.1 \%$ of the prominence in citations to empirical studies was to medicine and other biomedical sciences and professions, followed by the behavioral and social sciences with $18.7 \%$. Law fell significantly in citation prominence, but it was still represented at $6.4 \%$.

In the following chapter, I draw conclusions from the descriptive observations and interpretations of the stance interactions in context of this chapter and from the descriptive statistics of multi-level discourse structure, of stance structure, and of disciplinary prominence of Chapter 4. 


\section{Chapter 6}

\section{Conclusions and Future Work}

Text organization. The study illustrates some interesting connections between the macro and micro levels of text organization. The connection the authors draw between their principle of respect for autonomy and the practice of informed consent in clinical and research settings is made at a micro level in the first edition, with no signal of how they are to be related at the macro level of section titles. In this edition, the relation between the two is first drawn in the subsection "The functions of informed consent" in which the authors say that of the several functions informed consent performs, the protection of autonomy is the primary one.

Also, the authors' list of the elements of informed consent, given at Level 3 in the first edition and at Level 5 in the seventh, plays a major organizing role in both chapters as the elements in the list map to entire sections of the chapters. One could interpret this as a form of bottom-up control of textual organization, where the list functions in a like manner to a table of contents.

The seventh edition chapter (2012) appears more organized and seamlessly constructed than the first edition (1979) chapter. In the first edition chapter, the third section on "Refusal of Treatment" and the fourth section on "Autonomous Suicide" are clearly related to the chapter's theme. Nevertheless, they are organized more like add-on sections less integrated to the whole. 
"Refusal of Treatment" is about informed refusal, the negative side of informed consent. This is treated within the informed consent section in the seventh edition. "Autonomous Suicide" seems like a self-contained miniature essay that is an application of respect for autonomy. The ethical consideration of suicide appears to have been of current interest as a problem in bioethics, but it is completely dropped from the seventh edition chapter. The only mention in 2012 is to irrationally suicidal persons as one type of nonautonomous patient.

In the seventh edition (2012) chapter, the connection between respect for autonomy and informed consent is more integrated and is signaled at the macro level by the section titles. The first mention of the term "informed consent" is in the subsection on "The Principle of Respect for Autonomy." Next, the first sub-subsection under the subsection "Complexities in Respecting Autonomy" is titled "Varieties of autonomous consent," a term that is a hybrid of the two concepts. Then, when the subject turns to the section on "THE MEANING AND JUSTIFICATION OF INFORMED CONSENT," autonomy continues to be a central topic associated with informed consent.

The distribution of text and of stances between levels provides further evidence of a different degree of organization between the chapters. In the first edition, the distribution of text between levels appears relatively arbitrary and is given uneven development. Only the opening paragraph is at Level 1, while two-thirds of the text is at Level 3. Very little text is at Level 4, and Levels 5 and 6 contain about the same amount of text. The stance text within those levels is also uneven. As discussed in Chapter 4, the amount of stance text at Levels 1,3 , and 6 is close to what would be expected by chance 
based on all text at each level. However, less stance text than would be expected by chance occurs at Levels 2 and 4, while much more than expected occurs at Level 5.

By contrast, the text is more evenly distributed between levels in the seventh edition (2012) chapter. A large portion of the text is at the Level 3, the subsection level (30.9\%), but Level 4, the sub-subsection level, is also proportionally large (40.9\%). The other levels have small but substantial amounts of text, ranging from $4.7 \%$ to $9.9 \%$. Also, the stance text in 2012 is more evenly distributed between levels, being close to what would be expected by chance at each level.

\section{Changes in the discussion of the concept of autonomy and of the principle of}

respect for autonomy. The discussion on autonomy grew in length by $79 \%$ between the first and seventh editions. The number of stances grew from 8 to 14, a $75 \%$ increase, but the overall length of stances only grew by $21 \%$. In the first edition, Beauchamp and Childress draw exclusive support in their development and presentation of their conception of autonomy and principle of respect for autonomy from Immanuel Kant and John Stuart Mill. The only two citations are to philosopher Robert Paul Wolff in opposition to his anarchistic interpretation of autonomy in Kant.

In the seventh edition, the concept of autonomy and of respect for autonomy do not change greatly, but they are more elaborated, and some additions are made. The discussion's citations document a considerable theoretical interest in autonomy since the first edition. An interesting empirical question is whether this represents a growth in academic consideration of autonomy that may be related to a growth during the period between editions in bioethical questions. The discussion on autonomy in the seventh edition responds to several criticisms of Beauchamp and Childress's treatment of the 
concept in the first and subsequent editions. If theoretical and empirical work on autonomy did grow during this period, a reasonable hypothesis would be that a significant proportion of this work was inspired by the textbook' first edition and its institutional adoption.

No classic philosopher is cited in reference to the autonomy discussion in the seventh edition chapter, but liberty and agency, the principal elements drawn from Kant and Mill, remain the key defining conditions for autonomy. Whereas the first edition include a subsection on "The autonomous person," and although other autonomy theories focus on a person's overall capacity for autonomy, the focus in the seventh edition chapter is on specific contexts of autonomous choice. The authors present their theory of autonomy in contrast to the split-level theory of autonomy of Gerald Dworkin and other contemporary philosophers, which was developed after the first edition of the Principles textbook. The split-level theory is claimed to set so high a bar on what qualifies as autonomy that the everyday choices of the average chooser would not be considered autonomous. In Beauchamp and Childress's theory, the three conditions of autonomy are intentionality, understanding, and non-control. Of these, understanding is an addition to the concept since the first edition. The motivation for the addition is unclear. Notably, understanding, like the condition of non-control (or voluntariness), are also among the authors' elements of informed consent, so their conception of autonomy could be interpreted to have become more in tune with their conception of informed consent.

The discussion of the principle of respect for autonomy is expanded and refined in the seventh edition. The first edition combined Kant's emphasis on autonomy as requiring mutual respect for the autonomy of oneself and others with Mill's emphasis on 
liberty of action. In the seventh edition, respect for autonomy is said to impose negative and positive obligations. The negative obligations concern not controlling others' pursuit of their chosen actions, the point drawn from Mill in the first edition. The positive obligations, however, draw from contemporary Kantians. We should not only refrain to use others as means to our ends, but we should also assist others in achieving their ends. In the medical context, examples include sharing any requested information and answering requests for assistance in decision making.

As in the first edition, arguments that autonomy is incompatible with authority are rejected. In the seventh edition, however, more contemporary examples of the rejected argument are cited. The rest of the concept of autonomy discussion in the seventh edition consists of responses to criticism of their treatment of autonomy in the first edition. The authors introduce the chapter by rejecting criticisms that their theory of autonomy is too individualistic, too rational, and too legalistic.

In the autonomy discussion proper, feminists, almost all from philosophy, are cited as the source of the "too individualistic" criticism. These cited authors developed versions of a concept of relational autonomy that they considered more adequate. "This conception of 'relational autonomy' is motivated by the conviction that persons' identities are shaped through social interactions and complex intersecting social determinants, such as race, class, gender, ethnicity, and authority structures" $(2012,106)$.

Beauchamp and Childress do not reject the concept of relational autonomy, but neither do they incorporate it into their theory. Instead, they claim that the concept belongs more in other parts of their principles framework, especially justice. This move seems unlikely to have been considered a satisfactory response to the feminist critics 
since they considered the problem to be with the first edition textbook's theory of autonomy itself and to autonomy's perceived centrality among the principles of the framework. Basically, Beauchamp and Childress argue that relational autonomy is fine so long as it doesn't impinge on their existing conception of autonomy, which they consider to be fundamentally important. They seem to consider any theory or practice that does not focus on respect for each individual patient or participant to risk a failure to respect autonomy at all.

As noted in Chapter 5, the concept of relational sociology is very sociological, but as in most of their autonomy discussion, predominantly philosophers and no behavioral or social scientists are cited in this connection. From my perspective as a relational sociologist, the authors take a position with theoretical vulnerabilities by not engaging sociological and psychological theories of the relational self and identities as a part of their development of the autonomy concept itself. Rather than sink the concept, as some critics of autonomy might assume should result from such engagement, such social scientific theories and empirical studies could possibly refine autonomy or some similar alternative to the concept that bolster the argument for some version of Beauchamp and Childress's principle. The authors imply that empirical studies like the two they cite enrich the principle, but do not indicate how. Instead, they fall back on a theoretically weaker argument that current legal, institutional, and professional standards require respect for autonomy in clinical and research settings.

As noted in Chapter 5, the predominant use of philosophers in the autonomy discussion in both editions follows a more general pattern of philosophers being cited in discussions of concepts in the autonomy chapters. This could be interpreted as an 
institutional move by the authors to reinforce a perception that conceptual analysis is the proper domain of philosophers.

The last subsection in the seventh edition's autonomy discussion includes most of the citations to disciplines other than philosophy. A legal scholar's criticism that "autonomists" like Beauchamp and Childress push choices on patients and participants whether they want them or not. Two empirical studies that were cited by the legal scholar as support for his criticism are summarized, and Beauchamp and Childress respond that all three of these works misunderstand how autonomy works in their framework.

What can we conclude from the fact that the authors made prominent use of classic philosophers in the first edition chapter but not at all in the seventh edition? They were not starting the subject from scratch with no bioethical literature on which to draw. One possible explanation is that they made a prominent use of Kant and Mill because the theories of these authors fit with their goals for their principle of autonomy. Another possible explanation is that drawing from classic thinkers is a common move in newer, less developed areas of academic literature. The authors use the respected names to help legitimate their principles framework and the bioethics field. By the seventh edition, neither Kant nor Mill nor any other classic philosopher is cited in the chapter. Only modern philosophers are cited in their place, such as a reference to "contemporary Kantians" $(2012,107)$.

Conclusions about changes in informed consent will be divided into the more general discussion and each of four discussions of major elements of informed consent, namely competence, disclosure of information, understanding, and voluntariness. 


\section{Changes in the discussion of autonomous consent and the meanings,}

justifications, and elements of informed consent. The length of the overall discussion of informed consent grew by $58 \%$ between the first and seventh editions. However, the general discussion of informed consent before its elements are each discussed in greater length doubled in length between editions, while the length of stances tripled. The number of stances increased from 4 to 7.

Case law and legal scholars were most prominent in the first edition general discussion of informed consent, which includes a section on informed refusals, with ethical codes, philosophers, and bioethicists also having significant prominence. This comports with the authors' statement that clinical informed consent derived from case law and that research informed consent derived from ethical codes.

The authors draw from legal scholar Alexander Capron's list of five functions of informed consent, but they take a stance that the primary function is the one that appears first on Capron's list, to protect patient and participant autonomy. They state that Capron's list of functions of informed consent can also be considered justifications for it, while adding that social utility and nonmaleficence are also justifications. Nevertheless, they reiterate their position that protecting autonomy is the principle justification, outweighing all others. As to the elements of informed consent, they list four. To the legal and regulatory emphasis on voluntariness and the disclosure of information they add the comprehension of information and the competence to consent.

In the seventh edition, the discussions of autonomy and informed consent are bridged by the subsection on "Complexities of Respecting Autonomy," which is focused on types of consent, explicit, implicit, and presumed, and potential problems with each, 
rather than on autonomy. Physicians and behavioral and social scientists are most prominent in this subsection, with 11 disciplines receiving some citations.

In discussions of the meanings, justifications, and elements of informed consent, philosophers are most prominent, continuing the pattern of philosophers having the primary role in conceptual analysis, but physicians, ethical codes, and law also make a significant contribution.

Beauchamp and Childress defend the place of protecting autonomy as the primary justification for informed consent. First, they take a stance against philosopher Onora O’Neill's claim that concepts of autonomy and respect for autonomy are too vague and imperfect a fit with informed consent. Second, they take a stance against scholars who would substitute shared decision making for informed consent, which Beauchamp and Childress argue can easily perpetuate paternal relationships in medicine. Third, while they concede that the feasibility of some informed consent practices within institutions should be taken into consideration, they insist that autonomous decision making remains the key consideration in these institutional practices. Fourth, they take a stance against a "fair transaction model" that had been proposed to replace their autonomous authorization model. The "fair transaction model" conceives of informed consent as a bilateral transaction which, like in the shared decision making model, Beauchamp and Childress argue is unsuitable for a model of informed consent. They say autonomous authorization is one-sided, not bilateral.

Also in the seventh edition, the four elements of informed consent are expanded to seven. However, this expansion does not alter the four core elements previous put forward, which are still the ones given the most attention in the subsequent discussion. 
Discussion of competence or the capacity for autonomous choice. This

element of informed consent is called competence in the first edition and the capacity for autonomous choice in the seventh. The discussion is placed before the general discussion of informed consent in this latter edition, presumably because the authors consider this capacity to be a precondition for informed consent. The length of the discussion doubled in the seventh edition. The number of stances increased from 1 to 9 , and the length of this stance text increased almost 37-fold.

Philosophers were most prominent in the first edition discussion of competence, though physicians also had a significant prominence. In the seventh edition, philosophers were still more prominent in the discussion of the concept of competence, but physicians and, to a lesser but significant extent, behavioral and social scientists were more prominent in the discussion of standards of competence. So, in connection with this element of informed consent, a disciplinary division of labor is evidenced where philosophers again are predominantly drawn upon for conceptual work, while physicians and behavioral and social sciences are drawn upon for technical and empirical work concerning competence.

Beauchamp and Childress's core position on competence is consistent between editions. In both, they maintain that competence should be judged in the context of particular types of consent decisions, as well as the timing of decisions in cases of intermittent or reversable competence. In this way, they seek to maximize the situations in which autonomy can be protected. This is in contrast with blanket judgments of incompetent personhood, and such blank judgments are attributed to many legal decisions in a stance in the latter edition. The other consistent part of their core position is that 
competence judgments should never be reduced to the empirical instruments used to measure competence. They should always also contain a normative element.

Two of the three stances in the introduction and conceptual part of the discussion are not in interaction with others. Instead, positions expressed in the first edition are given the added emphasis of evaluative language. These can be considered opening moves of interaction. The argument in the concept of competence discussion is also more developed and refined.

The seventh edition subsection on standards of competence is dense with new information that is organized into a number of enumerative structures, and this structure is more hierarchical than in the first edition, with some passages at Level 5. A lengthy sub-subsection on "The sliding scale strategy" of Grisso and Applebaum, a psychologist and a physician, respectively, contains the other six stances in the competence discussion. These stances are interrelated. The sliding scale model, for which greater risks are claimed to require higher standards of competence, is first given a couple of positive stances with regard to its positive aspects. However, it is rejected as inappropriate, as is a similar argument by another pair of authors with similar ideas. In its place, drawing support from the National Bioethics Advisory Commission, is a sliding scale of standards of evidence. In other words, riskier procedures would require higher standards of evidence of competence.

Discussion of disclosure of information. The discussion around the disclosure of information only grew $12 \%$ in length between the first and seventh editions. Stances only increased from 8 to 10 , and the overall length of those stances actually was a little briefer. 
The discussion of this element included a good amount of empirical work even in the first edition, though empirical work had a little more prominence in the seventh edition.

The author's position on standards of disclosure did not change. From the first to the seventh editions, they recommend the reasonable-person standard from law supplemented by as much of the subjective standard as is feasible for the needs of individual patients. This is not a position they were called upon to defend.

However, the prominence of disciplines changed. The first edition discussion was dominated by the behavioral and social sciences, with law also playing a prominent role. In the seventh edition, by contrast, medicine had the most prominence, with law and philosophy also playing a significant part. Law was predominant in the first edition discussion of standards of disclosure, with psychology also significant, but was only used in the discussion of the subjective standard in the seventh edition. Medicine was cited exclusively in connection with the professional standard in the latter edition.

As noted in Chapter 5, psychology (Stanley Milgram) and sociology (Laud Humphries and an Italian study) were used as the main examples of intentional nondisclosure in the first edition. These examples were entirely replaced by ones from medicine in the seventh edition, which indicates growth in the bioethics literature as represented by this textbook as well by the growth in medicine and other biomedical disciplines between editions.

The first edition discussion on randomized clinical trials as intentional nondisclosure was moved to a later chapter in the latter edition. This was replaced by a discussion of the therapeutic use of placebos. Medicine and other biomedical disciplines, followed by philosophy and, to some extent, psychology, were prominent in this context. 
This discussion is remarkable on how much empirical research on the use of placebos the authors use in their argument since Beauchamp and Childress do not treat the empirical work as beside the point of their moral argument. In light of the overall growth in prominence of medicine and other biomedical disciplines in the seventh edition to one equally that of philosophy, this part of the discussion suggests cooperation more than competition between these disciplines.

\section{Discussion of the comprehension or understanding of disclosed information.}

The discussion of comprehension doubled in length from the first to the seventh edition. However, the number of stances stayed roughly the same, from 4 to 5, while the length of those stances shrank by 38\%. Medicine and psychology were the most prominent disciplines in the first edition and remained so in the seventh. Nevertheless, the overall prominence score of these and other disciplines doubled, showing a growth in the bioethical literature brought into this discussion. The prominence of empirical work tripled, with co-authorship helping to explain many more disciplines being represented at least slightly.

Again, Beauchamp and Childress maintained the same basic positions between editions, such as the view that comprehension need not be complete so long as it is adequate. Also, they continued to recommend not allowing waivers of consent in general, while allowing hospital ethics boards and IRBs to make exceptions. What changes by the seventh edition is the addition of many suggestions from cognitive psychology, medical decision making, and from additional biomedical knowledge of ways to increase adequate understanding. Like in the discussion on the disclosure of information, the discussion on the understanding of information contains part of the growth of medicine 
and other biomedical disciplines and, in this case, of psychology in support of the authors' position. On balance, cooperation is again observed.

Discussion on voluntariness. The length of the discussion on voluntariness almost doubled. Stances increased from 1 to 2 , but the length of the stances in the latter edition were 10 times longer. The citations in the first edition were all to philosophy, but the number of disciplines represented and the overall prominence of all disciplines was much greater in the seventh. Philosophy was still prominent, but so were ethical codes, history, and others. Empirical studies contributed to the discussion.

The authors differentiate themselves in the seventh edition from other definers of voluntariness by preferring a comparatively narrow definition since a broader one makes voluntariness the same as autonomy. Also, they take a position against using the term coercion too loosely. Their first edition discussion, which centered on coercion and undue influence, changed in the seventh edition to a discussion of coercion, persuasion, and manipulation.

\section{Overall Conclusions}

This study's comparative analysis of the autonomy chapters in the first (1979) and seventh (2012) editions of Principles of Biomedical Ethics by Beauchamp and Childress has demonstrated that stance structures provide a framework for identifying, describing, and evaluating interactions in expository text. These are interactions not just between authors and texts but between academic disciplines.

The formal graphical analysis used, with graphical elements defined in terms of multi-level textual structures, did provide a discursive framework or scaffolding useful for identifying and analyzing stance structure. Since the discourse structure is 
hierarchical, the stance structure is also hierarchical. The expectation was that stances occurring at higher levels of the structure would be more central or important to the discourse. Past research (e.g., van Dijk, 1980) also suggests that discourse at higher levels will tend to be more general.

The stances examined in this study did tend to be more general at higher levels. The chapters also provided some evidence that the stances at higher levels could be considered more central or important. In both the chapter-level introduction and conclusion of the seventh edition chapter, Beauchamp and Childress respond to commentators who had claimed that their principle of autonomy dominates or holds a more prominent place within their framework of four bioethical principles by denying that that is the case. By taking this stance in both the chapter-level introduction and repeating it again in the chapter-level conclusion, this can be interpreted as the stance most central to the chapter.

Examining stance structure also revealed that, in a number of instances, stances within a given topical section of text were found to be interrelated like parts of a common stance. The study also found that stances within a given text segment can and do occur either at the beginning, the middle, or the end of a segment, but that they occur most often at the end.

The analysis of stance interactions also provided a valuable insight on the contexts in which citations are made. Stances positively aligned with other authors were frequently stated more briefly and were frequently signaled by stance markers like, “[Author name(s)] appropriately argue that..." or "[Author name(s)] correctly argue that..." Stances negatively aligned with other authors tended to be longer, first laying out 
the others' arguments, and then responding to them in an evaluative stance. Some stances represented the first move in an interaction rather than a response to a claim by a previous author. Such a first move makes a claim that might later draw a response from other authors.

The introduction in this study of a measurement of the textual prominence of a citation, called a prominence score, has provided a more adequate means of analyzing the stance interactions between disciplines than citations counts alone could provide. Measuring the prominence of cited disciplines overall and within the context of different topic areas has allowed some insight into the changing interactions and influence in the construction and maintenance of the principle of respect for autonomy over this period. Some of the changes in the bioethics field, within the focus of this one concept, can be inferred from the textual analysis of this study.

The core aspects of the concepts did not change between editions, but additions and refinements of definition and argument were evident in the seventh edition. Also, much more empirical work was drawn upon in support and in challenge to the concepts.

Philosophy was most prominent in the first edition chapter and remained the most prominent single discipline in the seventh edition. However, medicine, other biomedical disciplines, and other miscellaneous disciplines in co-authorship with biomedicine, when considered together, slightly overtook philosophy in prominence. A division of labor was discerned in the seventh edition, with philosophy most prominent in conceptual analysis and the biomedical fields most prominent in technical and empirical contributions. Less prominent but also significant in these technical and empirical contributions were the behavioral and social sciences, especially psychology. Beauchamp and Childress 
integrated these technical and empirical contributions in their arguments for their theory and recommendations concerning the principle of respect for autonomy and informed consent to a much greater extent in the seventh edition chapter. Ethical codes and ethical commission reports, along with case law and legal scholarship, continued to make their necessary but less prominent contributions.

The number of disciplines cited in the seventh edition increased dramatically. Many of these disciplines made their contribution through co-authorships in empirical studies, but the increased collaboration through co-authorship seen in the seventh edition citations provides evidence of a greatly expanded interdisciplinarity in bioethics.

The interactions between disciplines in the chapters do not provide direct evidence of conflict between philosophy and medicine or the other disciplines represented insofar as no overall patterns of stance alignment or disalignment between the disciplines was found. In other words, the authors were roughly as likely to take stances in opposition to philosophers or bioethicists or legal scholars as to biomedical and other scholars. The same goes for supportive stances.

In their claims in the autonomy chapters, Beauchamp and Childress draw for their arguments mostly from existing institutional arrangements in bioethics and from practical exigencies from the experience of bioethical practice (ethical theory and principles in the context of contemporary law and medical practice, including measures, procedures, diagnoses, etc.). They take what can be interpreted as a reform position as they are arguing for principles to guide more ethical biomedical practice within current institutional arrangements, rather than taking a more critical position that might seek to overturn those arrangements. 
Bioethics began with a growing perception that the rapid advances of science, including biomedical science, should not be left entirely in the hands of the scientists. Theology in the early days, and then philosophy, were the disciplines seen as best equipped to address the ethical quandaries raised by scientific and technological advances, and philosophers have supplied many of the ranks of bioethical work.

This study must leave as an open empirical question what implications the changes in disciplinary prominence observed might signal for relations of power between these disciplines. The growth in prominence of the medical and other biomedical sciences and professions around questions of autonomy and informed consent might be interpreted as a biomedical response to the establishment of bioethics. However, as already noted, the interactions between philosophy and the biomedical disciplines in the seventh edition were found to be more cooperative than oppositional. This could nevertheless be seen as consistent with a conclusion that Beauchamp and Childress's principles framework serves the purposes of biomedicine or at least does not seriously challenge them. Again, though, this study does not allow any conclusions to be drawn on the question.

Future work. This study provides suggestions for much future work. One potentially promising area concerns the refinement of the prominence measure adopted here. This measure could have important implications for the measurement and study of bibliographic networks and for quantitative assessments of researcher productivity. This potential needs to be explored and tested. If such testing finds the measure to be a valuable addition to current measures, then the potential of possible algorithms for the automated identification and calculation of prominence also need to be explored to make its adoption and use more practical on a larger scale. 
However, this study also demonstrates that matching citations with stances is a qualitative task. Computation techniques have commonly sought to define matches according to textual proximity, which in this case would be defined as the proximity to a stance statement. While this type of technique might be found to have an acceptable rate of false positive and false negative matches, it seems unlikely that it would be able to match the rate of a trained or expert qualitative analysis.

Another direction for future study would be to identify all parts of the stance acts as defined by Du Bois (2007) in terms of the parts of the stance triangle: the interacting authors, their respective stances toward a common stance object and the positioning this entails, the common stance object, and alignment/disalignment between the interactants. One potential use of such stance triangles (or triads) would be in constructing stance networks between interacting authors in multiple texts.

At least one article on the results and implications of the study for a linguistics audience, probably with a linguist co-author, is warranted. In a different article, statistical models could be developed and fitted to the data collected in the study. Yet another article could compare the results of the method used in this study with leading automated techniques, such as topic modeling and sentiment analysis.

The study's sample is small and could be expanded in a variety of directions, such as analyzing the autonomy chapter through more editions, or analyzing more chapters within one edition. The study also frequently found relationships between the stances occurring within a section, subsection, or sub-subsection, and patterns in these relationships could be explored. Finally, the relationship between stance structure and 
argumentation structure (e.g., as studied by computational linguists Pendszus and Stede, 2016) of the sample texts could be explored. 


\section{References}

Abbott, Andrew. 1988. The System of Professions. Chicago: University of Chicago Press. . 2001. Chaos of Disciplines. Chicago: University of Chicago Press.

. 2005. "Linked Ecologies: States and Universities as Environments for

Professions.” Sociological Theory, 23(3): 245-274.

Asher, Nicholas et al. 2017. "ANNODIS and Related Projects: Case Studies on the Annotation of Discourse Structure." Pages 1241-1264 in Nancy Ide and James Pustejovsky (eds.), Handbook of Linguistic Annotation. Dordrecht: Springer.

Asher, Nicholas and Alex Lascarides. 2003. Logics of Conversation. Cambridge, UK: Cambridge University Press.

Bail, Christopher A. 2014. "The Cultural Environment: Measuring Culture with Big Data." Theory and Society, 43(3): 465-482.

Beauchamp, Tom L. and James F. Childress. 1979. Principles of Biomedical Ethics. New York: Oxford University Press.

1983. Principles of Biomedical Ethics, Second Edition. New York: Oxford University Press.

. 1989. Principles of Biomedical Ethics, Third Edition. New York: Oxford

University Press.

1994. Principles of Biomedical Ethics, Fourth Edition. New York: Oxford University Press.

. 2001. Principles of Biomedical Ethics, Fifth Edition. New York: Oxford University Press.

. 2009. Principles of Biomedical Ethics, Sixth Edition. New York: Oxford

University Press.

2012. Principles of Biomedical Ethics, Seventh Edition. New York: Oxford University Press.

Benarama, Farah, Maiti Taboada, and Yannick Mathieu. 2017. "Evaluative Language Beyond Bags of Words: Linguistic Insights and Computational Applications."

Computational Linguistics: 43(1): 201-264.

Biber, Douglas and Susan Conrad. 2009. Register, Genre, and Style. Cambridge, UK: Cambridge University Press. 
Bourdieu, Pierre. 2010 [1984]. Distinction: A Social Critique of the Judgment of Taste. Abingdon, UK: Routledge.

Bourigault, Didier, Cécile Fabre, Cécile Frérot, Marie-Paule Jacques, Sylwia Ozdowska. 2005. "Syntex, analyseur syntaxique de corpus." Atala. Actes des 12èmes journées sur le Traitement Automatique des Langues Naturelles, 2005, Dourdan, France.

Colléter, Maud et al. 2012. "La Ressource ANNODIS Multi-échelle: Guide d'Annotation et Bonus." Technical Report 20, Carnets de grammaires, CLLE-ERSS. Université de Toulouse.

De Vries, Raymond, Robert Dingwall, and Kristina Orfali. 2009. "The Moral Organization of the Professions: Bioethics in the United States and France." Current Sociology, 57(4): 555-579.

Diesner, Jana and Kathleen M. Carley. 2005. "Revealing Social Structure from Texts: Meta-Matrix Text Analysis as a Novel Method for Network Text Analysis." Pp. 81-108 in V. K. Narayanan and D. J. Armstrong (Eds.), Causal Mapping for Information Systems and Technology Research: Approaches, Advances, and Illustrations. Harrisburg, PA: Idea Group Publishing.

Dijk, Teun A. van. 1980. Macrostructures: An Interdisciplinary Study of Global Structures in Discourse, Interaction, and Cognition. Hillsdale, NJ: Lawrence Erlbaum Associates. 1993. Elite Discourse and Racism. Thousand Oaks, CA: Sage Publications.

DiMaggio, Paul, Manish Nag, and David Blei. 2013. "Exploiting Affinities Between Topic Modeling and the Sociological Perspective on Culture: Application to Newspaper Coverage of U.S. Government Arts Funding." Poetics, 41(6): 570-606.

Ding, Ying, Guo Zhang, and Tamy Chambers. 2014. "Content-Based Citation Analysis: The Next Generation of Citation Analysis." Journal of the Association for Information Science and Technology, 65(9): 1820-1833.

Du Bois, John W. 2007. “The Stance Triangle.” Pp. 139-182 in Robert Englebretson (ed.), Stancetaking in Discourse: Subjectivity, Evaluation, Interaction. Amsterdam: John Benjamins Publishing Company.

Elliott, David L. 2017. "Investigating the Stance and Rhetorical Structure of Longer Spans of Written Academic Discourse." Paper presented at the Sunbelt XXXVII, the International Sunbelt Social Network Conference, May 30-June 4, in Beijing, PR China. 
. 2011. "Which Disciplines Have the Most Impact Today In the

Interdisciplinary Discipline of Bioethics?' Paper written for Professor Douglas Steinley for his course PSYC 9715 Multilevel Modeling at the University of Missouri.

Evans, John H. 2012. The History and Future of Bioethics: A Sociological View. Oxford, UK: Oxford University Press.

Fontdevila, Jorge. 2010. "Indexes, Power, and Netdoms: A Multidimensional Model of Language in Social Action." Poetics 38: 587-609.

Fontdevila, Jorge and Harrison C. White. 2013. "Relational Power from Switching Across Netdoms Through Reflexive and Indexical Language." Ch. 7, pp. 155-179 in François Dépelteau and Christopher Power (eds.), Applying Relational Sociology: Relations, Networks, and Society. New York, NY: Palgrave Macmillan.

Godart, Frédéric C. and Harrison C. White. 2010. "Switchings Under Uncertainty: The Coming and Becoming of Meanings." Poetics 38: 567-586.

Fox, Renée C. and Judith Swazey. 2008. Observing Bioethics. Oxford, UK: Oxford University Press.

Giora, Rachel. 2014. "Cognitive and Social Aspects of Coherence." Pp. 141-153 in Thomas M. Holtgraves (ed.), The Oxford Handbook of Language and Social Psychology. Oxford, UK: Oxford University Press.

Goffman, Erving. 1974. Frame Analysis: An Essay on the Organization of Experience. Boston: Northeastern University Press. . 1981. "Footing.” Pp. 124-159 in Forms of Talk. Philadelphia: University of Pennsylvania Press.

Gray, Bethany and Douglas Biber. 2015. "Stance Markers." Pp. 219-248 in Karen Aijmer (ed.), Corpus Pragmatics: A Handbook. Cambridge: Cambridge University Press.

Ho-Dac, Lydia-Mai, Cécile Fabre, Marie-Paule Péry-Woodley, and Josette Rebeyrolle. 2010. "On the Signalling of Multi-Level Discourse Structures." Pages 94-105 in the Proceedings of the $8^{\text {th }}$ MAD Multidisciplinary Perspectives on Signalling Text Organisation, March 2010, Moissac, France.

Ho-Dac, Lydia-Mai et al. 2012. "An Empirical Approach to the Signalling of Enumerative Structures." 2012. Discours (online), 10. http://journals.openedition.org/discours/8611 ; DOI : 10.4000/discours.8611

2011. "High-Level Discourse Structures: Topical Chains and Enumerative Structures in a Diversified Annotated Corpus. Corpus Linguistics. 
Hood, Susan. 2010. Appraising Research: Evaluation in Academic Writing. Basingstoke, UK: Palgrave Macmillan.

Hunston, Susan. 2011. Corpus Approaches to Evaluation: Phraseology and Evaluative Language. New York: Routledge.

Hyland, Ken. 2004 [2000]. Disciplinary Discourses: Social Interactions in Academic Writing. Ann Arbor: University of Michigan Press. 2012. Disciplinary Identities: Individuality and Community in Academic Discourse. Cambridge, UK: Cambridge University Press.

Jockers, Matthew L. 2014. Text Analysis with R for Students of Literature. Cham, CH: Springer.

Jonsen, Albert R. 1998. The Birth of Bioethics. Oxford: Oxford University Press.

Mann, William C. and Sandra A. Thompson. 1987. "Rhetorical Structure Theory: A Theory of Text Organization.” Reprinted from The Structure of Discourse. ISI/RS-87190, Marina del Rey, CA: Information Sciences Institute, Southern California University. 1988. "Rhetorical Structure Theory: Toward a Functional Theory of Text Organization.” Text, 8(3), 243-281.

Marcu, Daniel. 2000. The Theory and Practice of Discourse Parsing and Summarization. Cambridge, MA. The MIT Press.

Martin, J.R. and P.R.R. White. 2005. The Language of Evaluation: Appraisal in English. Basingstoke, UK: Palgrave Macmillan.

Mead, George Herbert. 1934. Mind, Self, and Society: From the Standpoint of a Social Behaviorist. Chicago, IL: University of Chicago Press.

Mead, George Herbert. 1938. The Philosophy of the Act. Chicago, IL: University of Chicago Press.

Mathet, Yann and Antoine Widlöcher. 2011. Glozz User's Manual 1.0. Downloaded March 26, 2018 from < http://www.glozz.org/>

McLean, Paul. 2017. Culture in Networks. Cambridge, UK: Polity Press. 2007. The Art of the Network: Strategic Interaction and Patronage in Renaissance Florence. Durham, NC: Duke University Press. 
Mische, Ann. 2011. "Relational Sociology, Culture, and Agency." Pages 80-98 in John Scott and Peter Carrington (eds.), The Sage Handbook of Social Network Analysis. London, UK: Sage Publications. 2008. Partisan Publics: Communication and Contention Across Brazilian Youth Activist Networks. Princeton, NJ: Princeton University Press.

Mohr, John and Petko Bagdanov. 2013. "Topic Models: What They Are and Why They Matter." Poetics, 41: 545-569.

Orfali, Kristina and Raymond G. DeVries. 2010. "A Sociological Gaze on Bioethics." Ch. 22, pp. 487-510 in William C. Cockerham (ed.), The New Blackwell Companion to Medical Sociology. Oxford, UK: Wiley-Blackwell.

Peldszus, Andreas and Mandred Stede. 2016. "Rhetorical Structure and Argumentation Structure in Monologue Text." Proceedings of the $3^{\text {rd }}$ Workshop on Argument Mining, pp. 103-112, Berlin, Germany, August 7-12, 2016.

Péry-Woodley, Marie-Paule, Ho-Dac, Lydia-Mai, Jesette Rebeyrolle, Ludovic Tanguay, and Cécile Fabre. 2017. "A Corpus-Driven Approach to Discourse Organisation: From Cues to Complex Markers." Dialogue and Discourse 8(1): 66-105.

Popping, Roël. 2000. Computer-Assisted Text Analysis. Thousand Oaks, CA: Sage Publications.

Power, Richard, Donia Scott, and Nadjet Bouayad Agha. 2003. "Document Structure." Computational Linguistics, 29(2): 211-260.

Small, Henry. 2011. "Interpreting Maps of Science Using Citation Context Sentiments." Scientometrics, 87: 373-388.

. 1982. "Citation Context Analysis." Pages 287-310 in B. Dervin and M.J. Voigt (eds.), Progress in Communication Sciences, Volume 3. Norwood, NJ: Ablex.

Spillman, Lyn. 2014. "Mixed Methods and the Logic of Qualitative Inference." Qualitative Sociology, 37: 189-205.

Tilly, Charles. 2008. Contentious Performances. Cambridge, UK: Cambridge University Press.

. 1997. "Parliamentarization of Popular Contention in Great Britain, 17581834." Theory and Society, 26: 245-273.

. 1995. Popular Contention in Great Britain, 1758-1834. Cambridge, MA: Harvard University Press. and Lesley J. Wood. 2003. "Contentious Connections in Great Britain, 182834." Pages 147-172 in Social Movements and Networks: Relational Approaches to 
Collective Action, edited by Mario Diani and Doug McAdam. Oxford, UK: Oxford University Press.

Toboada, Maite and William C. Mann. 2006a. "Rhetorical Structure Theory: Looking Back and Moving Ahead. Discourse Studies, 8(3), 423-459.

Teufel, Simone. 2010. The Structure of Scientific Articles: Applications to Citation Indexing and Summarization. Stanford, CA: Center for the Study of Language and Information.

Toulmin, Stephen. 1958. The Uses of Argument. Cambridge, UK: Cambridge University Press.

White, Harrison C. 2008. Identity and Control: How Social Formations Emerge. Princeton: Princeton University Press.

White, Harrison C and Frédéric C. Godart. 2010. "Relational Language: The Example of Changes in Business Talk." Relationale Soziologie, 273-289.

White, Howard D. 2011. "Scientific and Scholarly Networks." Pages 271-285 in The Sage Handbook of Social Network Analysis, edited by John Scott and Peter J. Carrington. Thousand Oaks, CA: Sage. . 2004. "Citation Analysis and Discourse Analysis Revisited." Applied Linguistics, 25(1): 89-116.

Widlöcher, Antoine and Yann Mathet. 2012. “The Glozz Platform: A Corpus Annotation and Mining Tool.” Pages 171-180 in Cyril Concolato and Patrick Schmitz (eds.), Proceedings of the ACM Symposium on Document Engineering, Sept. 2012, Paris, France.

Wolf, Florian and Edward Gibson. 2006. Coherence in Natural Language: Data Structures and Applications. Cambridge, MA: The MIT Press.

Zhao, Dangzhi and Andreas Strotmann. 2015. Analysis and Visualization of Citation Networks. Morgan and Claypool. 


\section{Appendix A}

\section{Annotated Chapter 3, "The Principle of Autonomy," from Beauchamp and Childress, $1^{\text {st }}$ Ed., (1979)}

3

\section{The Principle of Autonomy}

Diverse figures in philosophy, including Kant, Nietzsche, Sartre, R. M. Hare, and Robert Paul Wolff, have held that morality in some sense requires autonomous persons. Their views are different, however, because they select different themes from a family of ideas associated with autonomy: freedom of choice, choosing for oneself, creating one's own moral position, accepting ultimate responsibility for one's moral views, etc. Because of these divergent interpretations, we shall examine the concept of autonomy before trying to develop a moral principle of autonomy and sketching its implications for biomedical ethics.

\section{The concept of autonomy}

\section{The autonomous person}

Autonomy is a form of personal liberty of action where the individual determines his or her own course of action in accordance with a plan chosen by himself or herself. The autonomous person is one who not only deliberates about and chooses such plans but who is capable of acting on the basis of such deliberations, just as a truly independent government has autonomous control of its territories and policies. A person's autonomy is his or her independence, self-reliance, and self-contained ability to decide. A person of diminished autonomy, by contrast, is highly dependent on others and in at least some respect incapable of deliberating or acting on the basis of such deliberations. Institutionalized populations such as prisoners and the mentally retarded may have diminished autonomy. A form of psychological incapacitation afflicts the retarded, while a severely restricted social environment curtails the autonomy of prisoners. The most general idea of autonomy is that of being one's own person, without constraints either by another's action or by a psychological or physical limitation. The term "autonomy" is thus quite broad, for it can refer to both the will and action in society; and both internal and external constraints on action can limit autonomy.

Two figures in the history of philosophy have shaped our understanding of autonomy as, respectively, freedom of the will and freedom of action. These figures are Immanuel Kant (a rule deontologist) and John Stuart Mill (a utilitarian). In his Groundwork of the t 
Metaphysics of Morals and other writings, Kant contrasted heteronomy (rule by other persons or conditions) and autonomy. Autonomy is governing oneself, including making one's own choices, in accord with moral principles which are one's own and which are universalizable, i.e., can be willed to be universally valid for everyone. Under "heteronomy," Kant included both external and internal determinations of the will, bunot moral principles. While one's own self-imposed rule obliges one to so act, one is only complying with a self-legislated rule. Coerced actions are obviously heteronomous, but Kant also regarded acting from desire, impulse, and habit as heteronomous. Thus, a person who acts out of desire, rather than reason, is not acting autonomously, for heteronomy is subjection of the will to any rule or motive outside itself.

Whereas Kant was largely concerned about the autonomy of the will, Mill was more concerned about the autonomy of action. As Mill recognized, the latter is more difficult to justify than the former. In On Liberty, Mill argues that social and political control over individual actions is legitimate only if necessary to prevent harm to other individuals affected by those actions. He construes the principle of utility to permit all citizens to develop their potential according to their own convictions, as long as they do not interfere with a like expression of freedom by others. The promotion of autonomous expression in his view maximizes the benefits for all concerned. Conformity to established patterns reduces individual productivity and creativity which, if developed, could benefit the society. The society thus benefits in proportion as individuals develop their own natural talents and facilities for judgment. In his discussion of individuality, Mill holds that a person "without character" is one who is controlled by his environment--church, state, parents, family, etc.--whereas a person with true character is one of genuine individuality who takes from the culture only what he finds valuable. The latter person can make new discoveries and develop new practices.

For our purposes, Kant's main contribution to a theory of autonomy is his discussion of self-legislation: the reasons for actions for autonomous persons are their own reasons, and they are principled rather than arbitrary reasons. This notion of self-directed action based on a rational principle accepted by the agent is the central ingredient in "autonomy" in the remainder of this chapter. "Acceptance by the agent" needs emphasis. Kant is often interpreted as holding that each individual person must make (author or originate) his own moral principles. Because this extreme interpretation denies much that we know about the moral life, we will here understand Kant to mean that each individual must will the acceptance of his principles. Finally, while Mill's views on autonomous choice in many ways parallel Kant's, Mill's concerns about the tyranny of society led to idealistic notions about freeing oneself from society and becoming virtually a sovereign, except where others are involved. In this discussion of autonomy and subsequently in our treatment of paternalism in Chapter 5, we will see both the importance and the limits of this ideal.

\section{Respect for autonomy and the principle of autonomy}

It is one thing to be autonomous and to apprehend that others are acting autonomously, but quite another to be respected as an autonomous agent and to respect the autonomy of 
others. To respect autonomous agents is to recognize with due appreciation their own considered value judgments and outlooks even when it is believed that their judgments are mistaken. To respect them in this way is to acknowledge their right to their own views and the permissibility of their actions based on such beliefs. And to grant them this right is to say that they are entitled to such autonomous determination without limitations on their liberty being imposed by others. This conclusion follows from Mill's views on individualism and social liberty, but it also has an important basis in Kant's thought. To respect autonomy for Kant is bound up with conceiving the other person as having unconditional worth, solely because persons are ends in themselves determining their own destiny and are not to be treated merely as means. To treat a person merely as a means always involves a violation of autonomy for Kant, because the person is then being treated in accordance with rules not of his own choosing. To show a lack of respect for an autonomous agent, then, is either to reject that person's considered judgments or to deny him the freedom to act on those considered judgments. For Kant a moral relation between persons is always one where there is mutual respect for autonomy--where both are autonomous, of course. It is hard to find fault with this particular point in his argument.

The moral notion of respecting the autonomy of other persons can, for our purposes, be formulated as a principle of autonomy that should guide our judgments about how to treat self-determining moral agents. It follows from the views advanced by Mill that insofar as an autonomous agent's actions do not infringe the autonomous actions of others, that person should be free to perform whatever action he wishes--even if it involves serious risk for the agent and even if others consider it to be foolish. We shall later in this chapter discuss those occasions on which a rational agent expresses an autonomous wish to take his own life and those occasions on which it might be permissible to restrain such autonomous actions. Whether or not there are limits to the valid expression of autonomy, Mill is surely right to insist that in self-regarding actions we ought to be as free as possible to do as we wish. (See Chapter 5 for some possible qualifications.) This is the first aspect of the principle of autonomy.

The second aspect follows from Kant's position: in evaluating the self-regarding actions of others we ought to respect them as persons with the same right to their judgments as we have to our own. This aspect of the principle of autonomy is often referred to as the principle of respect for persons, because it demands respect not for a utilitarian or any other reason except that another is a person and therefore rightfully a rational determiner of his or her own destiny. So far as our actions in regard to others are concerned, it is doubtful that the approaches taken by Mill and Kant lead to significantly different courses of action. Mill's view leads to a moral demand of noninterference with the autonomy of others in society, while Kant's leads to a moral demand that certain attitudes of respect be framed about the personhood and beliefs of others. In the end these two very different philosophers present views of autonomy which are both acceptable and in no major respects incompatible.

It is important, however, that the principle of autonomy not be interpreted either as absolute or as too broad in scope. Some persons are not in a position to act in a 
sufficiently autonomous manner, perhaps because they are immature, incapacitated, ignorant, coerced, or in a position in which they can be exploited by others. Infants and irrationally suicidal individuals are typical examples. The actions of such nonautonomous persons may be validly obstructed in order to protect them from harms that might result from their own actions. Those who defend autonomy have never denied that this interference is valid, because they regard such actions as substantially nonautonomous. The principle of autonomy thus applies exclusively to persons capable of autonomous choice.

\section{Autonomy and authority}

It is sometimes held that autonomy is such a supreme value that it is inconsistent with the authority of the state, social groups, or individuals who function in special contexts as authorities and who make decisions over the lives of autonomous agents. This radical position would reject, for example, the legitimacy of governmental implementation of restrictive public policies intended to protect and promote health. It also entails that medical authorities can never validly intervene in the lives of autonomous patients. One argument for this position is that the autonomous person is one who self-determines his actions through moral deliberation totally unimpeded by any authority's influence. ${ }^{1}$ In this theory, because autonomous persons must act on their own reasons, they should never submit to another person or authority simply because the other utters an imperative. Obviously a conflict between autonomy and all authority results, for it is a necessary condition of authority that a person be obeyed merely because that person occupies a position of authority; and it is a necessary condition of autonomy that a person must refuse all heteronomous influence by authorities. ${ }^{2}$ Because this conclusion might seem to follow from the philosophies of both Mill and Kant, it is worth considering whether autonomy is radically inconsistent with authority in the way this theory suggests.

\footnotetext{
We think there is no fundamental inconsistency, because the very notions of autonomy and authority employed in this theory are eccentric and indefensible. Common conceptions of nondictatorial political and social practices generally assume that provision of reasons is part of, not distinct from, the process of legitimate authoritative command. That is, reasons which justify commands are not regarded as isolated from command circumstances. Dutiful citizens are not expected to comply with authoritative commands without provision of reasons and merely because authorities have spoken. In democratic theories of the state, for example, authorities are not envisioned as issuing commands without justification. And the legitimacy of any command is regarded as contingent upon the command's not exceeding the limits of autonomously delegated authority. Moreover, we often gratefully appeal to authorities when we know of no other place to turn. If we want to know what should be done about an irregular heartbeat, or how to play tennis better, or whether an automobile's mileage rating is accurate, we consult with an authoritative individual and willingly - autonomously - rely on that person's determinations.
}

Moral principles are not disembodied rules, cut off from their cultural setting. Most, if not all, of our moral beliefs have arisen from shared experiences and tacit social 
agreements and arrangements. Morality is by its very nature not an individual-centered phenomenon, as even Kant and Mill usually acknowledge. The notions of virtuous conduct, acceptable forms of loving, kinds of respect owed others, and many other moral views have been adopted largely, and willingly, from cultural arrangements. In some cases a principle could not be a moral principle and stand in abstraction from such an arrangement. It would then just be an individual principle. Codes of medical ethics, for example, do not allow individual authorship, and to act against them merely on grounds of individual principle is to act immorally by the standards of that community, unless there is something about the codes incompatible with morality itself.

One can, of course, act autonomously by rejecting all these social understandings of morality. This action would be, as Nietzsche put it, a transvaluation of values. But, as we have seen, it does not follow that because it is an autonomous action it is morally acceptable or even morally principled. It also does not follow that when one acts on a principle widely shared in society that one acts nonautonomously. Autonomy is perfectly compatible with authority, as long as the authority is autonomously accepted-whether it be a social, political, or religious authority. As Kant rightly pointed out, autonomy is compatible even with a rigid understanding of the objectivity and authority of all moral principles (as a system that applies to everyone). To this it may be added that autonomy is compatible with moral traditions, even if these traditions can never be taken as conclusive authorities in and of themselves. Autonomy is thus far more closely linked to the notion of reflective individual choice or acceptance of a view than it is to the notion of rejection of authority and traditional views.

This conclusion about the compatibility of autonomy and both delegated authority and moral tradition holds for medical contexts as well as for political ones. The authority assumed by medical professionals presents many of the difficulties about autonomy and consent that arise in the medical setting. We shall see that a number of interesting paradoxes of autonomy emerge in medical contexts because of the condition of the subject, on the one hand, and the authoritative position of the medical professional, on the other. There will be a number of occasions (both here and in the section on paternalism in Chapter 5) where we may doubt that authority and autonomy are in fact compatible. These contexts will usually be ones, however, where authority either is not delegated or is itself questionable as an authority.

\section{Informed consent}

The voluntary consent of the human subject is absolutely essential.

This means that the person involved should have the legal capacity to give consent; should be so situated as to be able to exercise free power of choice, without the intervention of any element of force, fraud, deceit, duress, overreaching, or other ulterior form of constraint or coercion; and should have sufficient knowledge and comprehension of the subject matter involved as to enable him to make an understanding and enlightened decision. This latter element requires that before the acceptance of an affirmative decision by the experimental subject there should be made known to him the nature, duration, and purpose of the experiment; the methods and means by which it is to be conducted; all inconveniences and hazards reasonably to be expected; and the 
effects upon his health or person which may possibly come from his participation in the experiment. (Nuremberg Code, Rule I; See Appendix II)

The horrible story of experimentation in concentration camps led to serious concern about the use of nonconsenting subjects in questionable and sometimes brutal experiments. Indeed, since the Nuremberg trials the issue of informed consent has received more attention than any ethical issue in biomedical research involving human subjects. The Nuremberg Code cited above is one result, but controversies about informed consent have also arisen in other quarters. In American law, for example, the doctrine of informed consent has gradually emerged from malpractice cases involving nonconsensual touching of the patient's body - a form of intentional interference qualifying as battery. Touching without consent, where patients are capable of consent, has been found unacceptable, irrespective of considerations of the quality of care. As a rough generalization, it can be said that most recent discussions of informed consent can be traced historically to two sources: (1) Standards for medical practice have derived from case law, and (2) standards for research have grown from their roots in both the Nuremberg Code and the Declaration of Helsinki.

\section{The functions of informed consent}

In recent years virtually all medical and research codes of ethics have held that physicians must obtain the informed consent of patients before undertaking significant therapeutic or research procedures. While these consent measures have largely been designed to protect the autonomy of patients and subjects, they also serve other functions. Alexander Capron has helpfully identified several important functions: ${ }^{3}$

(1) The promotion of individual autonomy

(2) The protection of patients and subjects

(3) The avoidance of fraud and duress

(4) The encouragement of self-scrutiny by medical professionals

(5) The promotion of rational decisions

(6) The involvement of the public (in promoting autonomy as a general social value and in controlling biomedical research)

Capron correctly argues that informed consent serves each of these several functions, but, both historically and contemporarily, the primary function it serves is the protection of individual autonomy. Autonomy is fostered by informed consent procedures in at least two ways. First, at the level of the unique relationship between patients or subjects and medical professionals, autonomy is protected because persons are granted the right to make decisions affecting their lives, even though the health professional may possess far more information and training. A second and rather different way of protecting autonomy was suggested by Mill. By establishing mechanisms in society that promote individual thought and initiative, Mill believed that the interests of both society and the individual would be enhanced. An extension of his argument is the following: to the extent violations of autonomy are institutionally condoned, we all stand to suffer, because the right to make such choices will in general be impaired or even eliminated by this 
institutional arrangement. This latter consideration, as advanced by Mill, will become of major significance in Chapter 5, where the subject of paternalism is investigated.

\section{The justification of informed consent}

The functions of informed consent mentioned by Capron can also be reconstructed as formal justifications of the requirement that informed consent be obtained. Thus, one justification of the requirement is that of protecting patients and subjects by preventing harm to them - a justification based on the principle of nonmaleficence. This justification is especially appropriate for legal requirements governing consent. As we shall see, the law of battery protects against unauthorized touching; and the law of negligence holds researchers responsible for certain deviant procedures they might employ. ${ }^{4}$ Second-party consent, or consent on behalf of a person given by another, can be similarly justified. Nonetheless, this justification in terms of the principle of nonmaleficence is not fundamental to moral justifications of first-party consent. While a person's own decision may indirectly function to prevent harm, he may also autonomously choose a greater risk than others would choose for him. The principle of autonomy justifies allowing a person this option of greater risk.

Another important justification for informed consent is based on the principle of utility: informed consent will maximally protect and benefit everyone in society, including health professionals, patients, and the institutions of medical practice and research themselves. Rules of consent serve to protect and benefit patients and professionals, to allay public fears (especially about research), to encourage self-scrutiny by physicians and investigators, and to maintain relations of trust. This justification is closely related to Capron's fourth and sixth functions.

Even though both the justification based on utility and the justification based on nonmaleficence are appropriate for some consent requirements, neither is the primary justification of informed consent. Both the historical roots and the primary justification of informed consent are located in the principle of autonomy - not in the principles of nonmaleficence or utility. There is a moral duty to seek a valid consent because the consenting party is an autonomous person, with all the entitlements that status confers. By contrast, neither utility nor nonmaleficence leads to this strong conclusion, for both would justify not seeking consent in some circumstances - utility when it would not maximize the social welfare and nonmaleficence when no apparent harm would result. When informed consent is justified by the principle of autonomy, it is introduced, as Robert Veatch puts it, "not to facilitate social benefits, but as a check against them," for persons have rights independent of such considerations as immediate social utility and risk to patients or subjects.

This view has long-standing appeal in the law, where it is somewhat more fully developed than in writings on moral philosophy. Justice Cardozo's statement in behalf of autonomy is well known: "Every human being of adult years and sound mind has a right to determine what shall be done with his own body; and a surgeon who performs an operation without his patient's consent commits an assault, for which he is liable in 
damages. . . . this is true except in cases of emergency where the patient is unconscious and where it is necessary to operate before consent can be obtained." ${ }^{\prime 6}$ An updated and in some ways even stronger view of this sort is found in the landmark Natanson v. Kline opinion, where it is argued that

Anglo-American law starts with the premise of thoroughgoing self-determination. It follows that each man is considered to be master of his own body, and he may, if he be of sound mind, expressly prohibit the performance of lifesaving surgery, or other medical treatment. ${ }^{7}$

In short, the fact that we would often seek to obtain informed consent, even when it does not maximize immediate social utility and even when subjects and patients are not being protected against risk, indicates that autonomy and not some other principle is the basic justifying principle.

\begin{abstract}
As previously mentioned, nonautonomous persons must sometimes be protected by securing the informed consent of a second person who is appropriately related to the patient or subject. Parents, legal guardians, and perhaps a patient-designated friend all might qualify as a second party whose consent or permission is morally valid. The need for this derivative form of consent arises both when persons are incapable of consenting, e.g., when comatose, or in infancy, or emotionally distraught, and also when an informed consent is only doubtfully present. In the case of patients who are mentally ill, for example, we may on occasion reasonably doubt the validity of consent; and for classes of persons such as children and prisoners the ability of individuals to give a free and informed consent to biomedical or behavioral research may at times be doubtful. In these cases, where we might fall into error, it seems best to err on the side of ethical conservatism: we should strive not to deny an important medical benefit when a person is incapable of knowledgeably accepting it, even if - after careful examination - we are uncertain about the validity of a consent or refusal. By contrast to the justification for obtaining first-party consent, which is based on protecting autonomy, the justification for obtaining second-party consent derives largely and perhaps exclusively from the moral demand that subjects and patients be protected from harm-a demand derived from the principles of nonmaleficence and beneficence. (See Chapters 4 and 5.)
\end{abstract}

\title{
The elements of informed consent
}

Whether first parties or second parties are in question, it is generally agreed that informed consent must be solicited whenever a procedure is intrusive, whenever significant risks might be run to persons, and whenever the purposes of the procedure might be questionable. But there is controversy concerning the elements that constitute informed consent.

Medical and research codes, as well as federal regulations, have traditionally emphasized that the act of consent must be genuinely voluntary and that there must be adequate disclosure of information; but there are actually several distinct elements of informed consent, each containing its own separate issues. The information element of informed consent refers to adequate disclosure of information and adequate comprehension by patients or subjects of what is disclosed, while the consent component refers to a 
voluntary decision on the part of a competent person. But how much and what types of information must be imparted, and how well must it be understood? Is consent valid if it is given under conditions of social pressure or if the consent is irresponsible? Underneath these questions is the need for a detailed analysis of the concept of informed consent that raises the moral problems unique to each element. Accordingly, each of the following four elements and the issues each raises will now be discussed:

\section{Information Elements \\ 1. Disclosure of Information \\ 2. Comprehension of Information \\ II. Consent Elements \\ 3. Voluntary Consent \\ 4. Competence to Consent}

Each of these four components should be understood as a necessary condition of valid informed consent. However, this broad generalization will have to be qualified and refined as each of the elements is studied. We begin with the last of the four elements in the above chart.

\section{Competence}

Competence to consent could perhaps be more appropriately described as a presupposition of informed consent than as an element of informed consent. Logically, competence is a precondition of acting voluntarily and apprehending information. It is fundamental in biomedical contexts, because certain physical and mental defects can result in a situation where patients and subjects are not - in psychological fact or in lawable to give informed consent. Obviously many conditions external to an agent may inhibit voluntary action, but many internal conditions may also limit voluntary consent. It is usually the latter that give rise to questions about competence. For example, minors commonly are not capable of responsible actions, while the mentally disabled and the comatose present even more troublesome cases.

The concept of competence is a multidimensional one. Competence and incompetence are often assessed by diverse and even inconsistent theories of comprehension, rationality, freedom, physiological state, etc., and judgments of incompetence often apply to a limited range of decision making, not to all decisions made by a person. Some persons who are legally incompetent may be competent to conduct most of their personal affairs, and vice versa. The same person's ability to make decisions may vary over time, and the person may at a single time be competent to make certain practical decisions but incompetent to make others. For example, a person judged incompetent to drive an automobile may not be incompetent to decide to participate in medical research, or may be able to handle simple affairs easily, while faltering before complex ones. Accordingly, the notions of limited competence and intermittent competence are useful, because they require a statement of the precise decisions a person can make, while avoiding the false dichotomy of "either competent or incompetent." Use of these notions would preserve 
maximum autonomy, justifying intervention only in those areas where a person clearly is of questionable competence.

Each class of possible subjects who might be classified as incompetent should therefore be considered separately, especially where unfair evaluations might occur. For example, from the fact that persons have been admitted to institutions on grounds of incompetence, it does not follow that they are incompetent. Questions of the need for their consent, and of its validity, depend in complex ways on the precise nature of their incompetence to consent, their previous declarations, and on the precise constraints characteristic of their conditions of life. Some patients and research subjects, such as children, have inherent limits on their capacity to understand and consent. Still other subjects may not be capable of understanding information, while successfully assimilating part of the information. is easy to violate the autonomy of members of such groups, and sometimes extraordinary measures must be taken in order not to invalidate the consent process. For example, those who have a severely limited capacity to understand may want to consult with other persons, who may also have to be informed and ultimately may become the consenting party.

Two cases included in the Appendix (\#13 and \#8) illustrate the difficulties often encountered in attempting to judge competence. In one case a sixty-eight-year-old man with kidney disease and multiple additional problems also develops intermittent psychotic behavior. The psychiatric diagnosis is that of chronic psychotic organic brain syndrome resulting from cerebral arteriosclerosis. Nonetheless, two psychiatrists declare the patient competent to make fundamental decisions affecting his treatment, based on behavioral and psychiatric indications. Because the patient exhibits what his attending physician regards as erratic and irrational behavior, the psychiatrists' declaration of competence is reluctantly accepted by the physician and by certain members of the family. In this difficult case the patient's behavior is perhaps best understood in terms of limited and intermittent competence. In the second case, a man who generally exhibits normal behavior patterns is involuntarily committed to a mental institution because of certain bizarre actions that follow from his unique and unorthodox religious beliefs. Because the man's religious beliefs lead to serious self-destructive behavior (pulling out an eye and cutting off a hand), he is judged incompetent, despite his generally competent behavior and despite the fact that his peculiar actions follow "reasonably" from hismany would say, equally peculiar-religious beliefs. While this puzzling case probably cannot be understood in terms of intermittent competence, it may be that the notion of limited competence again applies.

Perhaps the major question in recent years about competence centers on standards for its determination. Conventional standards isolate various abilities to comprehend information and to reason about the consequences of one's actions. In particular, a person is said to be incompetent unless both capable of processing a certain amount of information and capable of choosing both ends and the means to those ends. The most promising headway toward a useful definition has come through criminal and civil law. Courts have disagreed on which of the following three properties is most crucial to a determination of competency: ${ }^{8}(1)$ capacity to reach a decision based on rational reasons, 
(2) the reaching of a reasonable result through a decision, or (3) the capacity to make a decision at all. Without attempting to distinguish all the arguments and possible reasons for adopting any one of these three standards, it seems reasonable to combine them as follows: a person is competent if and only if that person can make decisions based on rational reasons. In biomedical contexts this standard entails that a person must be able to understand a therapy or research procedure, must be able to weigh and must be able to make a decision in the light of such knowledge and through such abilities, even if the person chooses not to utilize the information.

But what about those who are incompetent? It is here that the problem of justifying second-party consent arises. The matter is relatively simple for therapeutic treatment: the second party is designated to act in the best interests of the incompetent person. However, in cases of research that does not hold out the prospect of direct benefit to subjects-e.g., infants-how can their involvement be justified? The general justification for such research is utilitarian: the promotion of the interests of all members of society through the research. Those appointed as second parties will be called upon to consider the significance of research procedures in the light of this goal when deciding whether or not to allow incompetents to become involved. In effect they are designated to decide about the involvement of incompetents on the same basis as any of us might consider our own involvement, while protecting any special interests or views held by the incompetent.

\begin{abstract}
A further problem is that the term "competence" often functions to hide a significant value judgment about another person. A person who appears to others to be irrational or unreasonable might be declared incompetent in order that "treatment" may be provided. Such a declaration readily hides a value judgment about what a rational person ought to consent to do, presented in the guise of an empirical determination of incompetence. Jeffrie Murphy has recently argued for a presumably objective theory of competence based on the idea that a person may be incompetent in various ways if the person is so ignorant, compulsive, or devoid of reason that he cannot make important decisions. Still more important is Murphy's recognition that all such theories have troublesome borderline cases:
\end{abstract}

[T] he vast majority of cases that confront us will be borderline - cases in that greyish area between full competence and obvious incompetence. The real problem that will face us, then, is what to do in the borderline cases. When in doubt, which way should we err - on the side of safety or on the side of liberty?

It is vital that we do not adopt analyses of "incompetence" or patterns of argument that obscure the obviously moral nature of this question. ${ }^{9}$

It is thus seldom a simple empirical question as to whether a person is or is not competent. If precise criteria were available for making such determinations, the grey area would vanish. But since such criteria are not available, moral judgments about what to do with possibly incompetent persons cannot be avoided.

\title{
Disclosure of information
}


Most medical and research codes specify conditions under which a person can be said to have sufficient information on the basis of which he or she could make an informed choice. Commonly mentioned as necessary items of disclosure are contemplated procedures, alternative available procedures, anticipated risks and benefits, and a statement offering the person an opportunity to ask further questions and to withdraw at any time (in the case of research). Several writers on the subject of informed consent have proposed additional or supplementary conditions - for example, statements of the purpose of the procedure, the uncertain risks involved, persons in charge, and, if research is involved, how subjects were selected. Such lists could be indefinitely expanded, but many possible inclusions are not applicable to all areas of medical research and practice. Expansive lists of conditions are sometimes appropriate, while in other contexts they would waste precious time and might even prove to be damaging to patients or subjects. Accordingly, it is more important to determine which primary moral standards should govern the disclosure of information. We shall concentrate on this topic.

Standards of disclosure. One major question is how the distinction is to be drawn between adequately informed consent, on the one hand, and partially informed or even uninformed consent, on the other hand. Three general standards of disclosure have emerged in legal and ethical writings on informed consent: (A) What is operative in the
biomedical professions, B What the reasonable person would want to know, and C
What individual patients or subjects of research want to know. In the past there has been
a strong reliance on (A). For example, it was only recently reported that
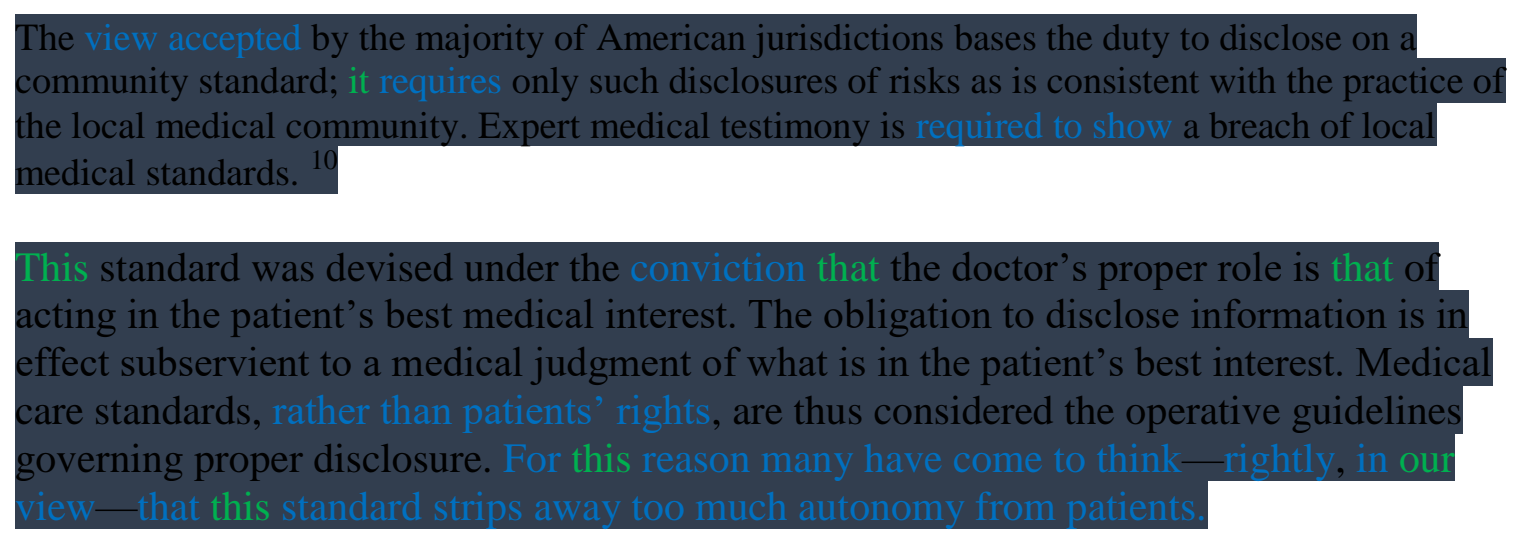

Lately this standard has been declining in significance, even in the courts, for two primary reasons. First, the amount of material information a person needs to make a decision is not a technical medical judgment, and is perhaps better within the comprehension of an average juror than an average physician. Second, medical custom often expresses the values and goals of the medical profession, but information provided to patients and subjects should be as free as possible of the values and goals of medical professionals, especially those doing research. The latter are more likely than most to believe in the scientific merit and social worth of their procedures; and they may well see risks and benefits in a quite different perspective than would others.

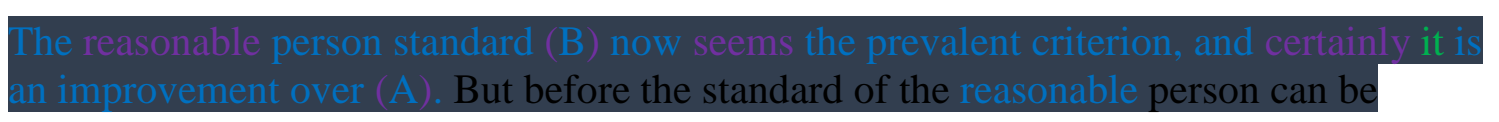




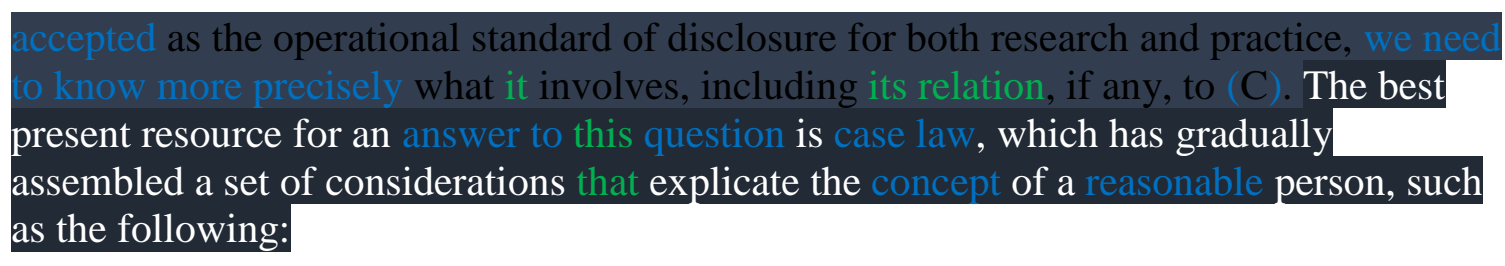

(1) All material information necessary for a decision must be given, as judged by persons
who would compose a jury rather than by expert testimony or by a medical body. ${ }^{11}$

(2) Known risks of significant bodily harm and death must be disclosed. ${ }^{12}$
(3) The reasonable person is a composite or ideal of reasonable persons in society, and
the individual subject is not in question. The latter standard might be too subjective and too much guesswork by physicians. ${ }^{13}$

(4) Standards of disclosure in medicine are not different from those of other professions where there is a similar fiduciary relationship..$^{14}$

\begin{abstract}
Although somewhat amorphous and open-ended, these legal criteria are useful for purposes of generalizing into moral contexts. However, even this claim is paradoxical. As Judge Robinson noted in Canterbury v. Spence, medical duties to disclose, as set forth in the law, are themselves ultimately based on moral considerations of autonomy. The judge calls these considerations "the patient's right of self-decision" and the patient's "prerogative to decide."15 The point is that duties of disclosure are at their root moral ather than legal or medical ones, and these moral duties inform both law and medicine as to the appropriate standards. What has been said, then, about general moral standards based on autonomy and present case law might be focused into the following minimum standard of disclosure: the patient or subject should be provided with information that a reasonable person in the patient's or subject's circumstances would find relevant and could reasonably be expected to assimilate. In this way the moral requirement to respect autonomy is translated into a consent standard.
\end{abstract}

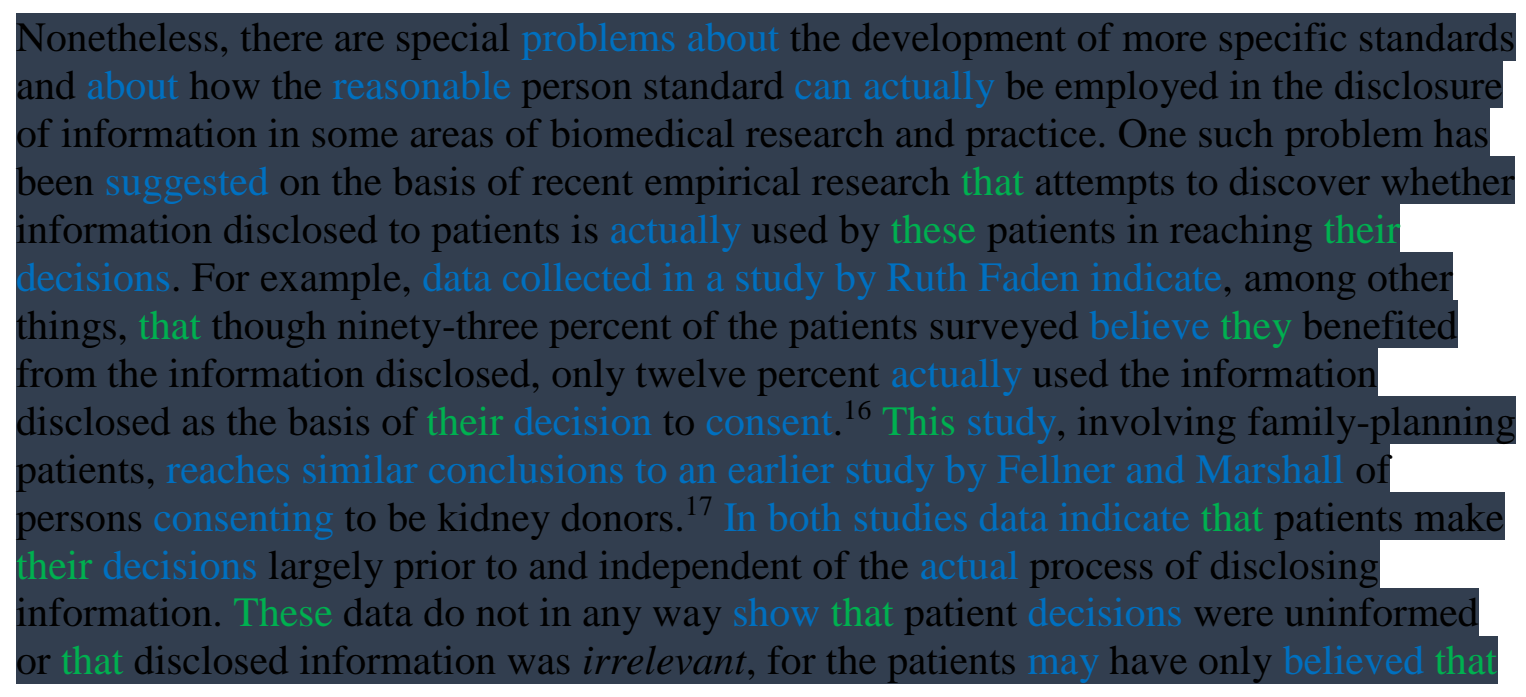



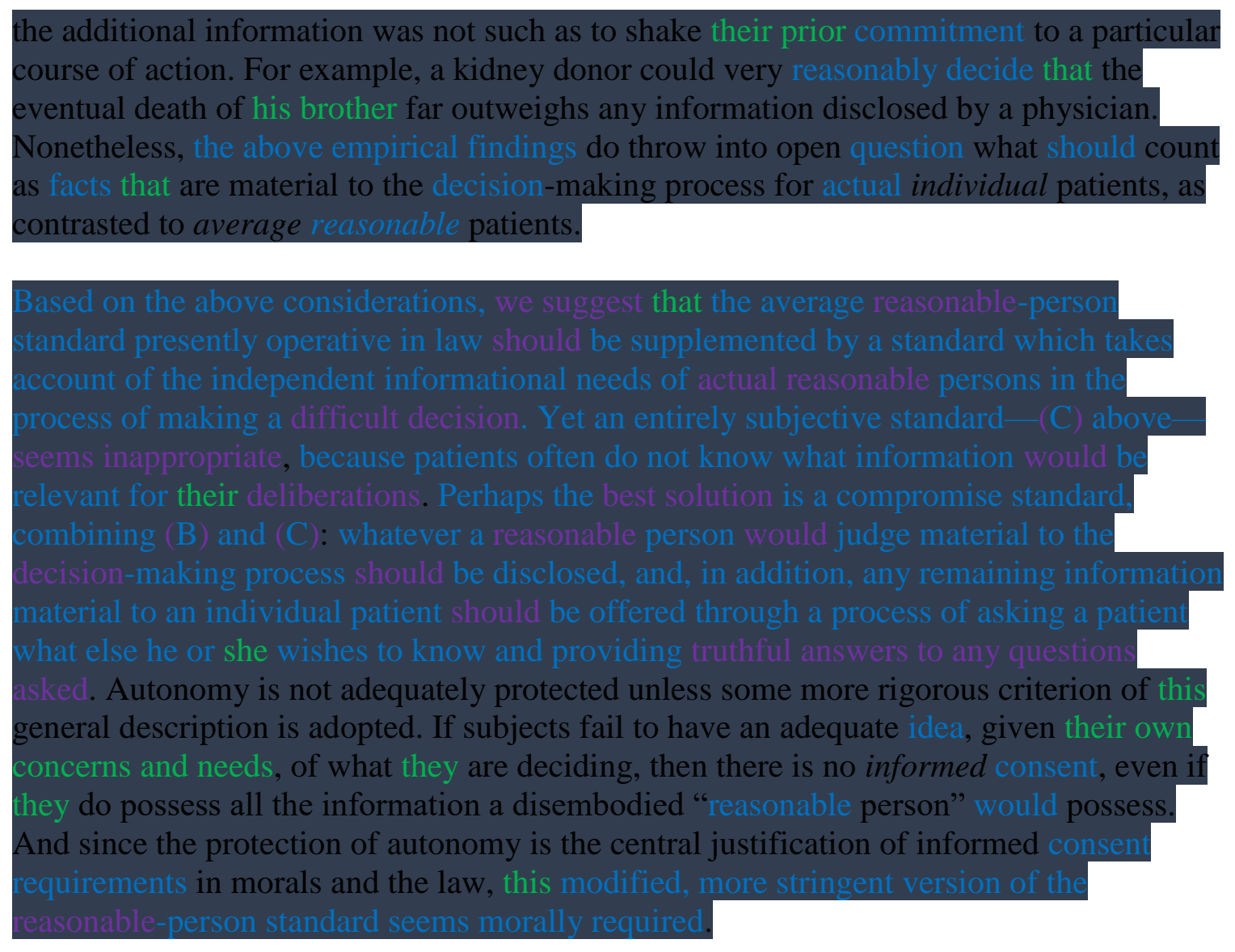

Intentional nondisclosure. This proposal involves practical difficulties, however. For example, in clinical medicine there is the legal doctrine of therapeutic privilege. According to this doctrine, a physician may intentionally and validly fail to disclose information, based on a judgment that to divulge the information would be potentially harmful to the patient or would otherwise be infeasible. When such practices involve deception or incomplete disclosure, ethical problems arise about autonomy and consent. For similar reasons, courts have increasingly curtailed physician latitude of judgment, just as they have increasingly required the use of the reasonable-person standard over standards operative in the medical professions. This trend, of course, holds only for patients capable of informed consent and not for patients who are unconscious or otherwise incapable of communicating. It also does not apply to cases where there is a severe impracticality of communicating with patients. Thus the doctrine of therapeutic privilege, judiciously interpreted to deal with such cases, is not intrinsically objectionable.

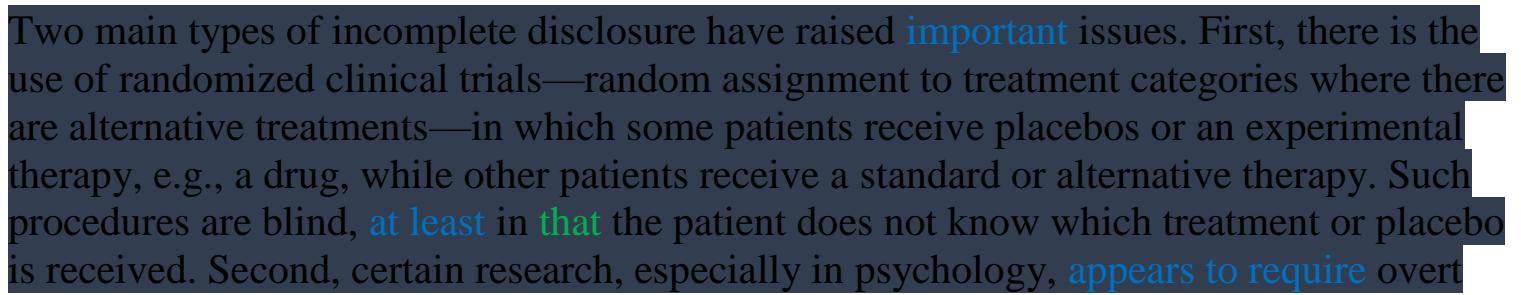



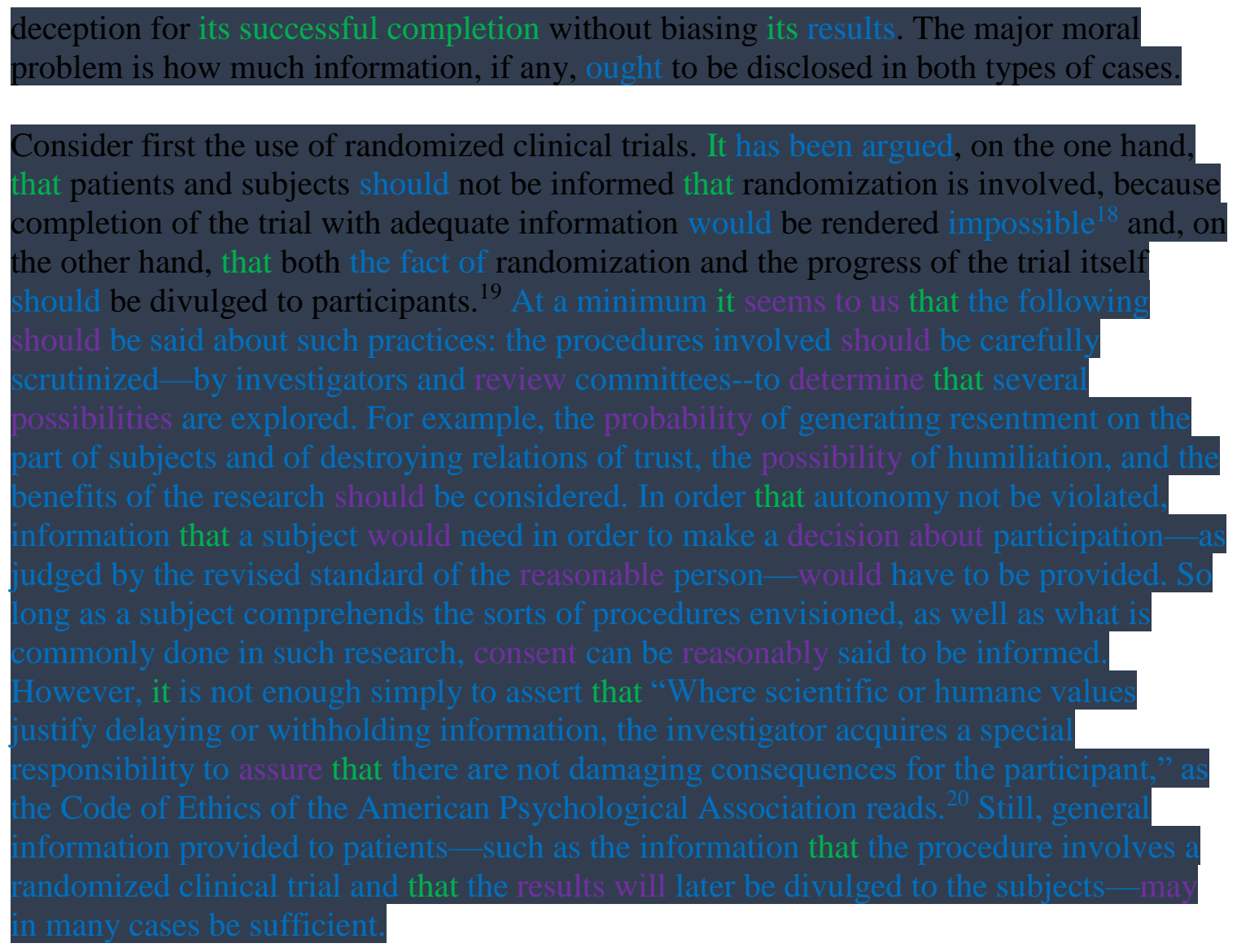

This approach to incomplete disclosures in randomized clinical trials can be more sharply formulated. Such research is justified only if:

1) There is no satisfactory alternative methodology which avoids the problem of withholding information.

(2) The subjects are informed that they are involved in a randomized clinical trial and might be receiving a placebo or a nonvalidated therapy.

3 The research is well designed, including provisions for the evaluation of the alternative therapies.

4) All therapies to be included have no substantial disparity in their prior probabilities of benefit.

5 Risks to patients are fully detailed prior to their consent and are minimal (e.g., not beyond the risk involved in a standard physical examination) if there is a risk that cannot be divulged.

6) Consent safeguards, such as a surrogate consent system, have been put in place wherever appropriate. 


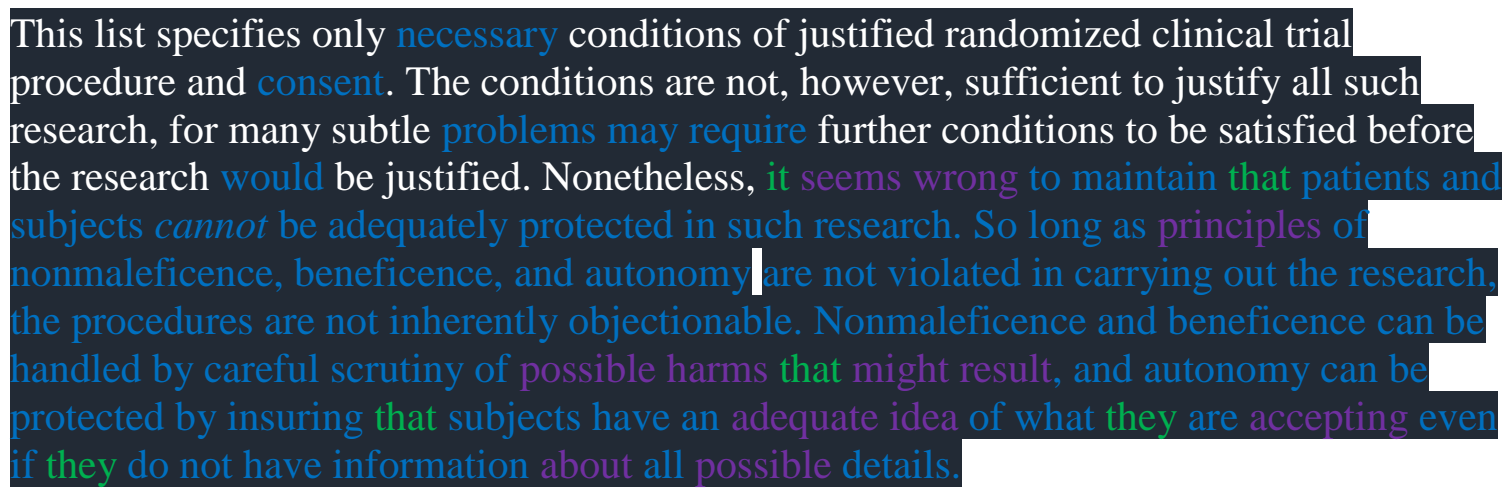

On the other hand, the six conditions listed above are not met in most of the biomedical and psychological research that involves intentional deception. Much of this research involves minor risk and only minor deception; but the deception is nonetheless often resented by subjects subsequent to their involvement. If the research is

might be argued that minor deception and minimal risks are outweighed by substantial benefits. The justification of such research would thus turn on a risk/benefit analysis. However, when substantial deception and/or substantial risk are present, justification becomes more problematic. Stanley Milgram's well-known experiments in which subjects were falsely informed that they would be supplying electroshock to other subjects provide examples of this sort. ${ }^{21}$ Another and perhaps more fascinating case is \#4 in the Appendix. In this case a social scientist using substantial deception placed homosexual subjects at risk of public disclosure and embarrassment and invaded their privacy. Also a remarkably revealing sociological study of the practices of Italian priests in hearing confessions of sexual sins-published in English as Sex and the Confessional $^{22}$--involved the deception of priests and the taping of their questions and advice. While these cases are more social-scientific than biomedical, they illustrate the point that deception (and resulting risk) can and does occur in the world of research.

Can research of this sort be justified? We do not see how it is possible to do so when
significant risk is involved, unless subjects can be informed that they are being placed at risk and consent to this placement. The critical question is thus whether subjects the risk of involvement in deceptive practices. If they do not, it of the principle of autonomy both to place them at risk and to deceive them. This conclusion is far from innocuous, since much research of this description has been carried out in the past and is still being considered by and in some cases approved by research review committees. Still, this conclusion does not imply that research involving deception cannot justifiably be undertaken. Relatively risk-free and significant research-especially in behavioral psychology and sociology - could not in some cases be undertaken without deception or incomplete disclosure. Examples would include studies of visual and other perceptual responses. Cases in which disclosure would invalidate the research should be distinguished from cases in which disclosure would be inconvenient, time consuming, or 


\section{Comprehension of information}

Just as a sufficient quantity of information is needed for a consent to be informed, so adequate comprehension of the information by subjects or patients is a necessary condition of a valid informed consent. Without sufficient comprehension a person cannot use the information in making decisions-should he or she elect to use the information. Many conditions other than mere lack of sufficient information can limit comprehension. Irrationality and immaturity can do so, for example. But even if there were no problems about competence, problems about adequate comprehension would remain, for information may be presented in a distorted way or in unsuitable circumstances so that communication of the information fails to occur.

It is sometimes argued that a patient or subject cannot comprehend enough information to give informed consent. Franz lngelfinger argues, for example, that "the chances are remote that the subject really understands what he has consented to," 23 and Robert Mulford similarly argues that "the subject is ordinarily not qualified to evaluate the true risks and expected benefits." 24 This position is based on an inadequate view of so-called "full" disclosure. So long as one clings to the ideal of complete disclosure of all possibly relevant knowledge, such claims about the limited capacity of subjects will be given credence. But if this ideal standard is replaced by an acceptable reasonable-person standard, there should no longer be any temptation to succumb to the lngelfinger-Mulford form of pessimism. From the fact that we are never fully voluntary, fully informed, or fully autonomous persons, it does not follow that we are never adequately informed, free, and autonomous. A different lesson is to be learned: because comprehension is both limited and difficult, we should strive harder in biomedical and educational contexts to foster information and to avoid undue influence. Apprehending one's medical situation is not substantially different from apprehending one's financial situation when consulting with a CPA, or one's legal situation when consulting with a lawyer, or even one's marital situation when consulting with a marriage counselor. The shades of understanding are manifold, but various degrees of apprehension may nonetheless be adequate for an informed judgment.

Another problem is whether we ought to recognize waivers of informed consent. What are we to say about those idiosyncratic individuals who choose to have less information than would a "reasonable" person? Robert Veatch has argued that anyone who refuses to accept as much information as the reasonable person would accept cannot be said to have apprehended the relevant information and, therefore, cannot be said to have given an acceptable consent-at least not to involvement in research. ${ }^{25}$ But is this view correct? Some persons do not want to know anything about what will be done. Indeed, some studies claim to show that over sixty percent of patients want to know virtually nothing about procedures or the risks of the procedures ${ }^{26}$ and other studies, as we have seen, indicate that only about twelve percent of patients use the information provided in reaching their decisions. ${ }^{27}$ 
There seem to be two major alternative ways of treating such persons. First, it might be maintained that when the reasonable-person standard is not being met, the contemplated procedure cannot be undertaken until sufficient information has been imparted, notwithstanding the person's autonomously expressed desire not to be informed. According to this approach, persons should be coerced against into receiving undesired information. Second, a contrasting view is that when a patient or subject has been sufficiently informed to know whether or not further information is wished, and when the right to further information has been waived, no further information should be provided. In this second view, the person's informed waiver is itself sufficient to constitute valid consent to therapy or research, even if it is not an informed consent to that procedure.

Either alternative presents risks. On the one hand, forced information is a prima facie violation of autonomy, and many circumstances can be imagined in which information waivers would be justified. For example, if a deeply committed Jehovah's Witness were to inform a doctor that he wishes to have everything possible done for him, but does not want to know if transfusions or similar procedures would be employed, it is hard to imagine a moral argument to the conclusion that he must be told. On the other hand, to consider the second alternative, the fact must be faced that patients commonly have an inordinate trust in physicians, and the general recognition of waivers of consent in research and therapeutic settings could make patients more vulnerable to those who would use far too abbreviated consent procedures merely because they are convenient.

There probably cannot be any general theoretical solution to this problem of waivers. Each case of consent and the possibility of a waiver will have to be considered in its own complexity. There may, however, be a procedural way to resolve the problem. There could be rules against allowing waivers, but these rules could be considered as specifying prima facie duties which can be relaxed after special consideration by deliberative bodies, such as institutional review committees and hospital ethics committees. Such rules would be developed to protect patients and subjects, but if protective bodies themselves were to find that the person's interest in a particular case was best protected by a waiver, they could allow the waiver. This procedural solution is not a mere avoidance of the problem. It would be easy to violate autonomy and to fail to live up to our responsibilities by inflexible rules which either permit or prohibit waivers. This procedural suggestion at least provides a flexible arrangement for meeting such problems.

A similar and related problem arises when patients or subjects reach their decisions on irrelevant grounds, even though they have been adequately informed. Such persons comprehend the relevant information but reach their decision based on emotional, irrational, or false views. For example, a person might falsely and irrationally believe that a doctor will not fill out his insurance forms unless he consents to a procedure the doctor has suggested; and he might persist in this belief even when informed of its falsity. Similarly, a sufficiently informed psychiatric patient capable of consent might consent to involvement in a nonpsychiatric, nontherapeutic research procedure under the false assumption that it is therapeutic. In these cases the adequate information that is both disclosed and apprehended plays no role in the decision to be involved in the research or 
to accept the therapy. The question then arises whether autonomous subjects should be coerced into giving up their false beliefs and irrational tendencies in order that they may decide on the basis of pertinent information alone.

In a general statement about the coercion of information, H. Tristram Engelhardt has argued that "One cannot try (nor should one) to force subjects who can be rational free agents to use that rationality and freedom to its fullest," 28 because informed consent only entails that patients and subjects make their own free and rational assessments. Robert Veatch has similarly argued that where subjects specifically object to further information or persuasion, the information should not be imposed. ${ }^{29}$ While these statements set forth commendable ideals, they do not imply that we should never coerce patients or subjects to further information. When a patient's or subject's autonomy is clearly limited by his own ignorance, as in the case of false belief, it may be legitimate to promote autonomy by attempting to impose the information. In this respect these cases resemble the waiver cases just discussed. In both, unsatisfactory apprehension leads to the problem, and, as with the waiver cases, the best general solution is probably a procedural one.

It might be argued that these conclusions about apprehension hold for therapeutic settings but do not fit research settings where persons would be involved in nontherapeutic research. In the therapeutic environment the physician acts to the end of a patient's best interests, but in research settings the person is used as a means to the investigator's ends. Nonetheless, we believe this distinction between the two settings largely irrelevant to the points made in this section about deficient apprehension. Factors such as the amount of risk involved and the person's identification with the purposes of research could make a decisive difference as to whether he should be involved, quite independent of whether it is a clinical or a research setting. Moreover, by participating in research, subjects might derive certain benefits which they could appreciate and which would be important to them, even though they consented on what the "reasonable person" would judge to be irrelevant grounds.

\section{Voluntariness}

Voluntariness connotes the ability to choose one's own goals, and to be able to choose among several goals if a wide choice is offered, without being unduly influenced or coerced to any of the alternatives by other persons or institutions. The mere absence of constraining influences may, however, not indicate that a subject is acting freely. On some occasions the person may have to be provided with the means to realize a chosen end, as well as given freedom of choice. For example, it makes no sense to say that a person is free to choose a nonvalidated therapy instead of a validated one, if only the validated one is actually made available. In contexts of informed consent, voluntariness is optimal when there is adequate disclosure, adequate comprehension, and a subject capable of choice who in fact chooses a specific action. However, the primary meaning of "voluntariness" is exercising choice about an action free of coercion or undue influence by another person. 
How shall we understand the notions of coercion and undue influence? Coercion occurs when one person intentionally uses an actual threat of harm or forceful manipulation to influence another. The harm could be physical, psychological, economic, etc. By contrast, undue influence occurs whenever someone uses an excessive reward or irrationally persuasive technique to induce a person to a decision the person might otherwise not reach. If admission to a hospital of persons needing care were made contingent upon their enrollment in a research protocol that was unrelated to their illness, undue influence would have been exerted. But if the only temptation inviting enrollment in a nontherapeutic research project is time off from one's work at no extra pay for the duration of the experiment, no undue influence would have been exerted. Coercion and undue influence are points on a continuum, and it is probably not possible to locate these points precisely.

Mere influence or pressure to make a decision, however, contrasts sharply with coercion and undue influence. We almost always make decisions in a context of competing wants, needs, familial interests, legal obligations, persuasive arguments, etc. Many inducements will thus be pressures but not unduly influential ones - though no sharp boundary line can perhaps be drawn in some cases between pressure to decide and undue influence. For example, a person may be pressured by an office solicitor to make a blood donation. The solicitation would normally be acceptable, but could become unacceptable if salary or year-ending bonus considerations were brought into the picture as inducements. Consent to therapy and research may therefore be voluntary and valid even when some pressures play a significant role in the decision.

Many examples indicate how these distinctions can be brought to bear on practical contexts of informed consent. In Case \#26 hepatitis research was being done on mentally retarded children in New York. One allegation surrounding this case is that the parents were "coerced" into "volunteering" their children. Allegedly they were coerced—or, as some would prefer to say, unduly influenced-because there was a waiting list for admission to the school and parents were told that their children could be immediately admitted if they were "volunteered" for the hepatitis study. If this allegation of manipulative tactics were true, which is still in doubt, it would be a clear case of an unwarranted action. On the other hand, there is nothing about admission to institutions or about institutions themselves which makes unfair influence inevitable. Even in generally coercive environments, such as prisons, it is sometimes possible that informed consent to medical and research procedures can occur. It may be especially important to insure that the right of autonomous determination is defended in such institutions, since there will be a natural presumption that voluntary action is impossible, e.g., in the case of research with prisoners. Yet in environments where many options are foreclosed, not all options need be so. There is no reason why prisoners could not validly consent to medical research - say, in the form of drug testing - if coercive tactics were not specifically involved, and if undue inducements, such as large amounts of money, were not allowed. Thus, a distinction ought to be drawn between generally coercive environments and individual acts of coercion. Informed consent may be valid in the former, but cannot be in the latter. 


\section{Refusal of treatment}

Occasionally patients who have the capacity to give informed consent to therapies refuse to do so. While these refusals can, of course, occur in non-life-threatening circumstances, the major controversies have emerged from life-threatening contexts. In this section we will concentrate on life-threatening refusals, reserving non-life-threatening decisions for Chapter 5. The major cases to be discussed here involve refusal of some medical therapy presumably necessary to sustain life. Examples include refusal to allow a blood transfusion, or an amputation, or further treatment using kidney dialysis. While patients have refused treatments such as blood transfusions because of their religious convictions, the ethical issues are broader than freedom of religious conscience, for many patients refuse treatments for nonreligious reasons. There are also problems of second-party refusal in the case of children and certain classes of incompetent patients, which we will reserve for the chapter on nonmaleficence. In this section we will concentrate on refusals by competent adult patients, where the critical question is, "What are the implications and limits of the principle of autonomy?"

The "Patient's Bill of Rights" (See Appendix II) holds that "the patient has the right to refuse treatment to the extent permitted by law and to be informed of the medical consequences of his action." Unfortunately, this right of refusal cannot be specified without a discussion of the law, and even then we have to ask whether the law is morally sound, e.g., whether it adequately expresses the principle of autonomy.

While the law is at present tentative and uncertain in this area, courts appear to be moving in the direction of greater latitude of patient choice, unless there is questionable competence. A number of recent legal cases suggest that the patient's informed refusal should be decisive. In Erickson v. Dilgard ${ }^{30}$ a patient with intestinal bleeding deliberately refused, on religious grounds, a transfusion necessary for continued life. The court upheld the patient's decision on grounds of the protection of individual choice. Similarly, in In re Estate of Brooks, ${ }^{31}$ it was held that free religious exercise, when there is competent refusal of therapy, is constitutionally sufficient to prevent physicians from compelling the therapy, even when it is known by both patient and physician that death will ensue. In the first case, bodily self-determination was regarded as an inviolable right, while in the second, free exercise of religion was cited as the basic right. But patient refusal was nonetheless decisive in both. ${ }^{32}$

By examining some cases, we can both illustrate some of the complexities and indicate some conditions under which patient choice may justifiably be restricted. In Case \#11, a Jehovah's Witness refused to authorize blood transfusions for herself and her newborn daughter, and her husband also refused to authorize blood transfusions for either his wife or daughter. The judge refused to order transfusions for the woman, but did not accept the parents' proxy (second-party) refusal of therapy for the newborn daughter. In effect, he accepted a first-party refusal, but drew the line at that point and would not accept a second-party refusal for the incompetent child. Legal considerations of jurisdiction over the fate of the infant played a role in this decision, but moral grounds can also be cited for the judge's opinion. As we have seen, the doctrine of informed consent is applied 
differently to competent and incompetent parties because of considerations of autonomy and nonmaleficence: informed consent functions to protect the right of autonomous choice for competents but functions to protect incompetents from harm. This moral position probably underlies the judge's legal decision in this case.

In some cases a patient's refusal of lifesaving therapy may impose unjustified burdens on or bring excessive harm to others. The Georgetown College Case (see Appendix Case \#12) is an oft-cited example of a case where the seriousness of the consequences to others might override a patient's autonomous wishes. The court used the following reason, among others, to justify forcing a transfusion on an unwilling patient: "The patient, 25 years old, was the mother of a seven-month-old child.... The patient had a responsibility to the community to care for her infant. Thus, the people had an interest in preserving the life of this mother." ${ }^{13}$ It has also been argued that the child, even more than the community, is seriously damaged by the mother's decision. ${ }^{34}$ While we are uncertain of the actual status of obligations in this dilemmatic case, it provides the sort of case where pressing needs might be sufficient to override patient choice. In such circumstances, individual autonomy would seem appropriately overridden only for a moral reason which pertains to the welfare of others and not for paternalistic reasons. ${ }^{35}$

Despite the general endorsement of the patient's right to autonomous choice that we have suggested in this section, the limitations of this view should be appreciated. First, this approach does not consider hard cases of second-party refusals, where someone other than the patient must accept the burden of the decision--e.g., cases where a family member consents to the withholding or cessation of treatment for someone in a vegetative state. (See Chapter 4.) Second, almost all court cases and many common situations in hospitals involve patients of questionable capacity to consent. The conclusions we have reached do not apply to such patients. Only when there is an informed refusal, as judged by our modified reasonable-person standard, should a patient's decision be recognized. In cases of doubtful competence, it is better to err on the side of preserving life. Finally, as just noted, in some cases where persons might be acting irresponsibly and thereby harming another person (usually a dependent), their decisions may be overridden, even when informed and voluntary. Such cases will be rare; but it cannot be determined a priori that sufficient moral grounds for overriding autonomous choices could never be present.

\section{Autonomous suicide}

Refusal of therapy in life-threatening circumstances is, of course, not the only way to terminate one's life. It is not even the most common way in some hospital populations, for many patients end their lives by carefully planned suicides. Not all suicides among such populations can correctly be classified as autonomous, but some can be, and in this section we evaluate critically certain views about the morality of autonomous suicide.

There is a rich literature by major figures in the history of philosophy and theology on the morality of suicide. In addition, certain contemporary currents have revived interest in this topic. First, as with refusal of treatment cases, biomedical technology has made it 
possible for seriously ill and injured persons to prolong their lives beyond the point at which, in former times, they would have died. The suicide rate is remarkably high in some of these populations, and many people have come to think that suicide can be justified in some of these cases. According to the World Health Organization, a reasonable estimate is that in reporting nations approximately 1,000 people commit suicide each day. While health conditions are obviously not always the motivating factor, they figure prominently in many suicides. For example, one study discovered that the incidence of suicide among patients on dialysis is "more than 100 times the normal population." It is not easy, however, to obtain accurate statistics about suicide, in part because many families tend to conceal the fact that a family member's death is a suicide. Even when it occurred under the exigencies of a prolonged illness, and perhaps was rational, families tend to conceal the fact of suicide.

Second, while criminal laws prohibiting suicide have been repealed recently in most jurisdictions in the United States, repeal is currently being debated in others. This debate turns more on moral than on legal considerations. Libertarian arguments have been successfully used to oppose criminal sanctions against suicide in most states, but a lively debate continues about the rightness and wrongness of taking one's own life. However, before we can assess this moral controversy, it is necessary to clarify the notion of "suicide" itself.

\section{The definition of suicide}

Ordinarily we would think that a death is a suicide if it is an intentionally caused selfdestruction and is not forced by the action of another person. However, we have just studied refusal of treatment cases that make it difficult to accept such a simple definition.

When persons suffer from a terminal illness or mortal injury and allow their own death to occur, we find ourselves reluctant to call the act a "suicide." But if a patient with a terminal illness takes his life by an active means, such as a revolver, we generally do refer to the act as one of suicide. The more we have patent cases of agents' actions that involve an intentionally and actively caused death, the more we are likely to classify the act as a suicide; but the more the context is one of merely allowing one's own death where a fatal condition is present, the less inclined we are to call the act a suicide. For example, if a seriously but not mortally wounded burn patient takes a weapon in hand and intentionally brings about his death, it is a suicide. But if a seriously burned patient is suffering terribly from a terminal wound and refuses yet another tubbing or blood transfusion, we are not likely to regard the death as a suicide. The passive nature of the death in the second case makes us reluctant to label it a suicide, whereas the active character of the death in the first case renders the death a suicide.

However, our concept of suicide is not quite as clear as these examples might suggest, for this analysis of suicide in terms of taking active steps seems mistaken in some cases. For example, a patient with a terminal condition might easily avoid dying for a long time but might choose to end his life immediately by not taking cheap and painless medication. 
We are not sure what to say in such cases, but it can be explained why our concept of suicide leaves us in this state of uncertainty.

Terms in their ordinary meaning often contain evaluative accretions from social attitudes that render them difficult to analyze. The meaning we have located for "suicide" seem to be a premiere instance of this problem. Because self-caused deaths are often revolting and inexplicable, an emotive meaning of disapproval has been incorporated into our use of "suicide." Because of this already attached disapproval, we find it hard to view acts of which we approve, or at least do not disapprove, as suicides. For this reason we have been led to the semantic exclusion of such actions from the realm of suicide. For example, when coercion, refusal of treatment, or sacrifice are present we are inclined not to attach the stigma of the label "suicide," and so generally exclude these actions. Terminal illness and altruistic reasons for suicide play a similar role. Because self-caused deaths under the latter conditions commonly are understandable, acceptable, and perhaps even laudable, semantic exclusion of them from the realm of the suicidal is tempting and is a fait accompli in the English language. We thus by the very logic of the term prejudice any pending moral analysis of the action of a suicide as being right or wrong, let alone praiseworthy or blameworthy.

Because this prejudicial feature infects our ordinary understanding of "suicide," it needs to be replaced by a more objective, even though stipulative, meaning for purposes of moral thinking. It will not be easy to employ a standard term in a nonstandard way in the discussions that follow, but our investigations of the morality and rationality of suicide will be enhanced by acceptance of an uncorrupted term. We propose, then, that suicide occurs if and only if one intentionally terminates one's own life--no matter what the conditions or precise nature of the intention or the causal route to death.

\section{The morality of suicide}

How are we to determine whether a particular act of suicide is or is not immoral? As with other moral issues, this question should be answered by reference to those moral principles that permit us to take a consistent position on the issues. We want to suggest, without further argument, that three moral principles are directly relevant to discussions of suicide.

(1) The first of these principles is the principle of autonomy itself. As we have seen, to show a lack of respect for an autonomous agent is either to show disrespect for that person's deliberate choices or to deny that person the freedom to act on those choices. It would, therefore, be a showing of disrespect to deny autonomous persons the right to commit suicide when, in their considered judgment, they ought to do so.

(2) A second principle often appealed to in discussions of suicide may be called the principle of human worth (or the sanctity of human life). According to this view human life has an intrinsic value irrevocably destroyed by suicide, which is therefore an act of killing that is morally wrong. As this principle is usually construed, it is permissible to allow someone to die instead of attempting heroic efforts to save them, but it is not 
acceptable to kill, because one then becomes morally responsible for an active destruction of life. From this view, the act of killing is wrong not because it produces social disutility and not because it violates autonomy. It is wrong merely because it is an intentional, active termination of human life. The principle is thus taken as independent of the principles previously discussed in this chapter, though it may be derivative from the principle of nonmaleficence. (See the discussion of the killing/letting die distinction in Chapter 4.)

One could have a number of different reasons for holding this second principle. It might be believed that life is a gift from God, and therefore is only to be terminated at God's own appointed moment. Or one might think that human life has a dignity that sets it apart from all nonhuman creatures. However, these views coalesce into a single deontological belief: human life has intrinsic value, and it is always a wrong-making characteristic of any action that it is an intentional termination of a human life. Still, there are stronger and weaker ways of interpreting this principle. On the strongest possible view, it is always wrong intentionally to terminate any human life, whatever the circumstances--whether in capital punishment cases, or as an act of self-defense, or by abortion, or by suicide, or by any means whatever. A markedly weak version of the principle would be that the intrinsic value of life itself is always a consideration when one is contemplating the intentional termination of a life--but it is only a consideration and not necessarily the most important or overriding consideration.

Few people would now defend either the strongest or the weakest version of this principle. A middle position--basically the construal that those who now defend this principle would support--is that killing is prima facie wrong and so permissible only if it is necessary to save the life of at least one other innocent person or if it is necessary to preserve a morally worthy society.

(3) The final moral principle relevant to discussing the morality of suicide is the principle of utility. As we have seen, utilitarians look to the consequences of actions to see what the impact on the interests and welfare of all concerned would be. The interests of the person contemplating suicide, the interests of dependents, the interests of relatives, etc., must all be considered in the calculation of positive values and disvalues. The fact that people love the person contemplating suicide and that they value the person's contribution to the community are all to be considered in making a moral assessment of the contemplated action. In an overwhelming number of cases a utilitarian calculation would show that more disvalue in the form of grief, guilt, and deprivation would be produced than value gained were someone to commit suicide. Hence the principle of utility would generally dictate that an act of suicide is not justified. However, there are cases where considerations about consequences would not automatically fall on the side of disvalue. For example, imagine someone suffering from apparently untreatable tic doulou-reux--an excruciatingly painful condition of the trigeminal nerve--and brain cancer as well. Suppose further that this person has neither dependents nor debts, that the suffering of this person's family has been protracted, and that everyone concerned believes death would be a merciful release. An intentional overdose taken by the person could satisfy 
the utilitarian demand that the greatest possible amount of value or at least the smallest possible amount of disvalue be brought about by the person's action.

Under the assumption that each of the above three moral principles is acceptable, each should be regarded as prima facie binding. That is, the principles assert prima facie duties, in some cases binding a person contemplating suicide and in other cases affecting those who might intervene to prevent suicides. As we discussed in Chapter 2, prima facie duties are more than rules of thumb, because they are always binding unless in conflict with stronger duties. They thus constitute binding moral reasons, even though they do not always prevail over competing prima facie duties. In the present context, this approach to morality may be applied as follows: to the extent the principle of autonomy or one of the other principles just mentioned is relevant, and does not come into conflict with other principles, it is our duty to observe the principle. Thus, if a suicide were genuinely autonomous and there were no powerful utilitarian reasons or reasons of human worth and dignity standing in the way, then we ought to allow the person to commit suicide, because we would otherwise be violating the person's autonomy. A similar analysis could be given for instances falling under each of the principles. This indicates that whether suicide is right or wrong is never a simple or absolute matter. The morality of suicide cannot be determined in abstraction from the facts of a person's own situation.

\begin{abstract}
A ready example of the use of prima facie reasoning about suicide is found in a famous essay on the subject by the eighteenth-century philosopher David Hume. In this essay he combined the principle of autonomy with the principle of utility to provide a powerful case in justification of certain types of suicide--though by no means did Hume draw the radical conclusion that all suicides can be justified by these two principles. His strategy was to show that the more one is removed from obligations to the community and the more one's life is plagued with suffering, the more justifiable is one's suicide. In the end he advances the largely utilitarian thesis that if the value of relieving one's misery by taking one's own life is greater than the value to the community of one's continued existence, then suicide is justified. This claim might be applied in biomedical contexts by reference once again to the desperate circumstances that often surround refusal of treatment cases. If one's life has become utterly miserable and pain management is impossible, while at the same time one's dignity and ability to relate to others are slipping away, then suicide would seem to be justified. This is not to say, of course, that it would be justified to encourage suicide or to assist a person in committing suicide. These acts present further moral problems. But this conclusion does entail that suicide under these circumstances is not morally improper and should not be an object of moral condemnation.
\end{abstract}

\title{
Problems of suicide intervention
}

If the principle of autonomy is strongly relied upon for the justification of suicide, then it would seem that there is a right to commit suicide, so long as a person acts autonomously and does not seriously affect the interests of others. Yet we certainly do not always act as if the suicide has such a right, for we often intervene to prevent suicide. In days past, for example, it was not uncommon for several persons to place themselves at risk of death in 
order to prevent a person from lying down on subway tracks in the path of an oncoming train. It is easy to understand why such interventions occur, as acts of humanity. And we may believe that we are justified in intervening in the lives of such individuals. But if they have a right to commit suicide, are we really justified? In the case of almost any other similarly intrusive action, we would agree with the person if he argued that his autonomy had been violated by those who intervened. For example, physicians can be successfully sued for malpractice if they coercively intervene in certain ways in the life of a patient. Yet in the case of suicide, we feel strongly inclined to say that we have obligations to suicidal persons, even when they are acting autonomously. But can we morally justify the conviction that intervention in the name of saving a life is better than nonintervention in the name of autonomy?

One account of our obligations, by a strong advocate of the principle of autonomy, is the following by Glanville Williams:

If one suddenly comes upon another person attempting suicide, the natural and humane thing to do is to try to stop him, for the purpose of ascertaining the cause of his distress and attempting to remedy it, or else of attempting moral dissuasion if it seems that the act of suicide shows lack of consideration for others, or else again from the purpose of trying to persuade him to accept psychiatric help if this seems to be called for. Whatever the strict law may be (and authority is totally lacking), no one who intervened for such reasons would thereby be in danger of suffering a punitive judgment. But nothing longer than a temporary restraint could be defended. I would gravely doubt whether a suicide attempt should be a factor leading to a diagnosis of psychosis or to compulsory admission to a hospital. Psychiatrists are too ready to assume that an attempt to commit suicide is the act of a mentally sick person. ${ }^{36}$

Yet many do not agree with Williams's estimate. There are two main reasons for disagreement. First, failure to intervene indicates a lack of concern about others and a diminished sense of moral responsibility in a community. Attempts to save a person from suicide in subways are now comparatively rare, and this seems to indicate how times have changed in large cities--and how disastrous the change has been. Second, many believe that most suicides are mentally ill or at least seriously disturbed, and therefore are not really capable of autonomous action. Notoriously, suicidal persons are often under the strain of temporary crises, under the influence of drugs or alcohol, and beset with considerable ambivalence, or simply wish to reduce or interrupt anxiety, while not wishing to die.

Many psychiatric and legal authorities can be cited in support of the belief that suicides are almost always the result of maladaptive attitudes needing therapeutic attention. Their underlying conviction is that the suicidal person suffers from some form of disease or irrational drive to kill himself, and that it is the business of medicine or behavioral therapy to cure the illness and prevent the patient from self-destruction. Freudians even argue that suicide is created by a breakdown of ego defenses and a release of destructive forces. These forces are said to reflect the ambivalent relationship to love objects with whom a person identifies. While no single theory presently suffices for the understanding of the motivation to suicide, many such accounts characterize suicide as substantially nonvoluntary and therefore as nonautonomous. Also, other suicidal persons who are not 
ill nonetheless may not be in a position to act autonomously, either because they are immature, ignorant, coerced, or in a vulnerable position in which they might be exploited by others.

\begin{abstract}
In all cases these nonautonomous persons are due all the same protections of moral rules afforded to autonomous persons. One way of respecting them as persons is by direct intervention in their lives intended to protect them against harms resulting from their illness, immaturity, psychological incapacitation, ignorance, or possible exploitation-e.g., by coercively preventing their suicide. These might be medical interventions, coercive institutionalizations, or some other method of prevention. Those who are defenders of autonomy have never denied that this interference is valid, because they regard such suicidal actions as nonautonomous. They regard the principle of autonomy and the derivative right to commit suicide as extending only to those capable of autonomous choice. On the other hand, some suicides are genuinely autonomous suicides; yet we still may feel compelled to intervene in order to prevent the potential suicide from taking his life. Because virtually everyone is agreed that nonautonomous suicidal actions should be prevented by intervention, the only controversial question is whether these autonomous suicides should be similarly prevented. This issue properly falls under the problem of paternalism, a problem to be treated in Chapter 5. We shall, therefore, defer further discussion of the morality of suicide intervention until this future discussion of paternalism.
\end{abstract}

\title{
Conclusion
}

Our analysis of suicide leads to the conclusion that there are good reasons for suicide in some circumstances, but that suicidal action may be cowardly and even morally wrong in other circumstances. In some cases one may have moral obligations not to commit suicide, while in other cases one may have the right or even a moral obligation to commit suicide--though the last situation would be extremely rare. This conclusion can be analyzed in terms of the account of prima facie duties discussed in Chapter 2. For example, merely because one has some obligations not to commit suicide, it does not follow that when all interests are taken account of, the actual obligation will be to abstain from suicide. Moreover, weak duties are sometimes overridden not only by stronger moral duties but also by strong prudential interests. Even though a daughter might beg her terminally ill father to stay alive for his last remaining month, his agony may nonetheless be sufficient to override the daughter's interest in his remaining alive. One valid reason for taking one's life in one's last days is to prevent a loss of one's own dignity, while at the same time sparing a family grief and financial loss. In doing so one may be maximizing not only one's own interests but the interests of all concerned.

At the same time, in determining whether to commit suicide, it is easy to exaggerate the direness of one's situation. One's desires, sufferings, and hopes in the present moment tend to overwhelm consideration of what one's desires, sufferings, and joys may be at future times. In the case of terminal illness, which provides one of the strongest justifications of suicide, an optimistic frame of mind is not likely to be cultivated. Indeed, the matter is likely to become worse daily. And in the case of depression--where there is 
not a terminal illness--from which the majority of suicides are committed, it is easy to miscalculate by substituting present feelings for rational calculations of future possibilities. The reason for this speculation about depression is the following: it is one thing to reach the conclusion, as we have, that autonomous suicide may be justified, but quite another to frame a realistic appraisal of the circumstances and of the actual state of mind of many persons who commit "autonomous" suicide. Ideally, a person contemplating suicide would take account of all relevant variables and future possibilities, but such contemplation often does not occur. Thus, questions about our obligations to prevent suicides will always be difficult because of our uncertainty as to whether they are or are not truly autonomous.

In any final assessment of the wrongness of an act of suicide, it is important to analyze two different judgments that might be reached. First, we might say that a suicide is seriously mistaken, and even morally wrong, but not blameworthy. Second, we might say that the suicide is both morally wrong and blameworthy. These judgments derive from the moral view that some wrong suicides may be excused. ${ }^{37}$ We can excuse some suicides if they act on false information, if they are of temporarily unsound mind, or when depression or some other psychological state overwhelms a person of an ordinarily even disposition. Perhaps the most compelling cases are those where a person acts altruistically but on false information in committing suicide. For example, a person might falsely believe that he has a disease that will produce prolonged agony and leave his family in financial ruin. We can sometimes say not only that such a person acted wrongly though excusably, but even that he acted commendably (though wrongly). Many who would absolutely forbid suicide fail to distinguish the objective wrongness of an action from the moral excusability and even praiseworthiness of that same action. One virtue of our analysis of suicide is that it permits us to make these important distinctions and to adjust our moral judgments about suicide accordingly.

\section{Notes}

1. Cf. Robert Paul Wolff, In Defense of Anarchism (New York: Harper and Row, 1970). See also Wolff's even stronger claims in his article, "On Violence," The Journal of Philosophy 66 (October 2, 1969).

2. Wolff, In Defense of Anarchism, pp. 4-6, 13f. In "On Violence" (p. 608), Wolff maintains that "obedience is heteronymy [sic]. The autonomous man is of necessity an anarchist" (our italics). We can only understand this necessity as logical necessity.

3. "Informed Consent in Catastrophic Disease and Treatment," University of Pennsylvania Law Review 123 (December, 1974): 364-76.

4. Cf. Charles Fried, Medical Experimentation (New York: American Elsevier, 1974), pp. $18 \mathrm{ff}$.

5. Robert M. Veatch, "Three Theories of Informed Consent: Philosophical Foundations and Policy Implications." National Commission for the Protection of Human Subjects of 
Biomedical and Behavioral Research, Appendix: Volume I. Belmont Report: Ethical Principles and Guidelines for the Protection of Human Subjects of Research

(Washington: DHEW Publication No. (OS) 78-0013, 1978).

6. Schloendorff v. New York Hospital. 211 N.Y. 125, 127, 129; 105 N.E. 92, 93 (1914).

7. Natanson v. Kline. 186 Kan. 393, 350 P.2d 1093 (1960), rehearing denied, 187 Kan. 186, 354 P.2d 670 (1960).

8. We are indebted to Professor Donald Bersoff of the University of Maryland Law School for suggesting this tripartite approach.

9. Jeffrie Murphy, "Incompetence and Paternalism," Archiv fiir Rechtsund-Sozialphilosophie 50 (1974): 465-86.

10. "Informed Consent and the Dying Patient," The Yale Law Journal 83 (1974), p. 1637. Much the same point is made in Canterbury v. Spence, 464 Federal Reporter, 2nd Series, 772 , where the standards operative in the biomedical professions are analyzed as of two types: (1) good medical practice standards, and (2) what a reasonable practitioner would disclose under the circumstances. See the excerpt from the case reprinted in Tom L. Beauchamp and LeRoy Walters, eds., Contemporary Issues in Bioethics (Encino, Calif.: Dickenson Publishing Co., 1978), p. 143. (Hereafter this anthology is abbreviated B-W.)

11. Cf. Wilkinson v. Vesey, 110 R.I. 606, 626; 295 A.2d 676, 688 (1972).

12. Cf. Cobbs v. Grant, 8 Cal. 3d 229, 502 P.2d I.

13. Cf. Canterbury v. Spence, 464 Federal Reporter, 2nd Series, 772, as reprinted in B-W, p. 144 (and also fn. 8). Cobbs v. Grant, however, seems more subjective in that it appeals to "the patient's need" to know as a critical standard.

14. Cf. Berkey v. Anderson, I Cal. APP. 3d 790, 805; 82 Cal. Reporter 67, 78 (1969).

15. Canterbury v. Spence, in B-W, p. 144.

16. Ruth R. Faden, "Disclosure and Informed Consent: Does it Matter How We Tell It?" Health Education Monographs 5 (1977): 198-215; and Ruth R. Faden and Tom L. Beauchamp, "Informed Consent and Decision Making: The Impact of Disclosed Information," Social Indicators Research (1979).

17. C. H. Fellner and J. R. Marshall, "Kidney Donors-The Myth of Informed Consent," American Journal of Psychiatry 126 (1970): 1245.

18. See some examples of randomized clinical trials in Chapter 7 below and also Thomas C. Chalmers, "The Ethics of Randomization as a Decision-Making Technique and the Problem of Informed Consent," as reprinted in B-W, pp. 426-30. 
19. See Fried, Medical Experimentation, pp. 25-36.

20. Ethical Principles in the Conduct of Research with Human Participants (Washington, D.C.: American Psychological Association, 1973), p. 2. Principle 8.

21. Stanley Milgram, "Behavioral Study of Obedience," Journal of Abnormal Psychology 67 (1963): 371-78; "Some Conditions of Obedience and Disobedience to Authority," Human Relations 18 (1965): 57-76; Obedience to Authority (New York: Harper \& Row, 1974).

22. Norberto Valenti and Clara di Meglio, Sex and the Confessional (New York: Stein and Day, 1974).

23. Franz J. Ingelfinger, "Informed (but Uneducated) Consent," as reprinted in B-W, pp. 434-35.

24. Robert D. Mulford, "Experimentation on Human Beings," Stanford Law Review 20 (November 1967): 106.

25. Veatch, "Three Theories of Informed Consent."

26. Cf. Ralph J. Alfidi, "Controversy, Alternatives, and Decisions in Complying with the Legal Doctrine of Informed Consent," Radiology 114 (January 1975), as reprinted in BW, p. 148.

27. Cf. the articles in footnote 16 above.

28. "Basic Ethical Principles in the Conduct of Biomedical and Behavioral Research Involving Human Subjects." National Commission for the Protection of Human Subjects of Biomedical and Behavioral Research, Appendix: Vol. I. Belmont Report, p. 8-22. (see footnote 5 above).

29. Veatch, "Three Theories of Informed Consent."

30. 244 Misc. 2d 27, 252 N.Y.S. 2d 705 (Sup. Ct. 1962).

31. 205 N. E. 2d 435 (1965). 32 Ill 2d 361.

32. These cases, as well as other similar ones, are intelligently discussed in a comprehensive article on the subject by Robert M. Byrn, "Compulsory Life-saving Treatment for the Competent Adult," Fordham Law Review 44 (1975): 1-36.

33. Application of the President and Directors of Georgetown College, Inc., 331 F. 2d 1000, p. 1008. Cf. also Byrn, op. cit., p. 33. These same issues are posed in In re Osborne. On some interpretations of the decision in Georgetown College, the judge's 
verdict was reached as much on grounds of questionable competence as on the utilitarian grounds cited above.

34. Norman Cantor, "A Patient's Decision to Decline Life-Saving Medical Treatment: Bodily Integrity Versus the Preservation of Life," Rutgers Law Review 26 (1973): 228, 251-54.

35. A case which in our judgment is paternalistic and unjustifiable for this reason is John F. Kennedy Hospital v. Heston 58 N.J. 576, 279 A 2d 670 (1971). A reversal of this approach is found in the appellate court decision in In re Estate of Brooks 32 Ill. 2d 361, 205 N.E. 2d 435 (1965), though the latter preceded the former by six years. In the former case, see especially pp. 584f, and in the latter, especially pp. $440 \mathrm{f}$.

36. "Euthanasia," Medico-Legal Journal 41 (1973): 27.

37. In this analysis we have drawn heavily from Brandt's useful discussion of the subject in "The Morality and Rationality of Suicide," in S. Perlin, ed., A Handbook for the Study of Suicide (New York: Oxford University Press, 1975), p. 124. 


\title{
Appendix B
}

\section{Annotated Chapter 4, "Respect for Autonomy," from Beauchamp and Childress, $7^{\text {th }}$ Ed., (2012)}

\author{
PART II \\ Moral Principles
}

4

\section{Respect for Autonomy}

The principle of respect for the autonomous choices of persons runs as deep in the common morality as any principle, but determining its nature, scope, or strength requires careful analysis. We employ the concept of autonomy and the principle of respect for autonomy in this chapter largely to examine individuals' decision making in health care and research, both as patients and as subjects (or "participants"1).

Although we begin our analysis of a framework of principles of biomedical ethics with the principle of respect for autonomy, the order of our chapters does not imply that this principle has moral priority over other principles. We do not hold, as some of our critics have suggested, that the principle of respect for autonomy always has priority over all other moral considerations. We also argue, in contrast to some of our commentators, that respect for autonomy is not excessively individualistic (to the neglect of the social nature of individuals and the impact of individual choices and actions on others), is not excessively focused on reason (to the neglect of the emotions), and is not unduly legalistic (highlighting legal rights while downplaying social practices and responsibilities).

\section{THE CONCEPT OF AUTONOMY AND THE PRINCIPLE OF RESPECT FOR AUTONOMY}

The word autonomy, derived from the Greek autos ("self") and nomos ("rule," "governance," or "law"), originally referred to the self-rule or self-governance of independent city-states. Autonomy has since been extended to individuals, but the precise meaning of the term is disputed. At a minimum, personal autonomy encompasses self-rule that is free from both controlling interference by others and limitations that prevent meaningful choice, such as inadequate understanding. The autonomous individual acts freely in accordance with a self-chosen plan, analogous to the way an independent government manages its territories and sets its policies. In contrast, a person of diminished autonomy is in some material respect controlled by others or incapable of deliberating or acting on the basis of his or her desires and plans. For example, cognitively challenged individuals and prisoners often have diminished autonomy. Mental incapacitation limits the autonomy of a person with a severe mental handicap, whereas coercive institutionalization constrains a prisoner's autonomy.

Virtually all theories of autonomy view two conditions as essential for autonomy: liberty (independence from controlling influences) and agency (capacity for intentional action). However, disagreement exists over the meaning of these two conditions and over whether additional conditions are required. ${ }^{2}$ How a theory can be constructed from these basic conditions is the first subject we will consider. 


\section{Theories of Autonomy}

Some theories of autonomy feature the abilities, skills, or traits of the autonomous person, which include capacities of self-governance such as understanding, reasoning, deliberating, managing, and independent choosing. ${ }^{3}$ However, our focus in this chapter on decision making leads us to concentrate on autonomous choice rather than on general capacities for governance and self-management. Even autonomous persons who have self-governing capacities and are, on the whole, good managers of their health sometimes fail to govern themselves in particular choices because of temporary constraints caused by illness, depression, ignorance, coercion, or other conditions that limit their judgment or their options.

An autonomous person who signs a consent form for a procedure without reading or understanding the form has the capacity to act autonomously, but fails to so act in this circumstance. Depending on the context, we might be able to correctly describe the act as one of placing trust in one's physician and therefore as an act that autonomously authorizes the physician to proceed. However, even if this claim were accurate, the act is not an autonomous authorization of the procedure because this person lacks material information about it. Similarly, some persons who are generally incapable of autonomous decision making can at times make autonomous choices. For example, some patients in mental institutions who cannot care for themselves and have been declared legally incompetent may still make some autonomous choices, such as stating preferences for meals, refusing medications, and making phone calls to acquaintances.

Split-level theories of autonomy. An influential group of philosophers has presented a theory of autonomy that requires having the capacity to reflectively control and identify with or oppose one's basic (first-order) desires or preferences through higher level (second-order) desires or preferences. ${ }^{4}$ Gerald Dworkin offers a "content-free" definition of autonomy as a "second-order capacity of persons to reflect critically upon their first-order preferences, desires, wishes, and so forth and the capacity to accept or attempt to change these in the light of higher-order preferences and values. ${ }^{5}$ An example is an alcoholic who has a desire to drink, but also a higher order desire to stop drinking. In a second example, a dedicated physician may have a firstorder desire to work exceptionally long hours in the hospital, while also having a higher order commitment to spend all of her evening hours with her family. Whenever she wants to work late in the evening and does so, she wants what she does not autonomously want, and therefore acts nonautonomously. Action from a first-order desire that is not endorsed by a second-order volition is not autonomous and represents animal behavior. Accordingly, in this theory an autonomous person has the capacity to reflectively accept, identify with, or repudiate a lower order desire independent of others' manipulations of that desire. This higher order capacity to accept or repudiate first-order preferences constitutes autonomy, and no person is autonomous without this capacity.

This theory is problematic, however, because nothing prevents a reflective acceptance, preference, or volition at the second level from being caused by and assured by a strong first-order desire. The individual's second-level acceptance of, or identification with, the first-order desire would then be the causal result of an already formed structure of preferences. Potent first-order desires from a condition such as alcohol addiction are antithetical to autonomy and can cause second-order desires. If second-order desires (decisions, volitions, etc.) are generated by prior desires or commitments, then the process of identifying with one desire rather than another does not distinguish autonomy from nonautonomy.

This theory needs more than a convincing account of second-order preferences and acceptable influences. I needs a way for ordinary persons to qualify as deserving respect for their autonomy even when they have not reflected on their preferences at a higher level. This theory also risks running afoul of the criterion of coherence with the principle of respect for autonomy discussed throughout this chapter. If reflective identification with one's desires or second-order volitions is a necessary condition of autonomous action, then many ordinary actions that are almost universally considered autonomous, such as cheating on one's spouse (when one truly wishes not to be such a person) or selecting tasty snack foods when grocery shopping (when one has never reflected on one's desires for snack foods), would be rendered nonautonomous in this theory. Requiring reflective identification and stable volitional patterns deeply narrows the scope of actions protected by a principle of respect for autonomy. 
Agnieszka Jaworska insightfully argues that choosing contrary to one's stable or accepted values need not constitute an abandonment of autonomy even if a choice contradicts the person's own professed, fixed set of values. For example, a patient might request a highly invasive treatment at the end of life against his previous judgment about his best interests because he has come to a conclusion that surprises him: he cares more about living a few extra days than he had thought he would. Despite his long-standing and firm view that he would reject such invasive treatments, he now accepts them. Jaworska's case is not uncommon in medical contexts. ${ }^{6}$

Few decision makers and few choices would be autonomous if held to the standards of higher order reflection in this split-level theory, which seems to present an aspirational ideal of autonomy rather than a suitable theory of autonomy for decision making of the sort under study in this chapter. A theory should not be inconsistent with pretheoretical assumptions implicit in the principle of respect for autonomy, and no theory of autonomy is acceptable if it presents an ideal beyond the reach of ordinary, competent agents and choosers.

Our three-condition theory. Instead of depicting such an ideal theory of autonomy, our analysis focuses on nonideal conditions. We analyze autonomous action in terms of normal choosers who act (1) intentionally, (2) with understanding, and (3) without controlling influences that determine their action. This account of autonomy is specifically designed to be coherent with the premise that the everyday choices of generally competent persons are autonomous.

1. Intentionality. Intentional actions require plans in the form of representations of the series of events proposed for the execution of an action. For an act to be intentional, as opposed to accidental, it must correspond to the actor's conception of the act in question, although a planned outcome might not materialize as projected. ${ }^{7}$ Nothing about intentional acts rules out actions that one wishes one did not have to perform. Our motivation often reflects conflicting wants and desires, but this fact does not render an action less than intentional or autonomous. Foreseen but undesired outcomes are often part of a plan of intentional action.

\section{Understanding. Understanding is the second condition of autonomous action. An action is not autonomous if the actor does not adequately understand it. Conditions that limit understanding include illness, irrationality, and immaturity. Deficiencies in the communication process also can hamper understanding. In our account, an autonomous action needs only a substantial degree of understanding and freedom from constraint, not a full understanding or a complete absence of influence. To restrict adequate decision making by patients and research subjects to the ideal of fully or completely autonomous decision making strips their acts of any meaningful place in the practical world, where people's actions are rarely, if ever, fully autonomous.}

3. Noncontrol. The third of the three conditions of autonomous action is that a person be free of controls exerted either by external sources or by internal states that rob the person of self-directedness. Influence and resistance to influence are basic concepts for this analysis. Not all influences exerted on another person are controlling. Our analysis of noncontrol and voluntariness later in this chapter focuses on coercion and manipulation as key categories of influence. We there concentrate on external controlling influences-usually influences of one person on another--but no less important to autonomy are internal influences on the person, such as those caused by mental illness. All of these conditions can limit voluntariness.

The first of the three conditions of autonomy--intentionality--is not a matter of degree: Acts are either intentional or nonintentional. However, acts can satisfy both the conditions of understanding and absence of controlling influence to a greater or lesser extent. For example, threats can be more or less severe; understanding can be more or less complete; and mental illness can be more or less controlling. Children provide a good example of the continuum running from being in control to not being in control. In the early months of life children are heavily controlled and display only limited ability to be in control: they exhibit different degrees of resistance to influence as they mature, and their capacity to take control and perform intentional actions, as well as to understand, gradually increases as they develop. 


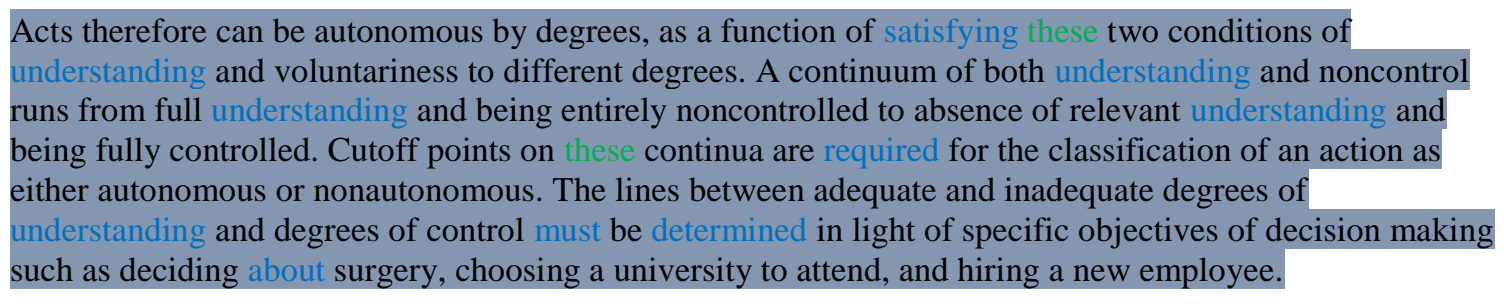

The line between what is substantial and what is insubstantial may appear arbitrary. However, thresholds marking substantially autonomous decisions can be carefully fixed in light of specific objectives such as meaningful decision making. Patients and research subjects can achieve substantial autonomy in decisions, just as substantially autonomous choice occurs in other areas of life such as choice of diet. The appropriate criteria for substantial autonomy are best addressed in a particular context.

\section{Autonomy, Authority, Community, and Relationships}

Some theorists argue that autonomous action is incompatible with the authority of governments, religious organizations, and other communities that prescribe behavior. They maintain that autonomous persons must act on their own reasons and can never submit to an authority or choose to be ruled by others without losing their autonomy. ${ }^{8}$ However, no fundamental inconsistency exists between autonomy and authority if individuals exercise their autonomy in choosing to accept an institution, tradition, or community that they view as a legitimate source of direction.

Choosing to follow medical authority is a prime example. Other examples are a Jehovah's Witness who accepts the authority of that tradition and who therefore refuses a recommended blood transfusion and a Roman Catholic who accepts the authority of the church and chooses against an abortion. That persons share moral norms with authoritative institutions does not prevent these norms from being autonomously accepted, even if these principles derive from traditions or from institutional authority. If a Jehovah's Witness who insists on adhering to the doctrines of his faith in refusing a blood transfusion is deemed nonautonomous on the basis of his religious upbringing and convictions, many of our choices based on our confidence in institutional authority will be likewise deemed unworthy of respect. In our account, a theory of autonomy that takes this course is morally unacceptable.

\footnotetext{
We encounter many limitations of autonomous choice in medical contexts because of the patient's dependent condition and the medical professional's authoritative position. On some occasions authority and autonomy are incompatible, but not because the two concepts are incompatible. Conflict arises because authority has not been properly presented or accepted. For example, an undue influence may have been exerted. Some critics of autonomy's prominent role in biomedical ethics question what they deem to be a model of an independent, rational will that is inattentive to emotions, communal life, social context, interdependence, reciprocity, and the development of persons over time. They charge that such an account of autonomy focuses too narrowly on the self as independent and rationally controlling. For instance, some writers have sought to affirm autonomy while interpreting it through relationships. ${ }^{9}$ This conception of "relational autonomy" is motivated by the conviction that persons' identities are shaped through social interactions and complex intersecting social determinants, such as race, class, gender, ethnicity, and authority structures. Persons are both interdependent and in danger of oppressive socialization and oppressive social relationships that impair their autonomy by conditions that unduly form their desires, beliefs, emotions, and attitudes and improperly thwart the development of the capacities and competencies essential for autonomy. ${ }^{10}$
}

We will largely address the challenges of relational autonomy through the ethical principles analyzed in Chapters 5 through 7. For instance, principles of justice provide a basis for condemning oppressive relationships and for determining which constraints on autonomous choice are and which are not ethically justified. In our view, relational conceptions of autonomy are defensible as long as they do not neglect or obscure the principal features of autonomy, as we analyze the concept in this chapter. 


\title{
The Principle of Respect for Autonomy
}

To respect autonomous agents is to acknowledge their right to hold views, to make choices, and to take actions based on their values and beliefs. Such respect involves respectful action, not merely a respectful attitude. It also requires more than noninterference in others' personal affairs. It includes, in some contexts, building up or maintaining others' capacities for autonomous choice while helping to allay fears and other conditions that destroy or disrupt autonomous action. Respect, so understood, involves acknowledging the value and decision-making rights of autonomous persons and enabling them to act autonomously, whereas disrespect for autonomy involves attitudes and actions that ignore, insult, demean, or are inattentive to others' rights of autonomous action.

The principle of respect for autonomy can be stated as both a negative obligation and a positive obligation. As a negative obligation, the principle requires that autonomous actions not be subjected to controlling constraints by others. It asserts a broad obligation that is free of exceptive clauses such as "We must respect individuals' views and rights so long as their thoughts and actions do not seriously harm other persons." Of course, the principle of respect for autonomy needs specification in particular contexts to function as a practical guide of conduct, and appropriate specification will incorporate valid exceptions. This process of specification will affect rights and obligations of liberty, privacy, confidentiality, truthfulness, and informed consent--all of which receive attention in this and subsequent chapters.

As a positive obligation, the principle requires both respectful treatment in disclosing information and actions that foster autonomous decision making. Many autonomous actions could not occur without others' material cooperation in making options available. Respect for autonomy obligates professionals in health care and research involving human subjects to disclose information, to probe for and ensure understanding and voluntariness, and to foster adequate decision making. As some contemporary Kantians have argued, the demand that we treat others as ends requires that we assist them in achieving their ends and foster their capacities as agents, not merely that we avoid treating them solely as means to our ends. ${ }^{11}$

These negative and positive sides of respect for autonomy are capable of supporting many more specific moral rules, some of which may also be justified, in whole or in part, by other moral principles discussed in book. Examples of such rules include the following:

\author{
1. Tell the truth. \\ 2. Respect the privacy of others. \\ 3. Protect confidential information. \\ 4. Obtain consent for interventions with patients. \\ 5. When asked, help others make important decisions.
}

Respect for autonomy has only prima facie standing, and competing moral considerations sometimes override this principle. Examples include the following: If our autonomous choices endanger the public health, potentially harm innocent others, or require a scarce resource for which no funds are available, others can justifiably restrict our exercises of autonomy. The principle of respect for autonomy often does not determine what, on balance, a person ought to be free to know or do or what counts as a valid justification for constraining autonomy. For example, a patient with an inoperable, incurable carcinoma once asked specifically, "I don't have cancer, do I?" The physician lied, saying, "You're as good as you were ten years ago." This lie infringed the principle of respect for autonomy by denying the patient information he may have needed to determine his future courses of action. Although the matter is controversial, such a lie might be justified by a principle of beneficence if certain major benefits will flow to the patient. (For the justification, see our discussions of paternalism in Chapter 6 and veracity in Chapter 8.)

Obligations to respect autonomy do not extend to persons who cannot act in a sufficiently autonomous manner--and who cannot be rendered autonomous--because, for instance, they are immature, incapacitated, ignorant, coerced, or exploited. Infants, irrationally suicidal individuals, and drug-dependent patients are examples. This standpoint does not presume that these individuals are not owed moral respect. ${ }^{12}$ In our 
framework, they have a significant moral status (see Chapter 3) that obligates us to protect them from harm-causing conditions and to supply medical benefits (see Chapters 5-7).

\section{The Triumph or Failure of Respect for Autonomy?}

Some writers lament the "triumph of autonomy" in American bioethics. They charge that autonomy's proponents sometimes disrespect patients by forcing them to make choices, even though many patients do not want to receive information about their condition or to make decisions. Carl Schneider, for example, claims that stout proponents of autonomy, whom he labels "autonomists," concern themselves less with what patients do want than with what they should want. He concludes that "while patients largely wish to be informed about their medical circumstances, a substantial number of them [especially the elderly and the very sick] do not want to make their own medical decisions, or perhaps even to participate in those decisions in any very significant way." 13

The duty of respect for autonomy has a correlative right to choose, but there is no correlative duty to choose. Several empirical studies of the sort cited by Schneider seem to misunderstand, as he does, how autonomous choice functions in a theory such as ours and how it should function in clinical medicine. In one study, UCLA researchers examined the differences in the attitudes of elderly subjects (sixty-five years or older) from different ethnic backgrounds toward (a) disclosure of the diagnosis and prognosis of a terminal illness, and (b) decision making at the end of life. The researchers summarize their main findings, based on 800 subjects (200 from each ethnic group): "Korean Americans (47\%) and Mexican Americans $(65 \%)$ were significantly less likely than European Americans $(87 \%)$ and African Americans $(88 \%)$ to believe that a patient should be told the diagnosis of metastatic cancer. Korean Americans $(35 \%)$ and Mexican Americans (48\%) were less likely than African Americans (63\%) and European Americans (69\%) to believe that a patient should be told of a terminal prognosis and less likely to believe that the patient should make decisions about the use of life-supporting technology (28\% and $41 \%$ vs. $60 \%$ and $65 \%$ ). Korean Americans and Mexican Americans tended to believe that the family should make decisions about the use of life support." Investigators in this study stress that "belief in the ideal of patient autonomy is far from universal" (italics added), and they contrast this ideal with a "family-centered model" focused on an individual's web of relationships and "the harmonious functioning of the family." 14

Nevertheless, the investigators themselves conclude that "physicians should ask their patients if they wish to receive information and make decisions or if they prefer that their families handle such matters." Far from abandoning or supplanting the moral demand that we respect individual autonomy, their recommendation accepts the normative position that the choice is rightly the patient's. Even if the patient delegates that right to someone else, the choice to delegate can itself be autonomous.

In a second study, this time of Navajo values and the disclosure of risk and medical prognoses, two researchers sought to determine how health care providers "should approach the discussion of negative information with Navajo patients" to provide "more culturally appropriate medical care." Frequent conflicts emerge, these researchers report, between autonomy and the traditional Navajo conception that "thought and language have the power to shape reality and to control events." According to the traditional conception, telling a Navajo patient recently diagnosed with a disease the potential complications of that disease may actually produce those complications, because "language does not merely describe reality, language shapes reality." Traditional Navajo patients may process various forms of negative information as dangerous to them. They expect instead a "positive ritual language" that promotes or restores health.

One middle-aged Navajo nurse reported that a surgeon explained the risks of bypass surgery to her father in such a way that he refused to undergo the procedure: "The surgeon told him that he may not wake up, that this is the risk of every surgery. For the surgeon it was very routine, but the way that my Dad received it, it was almost like a death sentence, and he never consented to the surgery." The researchers therefore found ethically troublesome those policies that, in compliance with the Patient Self-Determination Act, attempt to "expose all hospitalized Navajo patients to the idea, if not the practice, of advance care planning." 15

These two studies enrich our understanding of diverse cultural beliefs and values. However, several studies misrepresent what the principle of respect for autonomy and many related laws and policies require. They 
view their results as opposing rather than enriching the principle of respect for autonomy. A fundamental obligation exists to ensure that patients have the right to choose, as well as the right to accept or to decline information. Forced information and forced choice are usually inconsistent with this obligation. From this perspective, a tension exists between the two studies just discussed. One study recommends inquiring in advance to ascertain patients' preferences about information and decision making, whereas the other suggests, tenuously, that even informing certain patients of a right to decide may cause harm. The practical question is whether it is possible to inform patients of their rights to know and to decide without compromising their systems of belief and values or otherwise disrespecting them.

Health professionals should almost always inquire about their patients' wishes to receive information and to make decisions, and they should not assume that because a patient belongs to a particular community or culture, he or she affirms that community's worldview and values. The fundamental requirement is to respect a particular person's autonomous choices, whatever they may not be. Respect for autonomy is not a mere ideal in health care; it is a professional obligation.

\section{Complexities in Respecting Autonomy}

Varieties of autonomous consent. Consent sometimes grants permission for others to act in ways that normally would be unjustifiable--for instance, engaging in sexual relations or performing surgery. However, when examining autonomy and consent in this chapter, we do not presume that consent is either necessary or sufficient for certain interventions to be justified. It is not always necessary in emergencies, in public health interventions, in research involving anonymized data, and so forth; and it is not always sufficient because other ethical principles too must be satisfied--for example, research involving human subjects must pass a benefit-risk test and a fairness test in the recruitment of participants. ${ }^{16}$

The basic paradigm of the exercise of autonomy in health care and in research is express or explicit consent (or refusal), usually informed consent (or refusal). ${ }^{17}$ However, the informed consent paradigm captures only one form of consent. Consent may also be implied, tacit, or presumed; and it may be general or specific.

Implicit (or implied) consent is inferable from actions. Consent to a medical procedure may be implicit in a specific consent to another procedure, and providing general consent to treatment in a teaching hospital may imply consent to various roles for physicians, nurses, and others in training. Another form is tacit consent, which occurs silently or passively through omissions. For example, if the staff of a long-term care facility asks residents whether they object to having the time of dinner changed by one hour, a uniform lack of objection constitutes consent.

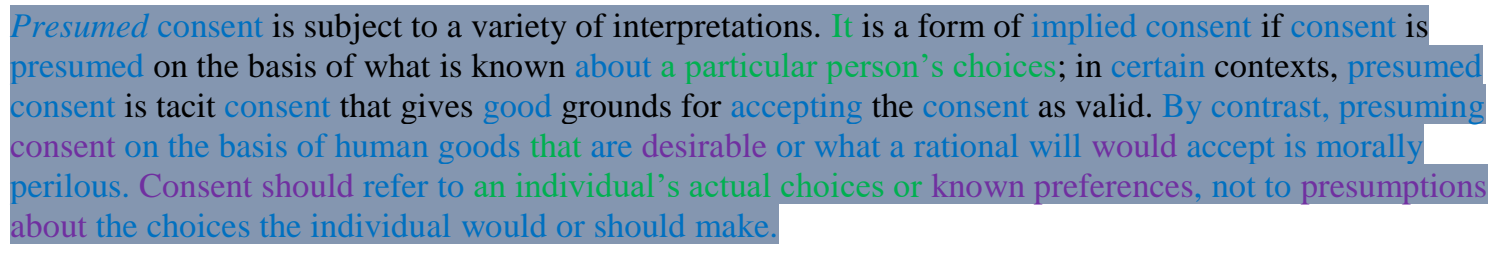

Different conceptions of consent have appeared in debates about teaching medical students how to perform intimate examinations, especially pelvic and rectal examinations. ${ }^{18}$ Often medical students have learned and practiced on anesthetized patients, some of whom have not given an explicit informed consent. For instance, many teaching hospitals have allowed one or two medical students to participate in the examination of women who are under anesthesia in preparation for surgery. Anesthetized patients have been considered ideal for teaching medical students how to perform a pelvic examination because the patients are relaxed and would not feel any mistakes. When questioned about this practice, some directors of obstetrics and gynecology programs have appealed to the patient's general consent upon entering a teaching hospital. Such consent typically authorizes medical students and residents to participate in for teaching and learning purposes. However, it is not specific as to which procedures might involve participation by medical students. 
It is debatable whether general consent is sufficient or whether specific informed consent is necessary in circumstances. We often seek specific informed consent when a procedure is invasive, as in the case of surgery, or when it is risky. Although pelvic examinations are not invasive or particularly risky by comparison to surgery, patients may object to the intrusion into their bodies, especially for education and training. Some women readily consent to the participation of medical students in such examinations, but others view the practice as a violation of their dignity and privacy. One commentator appropriately states that "the patient must be treated as the student's teacher, not as a training tool."19

Using anesthetized women who have given only a general consent may be highly efficient in clinical training, but in view of the importance of respect for autonomy, there are ethically preferable alternatives such as using anesthetized patients who have given specific informed consent or using healthy volunteers who are willing to serve as trainers or models. Either of these alternatives respects personal autonomy and avoids negative medical education. A study of medical students in the Philadelphia area found that the practice of conducting pelvic exams on anesthetized patients without specific informed consent desensitized physicians to the need for patients to give their consent before such procedures. For students who had finished an obstetrics/gynecology clerkship, consent was significantly less important (51\%) than for students who had not completed a clerkship (70\%). The authors conclude that "to avoid this decline in attitudes toward seeking consent, clerkship directors should ensure that students perform examinations only after patients have given consent explicitly." 20

Nonexpress forms of consent have been considered and sometimes adopted. In late 2006, the U.S. Centers for Disease Control and Prevention (CDC) changed its recommendations about HIV screening for patients in health care settings where various other diagnostic and screening tests are regularly performed. The recommendations moved away from specific, explicit informed consent, usually in written form, to general, implicit consent as part of the acceptance of medical care. Previous policies required specific disclosure of information and a decision to accept or refuse testing. ${ }^{21}$ For many commentators, this shift indicated that conventional public health measures were now being applied to HIV infection and AIDS, rather than being excluded on grounds of respect for the autonomy of patients and associated principles such as privacy and confidentiality. ${ }^{22}$

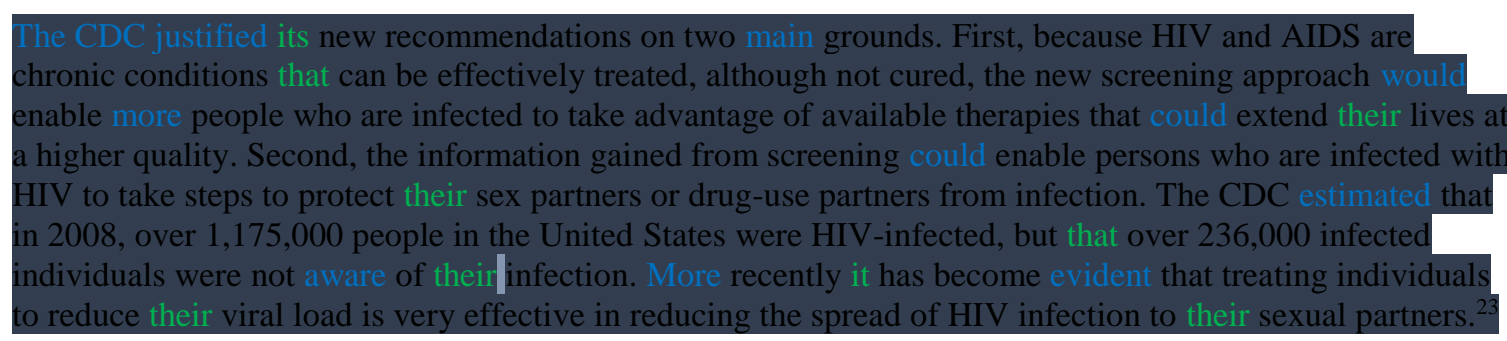

The CDC's new approach did not eliminate patient autonomy in health care settings--patients could still refuse testing--but, by shifting the default from "opt in" to "opt out," the CDC expected that more people previously unaware of their HIV infection would be tested and would gain knowledge that could benefit themselves and others. Despite its potential benefits, some critics of the "opt-out" policy warned that in the absence of a requirement for explicit, written informed consent, compromises of autonomy are inevitable and "compulsory" screening would occur in some contexts. According to one AIDS activist, "This is not informed consent, and it is not even consent, [but rather an attempt] to ram HIV testing down people' throats without their permission." ${ }^{24}$ Although an "opt-out" approach can be justified in such circumstances, this strategy can be ethically improved by the use of notification while retaining the possibility of "opting out."

Another context in which an opt-out approach, in the form of presumed or tacit consent, could, in principle, be justified is organ donation from deceased individuals. In the opt-in system in the United States, deceased organ donation requires express, explicit consent, whether by an individual while alive or by the next of kin after his or her death. Even though the information disclosed for the individual's consent is usually quite limited--for instance, in a cursory exchange when obtaining a license to operate an automobile--it is arguably adequate for purposes of postmortem organ donation. In view of the tremendous gap between the 
number of organs donated each year and the number of patients awaiting a transplant, many propose that the United States adopt an opt-out model for organ removal from deceased persons, as several European countries have done. This model shifts the default so that an individual's silence, or nonregistration of dissent, counts as consent. Two

To be ethically justifiable, such a policy would require vigorous efforts to ensure the public's understanding of the options they face as individuals, as well as a reliable, easy, and nonburdensome mechanism to use to opt out. Such a policy will not likely be adopted in the United States because of historical and legal commitments to individual choice. Even if it were adopted, it probably would not increase the number of organs for transplantation overall because, according to survey data, too many citizens would opt out; and opting out would prevent postmortem familial donations, which now provide a large number of transplantable organs. ${ }^{25}$

The varieties of consent we have now examined point to a fundamental question in this chapter: Who should seek what kind of consent from whom and for what?

Consents and refusals over time. Beliefs and choices shift over time. Ethical and interpretive problems arise when a person's present choices contradict his or her previous choices, which, in some cases, he or she explicitly designed to prevent possible future changes of mind from affecting an outcome. In one case, a twenty-eight-year-old man decided to terminate chronic renal dialysis because of his restricted lifestyle and the burdens his medical conditions imposed on his family. He had diabetes, was legally blind, and could not walk because of progressive neuropathy. His wife and physician agreed to provide medication to relieve his pain and further agreed not to put him back on dialysis even if he requested this action under the influence of pain or other bodily changes. (Increased amounts of urea in the blood, which result from kidney failure, can sometimes lead to altered mental states, for example.) While dying in the hospital, the patient awoke complaining of pain and asked to be put back on dialysis. The patient's wife and physician decided to act on the patient's earlier request not to intervene, and he died four hours later. ${ }^{26}$ Although their decision was understandable, respect for autonomy suggests that the spouse and physician should have put the patient back on dialysis to flush the urea out of his bloodstream and then to determine if he had autonomously revoked his prior choice. If the patient later indicated that he had not revoked his prior choice, he could have refused again, thereby providing the caregivers with increased assurance about his settled preferences.

In shifts over time the key question is whether people are autonomously revoking their prior decisions. Discerning whether current decisions are autonomous may depend, in part, on whether they are in character or out of character. Out-of-character actions can raise caution flags that warn others to seek explanations and to probe more deeply into whether the actions are autonomous, but they may turn out to be autonomous. Actions are more likely to be substantially autonomous if they are in character (e.g., when committed Jehovah's Witness refuses a blood transfusion), but acting in character does not necessarily indicate an autonomous choice. How, then, are we to determine whether actions are autonomous?

\section{THE CAPACITY FOR AUTONOMOUS CHOICE}

Many patients and potential research subjects are not competent to give a valid consent or refusal. Inquiries about competence focus on whether such persons are capable, cognitively, psychologically, and legally, of adequate decision making. Competence in decision making is closely connected to autonomous decision making, as well as to the validity of consent. Several commentators distinguish judgments of capacity from judgments of competence on the grounds that health professionals assess capacity and incapacity, whereas courts determine competence and incompetence. However, this distinction breaks down in practice, and we will not use it. When clinicians judge that patients lack decision-making capacity, the practical effects of these judgments may not differ from those of a legal determination of incompetence. ${ }^{27}$

\section{The Gatekeeping Function of Competence Judgments}


Competence or capacity judgments in health care serve a gatekeeping role by distinguishing persons whose decisions should be solicited or accepted from persons whose decisions need not or should not be solicited or accepted. Health professionals' judgments of a person's incompetence may lead them to override that person's decisions, to turn to informal surrogates for decision making, to ask the court to appoint a guardian to protect his or her interests, or to seek that person's involuntary institutionalization. When a court establishes legal incompetence, it appoints a surrogate decision maker with either partial or plenary (full) authority over the incompetent individual. Physicians and other health professionals do not have the authority to declare patients incompetent as a matter of law, but, within limits, they often have the de facto power to override or constrain patients' decisions about care based on assessments of limited capacity or incapacity.

Competence judgments have the distinctive normative function of qualifying or disqualifying persons for certain decisions or actions, but those in control sometimes incorrectly present these judgments as empirical. For example, a person who appears irrational or unreasonable to others might fail a psychiatric test, and therefore be declared incompetent. The test is an empirical measuring device, but normative judgments establish how the test is to be used to sort persons into the two classes of competent and incompetent, which determines how persons ought to be, or may permissibly be, treated.

\title{
The Concept of Competence 28
}

Some commentators hold that we lack both a single acceptable definition of competence and a single acceptable standard of competence. They also contend that no nonarbitrary test exists to distinguish between competent and incompetent persons. We will engage these issues by distinguishing between definitions, standards, and tests--focusing first on problems of definition.

\begin{abstract}
A single core meaning of the word competence applies in all contexts. That meaning is "the ability to perform a task." 29 By contrast to this core meaning, the criteria of particular competencies vary from context to context because the criteria are relative to specific tasks. The criteria for someone's competence to stand trial, to raise dachshunds, to answer a physician's questions, and to lecture to medical students are radically different. The competence to decide is therefore relative to the particular decision to be made. Rarely should we judge a person incompetent with respect to every sphere of life. We usually need to consider only some type of competence, such as the competence to decide about treatment or about participation in research. These judgments of competence and incompetence affect only a limited range of decision making. For example, a person who is incompetent to decide about financial affairs may be competent to decide to participate in medical research, or able to handle simple tasks easily while faltering before complex ones.
\end{abstract}

Competence may vary over time and may be intermittent. Many persons are incompetent to do something at one point in time but competent to perform the same task at another point in time. Judgments of competence about such persons can be complicated by the need to distinguish categories of illness that result in chronic changes of intellect, language, or memory from those characterized by rapid reversibility of these functions, as in the case of transient ischemic attack or transient global amnesia. In some of the latter cases competence varies from hour to hour. Here a determination of specific incompetence may prevent vague generalizations that exclude these persons from all forms of decision making.

These conceptual distinctions have practical significance. The law has traditionally presumed that a person who is incompetent to manage his or her estate is also incompetent to vote, make medical decisions, get married, and the like. The global sweep of these laws, based on a total judgment of the person, at times has extended too far. In one classic case, a physician argued that a patient was incompetent to make decisions because of epilepsy, ${ }^{30}$ although many persons who suffer from epilepsy are competent to decide in most contexts. Such judgments defy much that we now know about the etiology of various forms of incompetence, even in hard cases involving persons with mental retardation, with psychosis, or with uncontrollably painful afflictions. In addition, persons who are incompetent by virtue of dementia, alcoholism, immaturity, and mental retardation present radically different types and problems of incompetence. 


\begin{abstract}
Sometimes a competent person who can usually select appropriate means to reach his or her goals will act incompetently in some circumstances. Consider the following actual case of a hospitalized patient who has an acute disc problem and whose goal is to control back pain. The patient decided to manage the problem by wearing a brace, a method she had used successfully in the past. She believes strongly that she should return to this treatment modality. This approach conflicts, however, with her physician's unwavering and near-insistent advocacy of surgery. When the physician, an eminent surgeon who alone in her city is suited to treat the patient, asks her to sign the surgical permit, she is psychologically unable to refuse. Her illness increases both her hopes and her fears, and, in addition, she has a deferential personality. In these circumstances, it is psychologically too risky for her to act as she desires. Even though she is competent to choose in general, she is not competent to choose on this occasion.
\end{abstract}

This case indicates how close the concept of competence in decision making is to the concept of autonomy. Patients or prospective subjects are competent to make a decision if they have the capacity to understand the material information, to make a judgment about this information in light of their values, to intend a certain outcome, and to communicate freely their wishes to caregivers or investigators. Law, medicine, and, to some extent, philosophy presume a context in which the characteristics of the competent person are also the properties possessed by the autonomous person. Although autonomy and competence differ in meaning (autonomy meaning self-governance; competence meaning the ability to perform a task or range of tasks), the criteria of the autonomous person and of the competent person are strikingly similar.

Persons are more and less able to perform a specific task to the extent that they possess a certain level or range of abilities, just as persons are more and less intelligent and athletic. For example, in the emergency room an experienced and knowledgeable patient is likely to be more qualified to consent to or refuse a procedure than a frightened, inexperienced patient. It would be confusing to view this continuum of abilities in terms of degrees of competency. For practical and policy reasons, we need threshold levels below which a person with a certain level of abilities for a particular task is incompetent. Not all competent persons are equally able, and not all incompetent persons are equally unable, but competence determinations sort persons into these two basic classes, and thus treat persons as either competent or incompetent for specific purposes. Above the threshold, we treat persons as equally competent; below the threshold we treat them as equally incompetent. Gatekeepers test to determine who is above and who is below the threshold. Where we draw the line depends on the particular tasks involved. ${ }^{31}$

\title{
Standards of Competence
}

Questions about competence often center on the standards for its determination, that is, the conditions a competence judgment must satisfy. Standards of competence feature mental skills or capacities closely connected to the attributes of autonomous persons, such as cognitive skills and independent judgment. In criminal law, civil law, and clinical medicine, standards for competence cluster around various abilities to comprehend and process information and to reason about the consequences of one's actions. In medical contexts, physicians usually consider a person competent if he or she can understand a procedure, deliberate with regard to its major risks and benefits, and make a decision in light of this deliberation.

The following case illustrates some difficulties encountered in attempts to judge competence. A man who generally exhibits normal behavior patterns is involuntarily committed to a mental institution as the result of bizarre self-destructive behavior (pulling out an eye and cutting off a hand). This behavior results from his unusual religious beliefs. The institution judges him incompetent, despite his generally competent behavior and despite the fact that his peculiar actions coherently follow from his religious beliefs. ${ }^{32}$ This troublesome case is not one of intermittent competence. Analysis in terms of limited competence at first appears plausible, but this analysis perilously suggests that persons with unorthodox or bizarre religious beliefs are less than competent, even if they reason coherently in light of their beliefs. This policy would not be ethically acceptable unless specific and careful statements spelled out the reasons under which a finding of incompetence is justified.

Rival standards of incompetence. We focus on standards of incompetence, rather than competence, because of the legal, medical, and practical presumption that an adult is competent and should be treated as such in the absence of a determination of incompetence or incapacity. In the clinical context, an inquiry 
into a patient's competence to make decisions usually occurs only when the medical decision at stake is complex and involves significant risks or when the patient does not accept the physician's recommendation. ${ }^{33}$ The following schema expresses the range of inabilities currently required unde competing standards of incompetence presented in literature on the subject. ${ }^{3}$
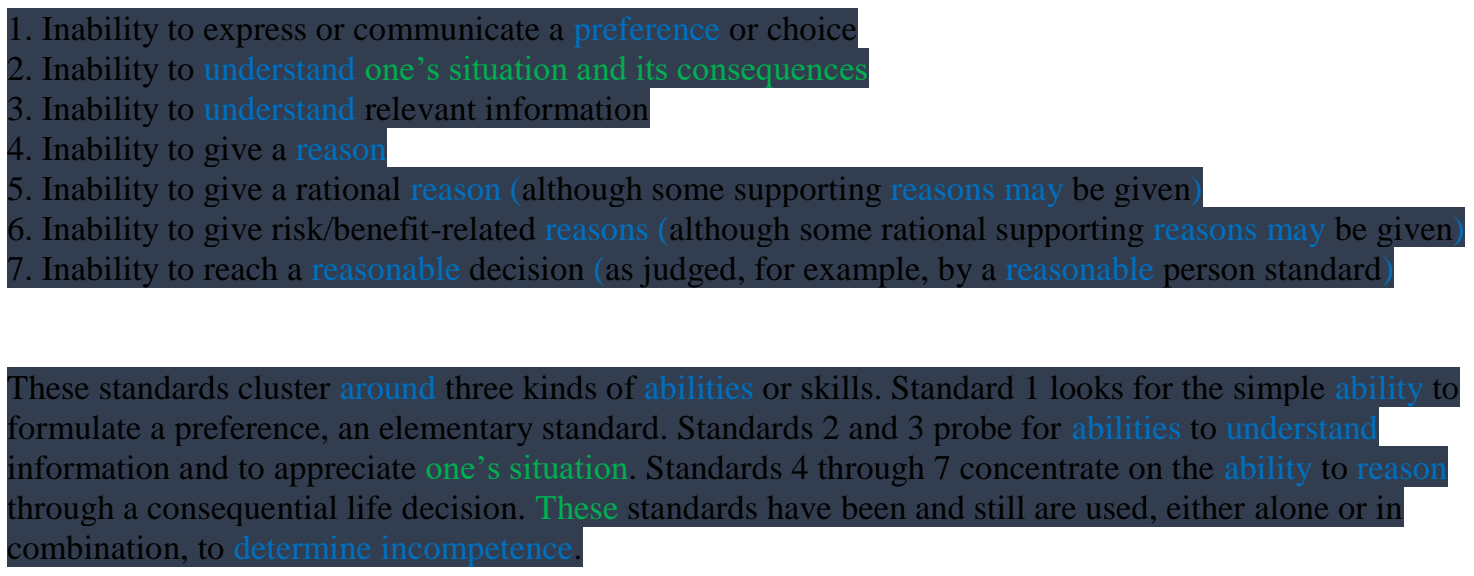

Testing for incompetence. A clinical need exists to turn one or more of these general standards into an operational test of incompetence that establishes passing and failing evaluations. Dementia rating scales, mental status exams, and similar devices test for factors such as time-and-place orientation, memory, understanding, and coherence. Although these clinical assessments are empirical tests, normative judgments underlie each test. The following ingredients incorporate normative judgments: ${ }^{3:}$
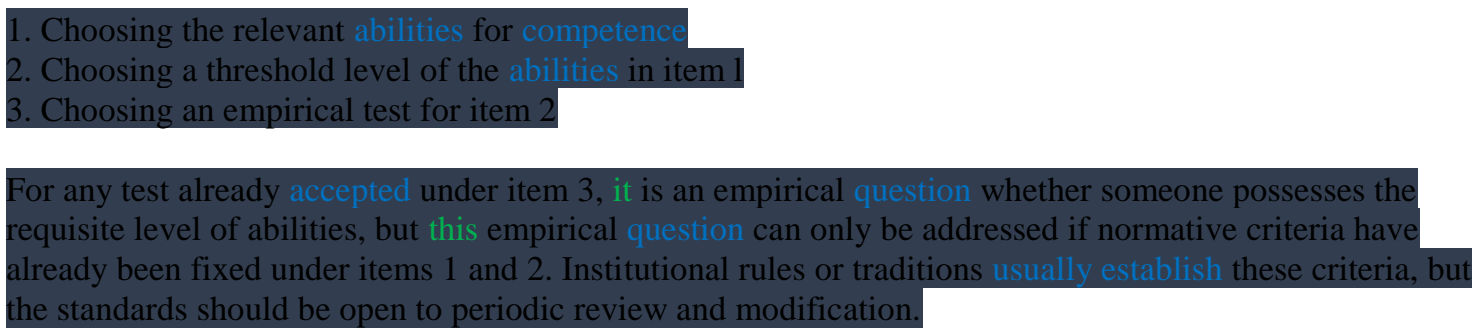

It is beyond the scope of our discussion to analyze and evaluate the numerous tests and instruments tha have been developed to assess decisional capacity for clinical treatment or research. Several reviews ${ }^{36}$ of $^{2}$ these instruments--one review examined twenty-three such instruments--have found that, even though thes instruments can aid clinicians' and researchers' assessment of decision-making competence, they produce variable results. Accordingly, it is premature to conclude that any one of them provides a satisfactory and reliable way to assess decision-making capacity. In the final analysis, the assessment of decisional capacity remains heavily a matter of clinical judgment, although some studies indicate that these clinical judgments too are often not reliable. ${ }^{37}$

The sliding-scale strategy. Properties of autonomy and of mental and psychological capacity are not the only criteria used in delineating competence standards. Many policies use pragmatic criteria such as efficiency, feasibility, and social acceptability to determine whether a person is competent to make decisions about medical care. For example, age has conventionally been used as an operational criterion of valid authorization or refusal of medical procedures. Established thresholds of age vary in accordance with a community's standards, with the degree of risk involved, and with the importance of the prospective benefits. From this perspective, standards of competence are connected to levels of experience, maturity, responsibility, and welfare.

Some writers offer a sliding-scale strategy for how to realize this goal. They argue that, as the risks of a medical intervention increase for patients, so should the level of ability required for a judgment of competence to elect or refuse the intervention. As the consequences for well-being become less substantial, 


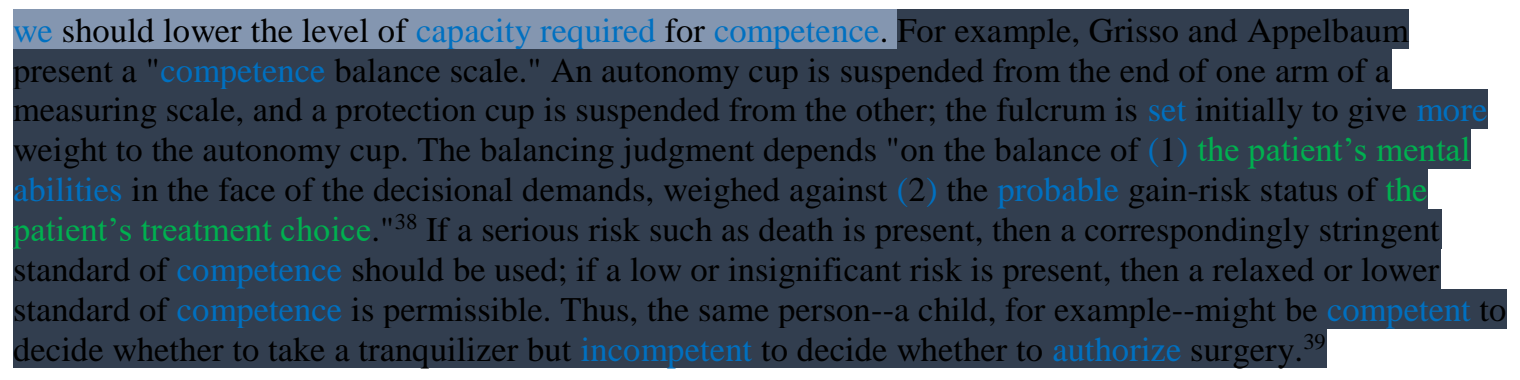

This sliding-scale strategy is attractive. A decision about which standard to use to determine competence depends on several factors that are risk-related. The sliding-scale strategy rightly recognizes that our interests in ensuring good outcomes legitimately contribute to the way we create standards. If the consequences for welfare are grave, the need to certify that the patient possesses the requisite capacities increases; but if little in the way of welfare is at stake, we can lower the level of capacity required for decision making. For example, if a patient with reversible dementia needs enteral nutrition to recover, a powerful reason exists for protecting that patient against rash or imprudent decision making and, accordingly, for adopting a more stringent standard of decision-making capacity.

Although the sliding-scale strategy may function as a valuable protective device, it creates confusion regarding the nature of both competence judgments and competence itself because of certain conceptual and moral difficulties. This strategy suggests that a person's competence to decide is contingent on the decision's importance or on some harm that might follow from the decision. This thesis is dubious: person's competence to decide whether, for example, to participate in cancer research does not depend on the decision's consequences. As risks increase or decrease, we can legitimately increase or reduce the rules, procedures, or measures we use to ascertain whether someone is competent; but in formulating what we are doing, we need to distinguish between a person's competence and the modes of ascertaining that person' competence. Leading proponents of the sliding-scale strategy hold the reverse view that competence itself varies with risk. For example, according to Allen Buchanan and Dan Brock, "Because the appropriate level of competence proper required for a particular decision must be adjusted to the consequences of acting on

that decision, no single standard of decision-making competence is adequate. Instead, the level of competence appropriately required for decision making varies along a full range from low/minimum to high/maximal." 40

This account is conceptually and morally perilous. It is correct to say that the level of a person's capacity to decide will rise as the complexity or difficulty of a task increases (deciding about spinal fusion, say, as contrasted with deciding whether to take a minor tranquilizer), but the level of competence to decide does not rise as the risk of an outcome increases. It is confusing to blend a decision's complexity or difficulty with the risk at stake. No basis exists for believing that risky decisions require more ability at decision making than less risky decisions.

We can sidestep these problems by recognizing that the level of evidence for determining competence should vary according to risk. As examples, some statutes have required a higher standard of evidence for competence in making than in revoking advance directives, and the National Bioethics Advisory Commission recommended a higher standard of evidence of competence to consent to participate in most research than to object to participation. ${ }^{41}$ These are counsels of prudence that protect patient-subjects. Whereas Brock and Buchanan propose that the level of decision-making competence itself belongs on a sliding scale from low to high in accordance with risk, we recommend placing only the required standards of evidence for determining decision-making competence on a sliding scale.

\section{THE MEANING AND JUSTIFICATION OF INFORMED CONSENT}

At least since the Nuremberg trials, which exposed the Nazis' horrific medical experiments, biomedical ethics has placed consent at the forefront of its concerns. The term informed consent did not appear until a 
decade after these trials (held in the late 1940s). It did not receive detailed examination until the early 1970s. In recent years the focus has shifted from the physician's or researcher's obligation to disclose information to the quality of a patient's or subject's understanding and consent. The forces behind this shift of emphasis were autonomy driven. In this section, we treat standards of informed consent as they have evolved through the regulation of research, case law, changes in the patient-physician relationship, and ethical analysis.

\section{The Justification of Informed Consent Requirements}

Virtually all prominent medical and research codes and institutional rules of ethics now hold that physicians and investigators must obtain the informed consent of patients and subjects prior to a substantial intervention. Throughout the early history of concern about research subjects, consent requirements were proposed primarily as a way to minimize the potential for harm. However, since the mid-1970s the primary justification advanced for requirements of informed consent has been to protect autonomous choice, a goal that institutions often bury in broad statements about protecting the rights of patients and research subjects.

In a series of books and articles on informed consent and autonomy, British philosopher Onora O'Neill has argued against the view that informed consent is justified in terms of respect for personal autonomy. ${ }^{42}$ O'Neill is suspicious of contemporary conceptions of autonomy and respect for autonomy, which she finds variable, vague, and difficult to tailor to acceptable requirements of informed consent. We agree that clarifications are needed, but we think that respect for autonomy does provide the primary justification of rules, policies, and practices of informed consent. O'Neill argues that practices and rituals of informed consent are best understood as ways to prevent deception and coercion; the process of informed consent provides reasonable assurance that a patient, subject, or tissue donor "has not been deceived or coerced."43 However, respect for autonomy in health care relationships requires much more than avoiding deception and coercion. It requires an attempt to instill relevant understanding, to avoid forms of manipulation, and to respect persons' rights.

\section{The Meaning and Elements of Informed Consent}

Some commentators have attempted to analyze the idea of informed consent in terms of shared decision making between doctor and patient, thus rendering informed consent and mutual decision making synonymous. ${ }^{44}$ However, informed consent should not be equated with shared decision making. Professionals obtain and will continue to obtain informed consent in many contexts of research and medicine in which shared decision making is a misleading model. We should distinguish (1) informational exchanges and communication through which patients elect interventions, often based on medical advice, from (2) acts of approving and authorizing those interventions. Shared decision making may be a worthy ideal in medicine, but the proposed process of decisions being shared is vague--with different conceptions of what exactly is shared. However interpreted, shared decision making as effective communication neither defines nor displaces informed consent. ${ }^{45}$ If shared decision making is presented as a plea merely for patients to be allowed to participate in decision making about diagnostic and treatment procedures, it continues the legacy of medical paternalism by ignoring patients' rights to consent or to refuse those procedures.

\footnotetext{
Two meanings of "informed consent."46 Two different senses of "informed consent" appear in current literature, policies, and practices. In the first sense, informed consent is analyzable through the account of autonomous choice presented earlier in this chapter: An informed consent is an individual's autonomous authorization of a medical intervention or of participation in research. In this first sense, a person must do more than express agreement or comply with a proposal. He or she must authorize something through an act of informed and voluntary consent. In an early and classic case, Mohr v. Williams (1905), a physician obtained Anna Mohr's consent to an operation on her right ear. While operating, the surgeon determined that the left ear actually needed surgery. A court found that the physician should have obtained consent to the surgery on the left ear: "If a physician advises a patient to submit to a particular operation, and the patient weighs the dangers and risks incident to its performance, and finally consents, the patient thereby, in effect, enters into a contract authorizing the physician to operate to the extent of the
} 
given, but no further." ${ }^{47}$ An informed consent in this first sense occurs if and only if a patient or subject, with substantial understanding and in absence of substantial control by others, intentionally authorizes a professional to do something quite specific.

In the second sense, informed consent refers to conformity to the social rules of consent that require professionals to obtain legally or institutionally valid consent from patients or subjects before proceeding with diagnostic, therapeutic, or research procedures. Informed consents are not necessarily autonomous acts under these rules and sometimes are not even meaningful authorizations. Informed consent refers here only to an institutionally or legally effective authorization, as determined by prevailing social rules. For example, a mature minor may autonomously authorize an intervention, but the minor's authorization may not be an effective consent under existing legal or institutional rules. Thus, a patient or subject can autonomously authorize an intervention, and so give an informed consent in the first sense, without effectively authorizing the intervention (because of some set of rules), and thus without giving an informed consent in the second sense.

Institutional rules of informed consent have typically not been assessed by the demanding standard of autonomous authorization. As a result, institutions, as well as laws and courts, sometimes impose on physicians and hospitals nothing more than an obligation to warn of risks of proposed interventions. "Consent" under these circumstances is not bona fide informed consent. The problem arises from the gap between the two senses of informed consent: Physicians who obtain consent under institutional criteria can and often do fail to meet the rigorous standards of the autonomy-based model.

It is easy to criticize institutional rules as superficial, but health care professionals cannot reasonably be expected to obtain a consent that satisfies the demands of rigorous autonomy-protecting rules in all circumstances. Autonomy-protecting rules may turn out to be excessively difficult or even impossible to implement. Hence, we should evaluate institutional rules not only in terms of respect for autonomy and autonomous authorization, but also in terms of the probable consequences of imposing unfairly burdensome requirements on institutions and professionals. Policies may legitimately take account of what is fair and reasonable to require of health care professionals and researchers. Nevertheless, we take as axiomatic that the model of autonomous choice (following the first sense of "informed consent") ought to serve as the benchmark for the moral adequacy of institutional rules of consent.

Franklin Miller and Alan Wertheimer challenge our view that the first sense of "informed consent" is the benchmark for judging the moral adequacy of institutional understandings and rules of informed consent. They propose a "fair transaction model" of the doctrine of informed consent in which, for example, investigators and their subjects are all treated fairly by giving due consideration to the reasonable limits of an investigator's responsibilities to ensure adequate understanding on the part of subjects who consent to research, the modest levels of comprehension expectable of some subjects, and the overall interests of subjects in participating in research. We welcome this approach as a way of interpreting our second sense of institutional informed consent, but the Miller-Wertheimer theory moves into unacceptably dangerous territory by altogether, and by design, abandoning the first sense of autonomous authorization and substituting the "fair transaction" model. Their model would be more suitable if it were presented as an explication of our second sense of "informed consent" and as a fairness-based analysis of requirements for various practical contexts in which informed consent is obtained. However, as their theory stands, these authors give a priority to fairness to all parties that loses sight of the central role of respect for the subject's or patient's autonomy. We see no justification for their claims that their model merits adoption "in place of the autonomous authorization model" and that "consent is a bilateral transaction," rather than the "onesided focus on the quality of the subject's consent" to which the autonomous authorization model is committed. We earlier argued, in treating the "shared decision-making" conception, that informed consent is misconceived as bilateral. Bilateral transactions of informational exchange often appropriately occur in consent contexts, but genuine informed consent is not reducible to a bilateral transaction. ${ }^{4}$

The elements of informed consent. Some commentators have attempted to define informed consent by specifying the elements of the concept, in particular by dividing the elements into an information component and a consent component. The information component refers to the disclosure (and often the comprehension) of information. The consent component refers to both a voluntary decision and an 

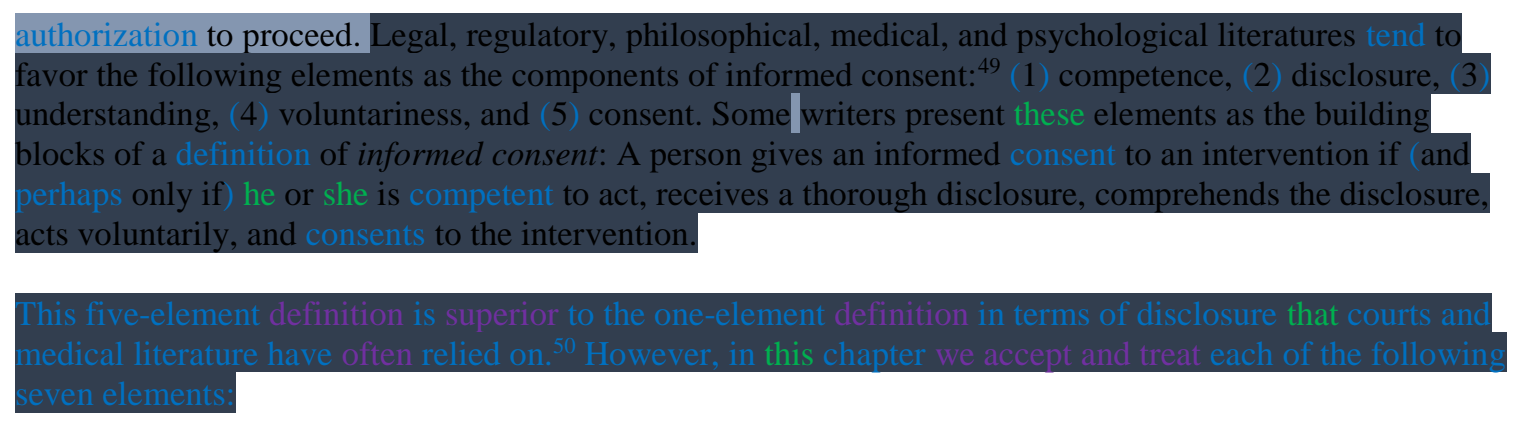

Threshold elements preconditions,

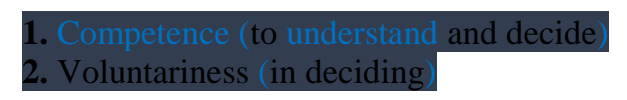

\section{Information elements}
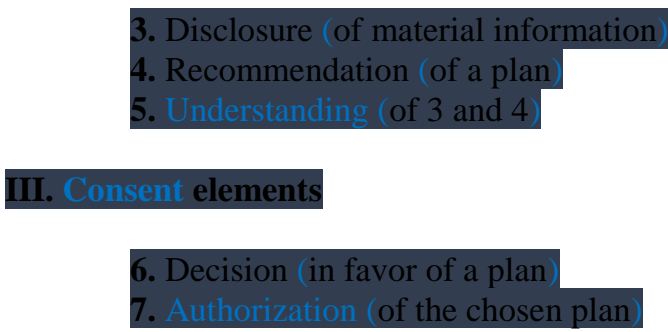

This list requires a brief explanation. First, an informed refusal entails a modification of items under III, thereby turning the categories into refusal elements, for example, "6. Decision (against a plan)." Whenever the expression "informed consent," we allow for the possibility of an informed refusal. Second, providing information for potential participants in research does not, and should not, necessarily involve making a recommendation number 4 ). Third, competer of obtaining informed consent, rather than as an element.

Having examined competence previously, we now concentrate on the critical elements of disclosure, understanding, and voluntariness.

\section{DISCLOSURE}

Disclosure is the third of our seven elements of informed consent. Some institutions and legal authorities have presented the obligation to disclose information to patients as the only major condition of informed consent. The legal doctrine of informed consent in the United States primarily has focused on disclosure because of a physician's obligation to exercise reasonable care in providing information. Civil litigation has emerged over informed consent because of injuries (measured in terms of monetary damages) that physicians intentionally or negligently have caused by their failures to disclose. The term informed consent was born in this legal context. However, from the moral viewpoint, informed consent has little to do with the liability of professionals as agents of disclosure and everything to do with the autonomous choices of patients and subjects.

Even so, disclosure usually does play a pivotal role in the consent process. Absent professionals' provision of information, many patients and subjects will have an insufficient basis for decision making.

Professionals are usually obligated to disclose a core set of information, including (1) those facts or descriptions that patients or subjects consider material when deciding whether to refuse or consent to a proposed intervention or involvement in research, (2) information the professional believes to be material, (3) the professional 's recommendation (if any), (4) the purpose of seeking consent, and (5) the nature and limits of consent as an act of authorization. If research is involved, disclosures should generally cover the 
aims and methods of the research, anticipated benefits and risks, any anticipated inconvenience or discomfort, and the subjects' right to withdraw, without penalty, from the research.

We could easily expand the list of basic information. For example, in one controversial decision, the California Supreme Court held that, when seeking an informed consent, "a physician must disclose personal interests unrelated to the patient's health, whether research or economic, that may affect the physician's professional judgment." ${ }^{51}$ Such a disclosure requirement has acquired greater moral significance as conflicts of interest have become more pronounced and problematic. We will examine this subject in Chapter 8.

\section{Standards of Disclosure}

Courts in the United States have struggled to determine which norms should govern the disclosure of information. Two competing standards of disclosure have become most prominent: the professional practice standard and the reasonable person standard. A third, the subjective standard, has also received some support, although courts have usually avoided it. These standards are morally, not merely legally, important.
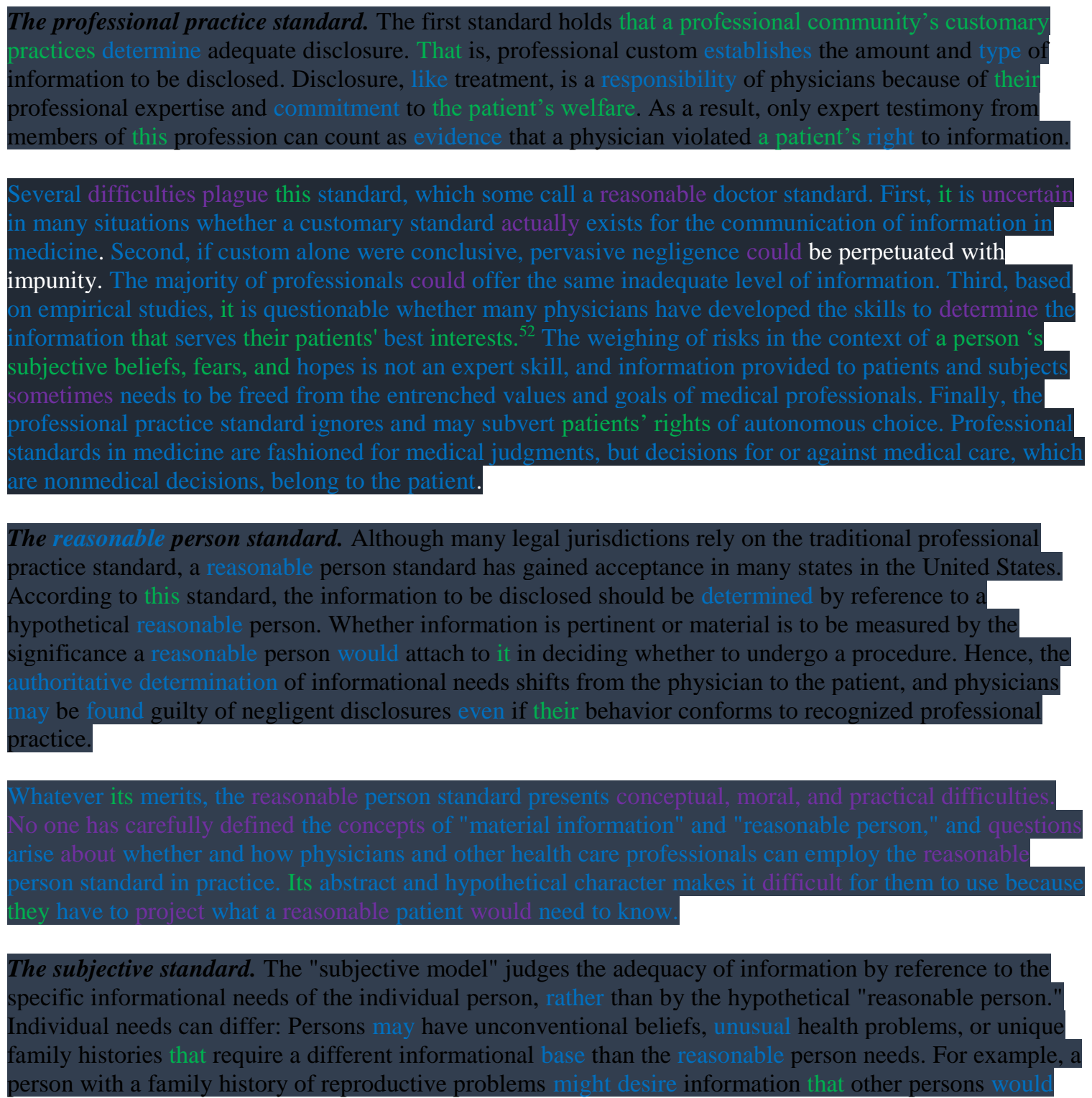

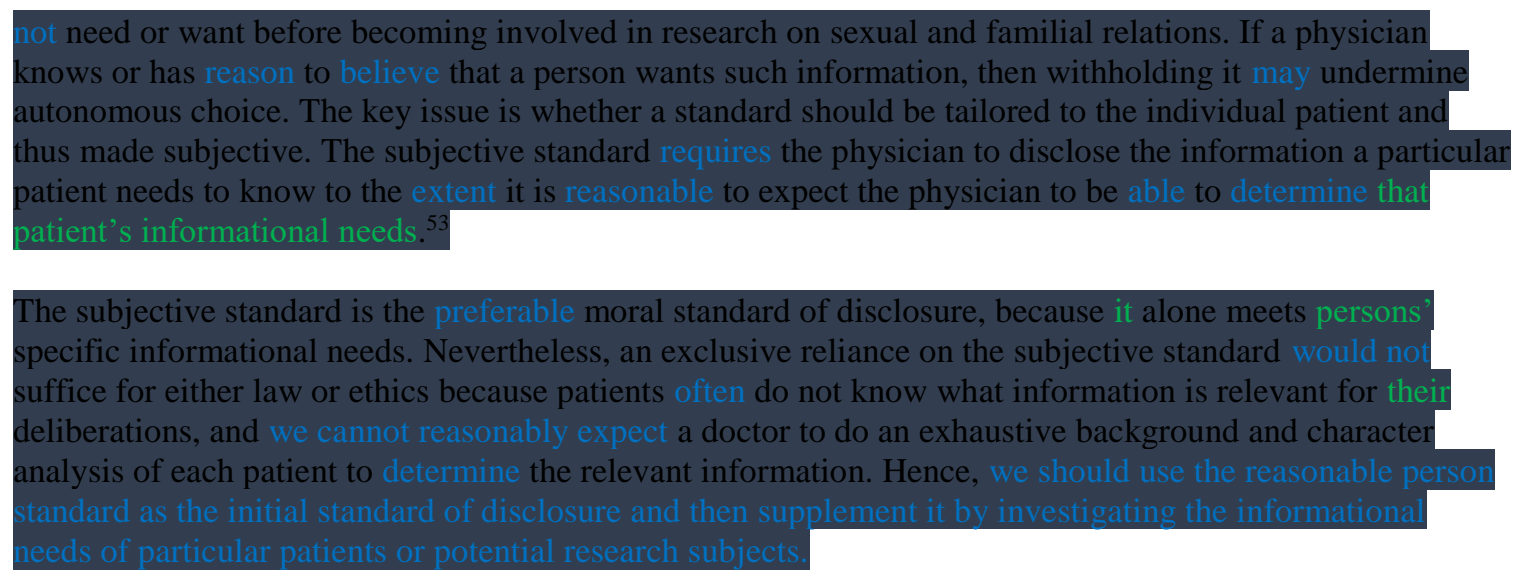

\section{Intentional Nondisclosure}

Some types of research are incompatible with complete disclosure, and in some clinical situations physicians claim that nondisclosures benefit the patient. Are these intentional nondisclosures justifiable?

The therapeutic privilege. Legal exceptions to the rule of informed consent allow the health professional to proceed without consent in cases of emergency, incompetence, and waiver. These three exceptive conditions are not controversial. However, one controversial exception is the therapeutic privilege, which states that a physician may legitimately withhold information based on a sound medical judgment the divulging the information would potentially harm a depressed, emotionally drained, or unstable patient. Possible and harmful outcomes include endangering life, causing irrational decisions, and producing anxiety or stress. ${ }^{54}$ Despite the protected status this doctrine traditionally has enjoyed, U.S. Supreme Court Justice Byron White once vigorously attacked the idea that possibly increasing a person's anxiety about a procedure provides grounds for an exception to rules of informed consent. ${ }^{55}$ White suggested that the legally protected status of the doctrine of therapeutic privilege lacks the security it once had.

All attempts to justify the therapeutic privilege are beneficence- and nonmaleficence-based because nondisclosure is aimed at the patient's good and at preventing harm from occurring. However, the precise content and formulation of the therapeutic privilege varies significantly across legal jurisdictions and institutional practices. Some formulations permit physicians to withhold information if disclosure would cause any deterioration in the patient's condition. Other formulations permit the physician to withhold information if and only if the patient's knowledge of the information would have serious health-related consequences, for example, by jeopardizing the treatment's success or by critically impairing relevant decision-making processes.

The narrowest formulation of the therapeutic privilege appeals to a circumstance of incompetence: A physician may invoke the therapeutic privilege only if he or she has sufficient reason to believe that disclosure would render the patient incompetent to consent to or refuse the treatment. This criterion does not conflict with respect for autonomy, because the patient would not be capable of an autonomous decision at the point a decision is needed. However, in our judgment it is ethically indefensible, even if legally permissible, to invoke the therapeutic privilege merely on grounds that the disclosure of relevant information might lead a competent patient to refuse a proposed treatment. (Related issues appear in our discussion of paternalism in Chapter 6 and of veracity in Chapter 8.)

Therapeutic use of placebos. The therapeutic use of placebos typically involves lack of transparency, incomplete disclosure, or even intentional deception. A placebo is a substance or intervention that the clinician believes to be pharmacologically or biomedically inert or inactive for the condition being treated. While "pure" placebos, such as a sugar pill, are pharmacologically inactive, active medications are sometimes used as "impure" placebos for conditions for which they are not medically indicated--for example, the prescription of an antibiotic for a common cold. Systematic evidence is lacking for the clinically significant benefits of most placebos, but patient and clinician reports indicate that placebos 
relieve some symptoms in as many as one-third of patients who suffer from conditions such as angina pectoris, cough, anxiety, depression, hypertension, headache, and the common cold. ${ }^{56}$ Placebos have also been reported to help some patients with irritable bowel syndrome, pain, and nausea. ${ }^{57}$

The provision or prescription of placebos is common in clinical practice, despite a weak body of evidence about their clinical benefits. In a national study of U.S. internists and rheumatologists, approximately half of the respondents reported that over the previous year they had prescribed placebo treatments on a regular basis, most often over-the-counter analgesics and vitamins. Slightly more than $10 \%$ had prescribed antibiotics or sedatives as placebo treatments; only a few had used saline or sugar pills as placebo treatments. Over $60 \%$ of those surveyed expressed a belief that the practice of prescribing placebos is ethically permissible. ${ }^{58}$

Beyond arguments against deception and failure to respect autonomy, ${ }^{59}$ objections to the therapeutic provision or prescription of placebos without adequate disclosure focus on their possible negative consequences, such as damage to a specific clinical relationship or to clinical relationships in general because of reduced trust. Some defenses of the use of placebos without specific disclosure require only that a patient consent to a generic treatment, using language such as "an effective pill" or "a powerful medicine." A related defense of placebos appeals to the patient's prior consent to the goals of treatment. Although such consent is not informed consent, these proposals might be acceptable if, prior to the initiation of the patient 's care, the patient were informed that a placebo might be used at some point in the treatment and he or she consented to this arrangement. ${ }^{60}$

The American Medical Association (AMA) has taken a similar approach by adopting a policy that bans the provision or prescription of a substance that the physician believes will have "no specific pharmacological effect upon the condition being treated" unless the patient has given an informed consent to the use of such a substance. The rationale is that this policy enables the physician to respect the patient's autonomy and to foster a trusting relationship, "while the patient still may benefit from the placebo effect." 61 The AMA's position is strongly justified because it removes the major ethical objection to deceptive placebo use, namely, that it violates the principle of respect for autonomy and the requirements of informed consent.

Evidence indicates that the placebo response or placebo effect can sometimes be produced without nondisclosure or deception. For example, the placebo response sometimes occurs even if patients have been informed that a particular substance is pharmacologically inert and still consent to its use. ${ }^{62}$ The mechanisms of placebo responses are poorly understood, but several hypotheses have been proposed, frequently centering on the healing context, with its symbolic significance and its rituals, including the ritual of taking medications, and on the professional's care, compassion, and skill in fostering trust and hope. ${ }^{63}$ However, in prescribing placebos, clinicians sometimes bypass opportunities for effective communication with patients. Communication and understanding can be fostered by admitting uncertainty; exploring patients' concerns, outlooks, and values; and inviting patients to be partners in the search for therapeutic options.

Withholding information from research subjects. Problems of intentional nondisclosure in clinical practice have parallels in research in which investigators sometimes need to withhold some information from subjects. Occasionally, good reasons support nondisclosure. Scientists could not conduct vital research in fields such as epidemiology if they always had to obtain consent from subjects for access to medical records. Officials often justify using such records without consent to establish the prevalence of a particular disease. This research is commonly only the first phase of an investigation intended to determine whether to trace and contact particular individuals who are at risk of disease, and the researchers often must obtain their permission for further participation in research. Sometimes, however, researchers need not contact individuals at all, for example, when hospitals strip personal identifiers from their records so epidemiologists cannot identify individual patients. In other circumstances, researchers only need to notify persons in advance about how they will use data and to offer these persons the opportunity to refuse to participate. In short, disclosures, warnings, and opportunities to decline involvement are sometimes legitimately substituted for informed consent.

Many other forms of intentional nondisclosure in research are more difficult to justify. For instance, debate arose about a study, designed and conducted by two physicians at the Emory University School of Medicine, to determine the prevalence of cocaine use and the reliability of self-reports of drug use among 
male patients in an Atlanta walk-in, inner-city hospital clinic serving low-income, predominantly black residents. In this study, approved by the institutional human investigations committee, researchers asked weekday outpatients at Grady Memorial Hospital to participate in a study about asymptomatic carriage of sexually transmitted diseases (STDs). The participants provided informed consent for the STD study, but not for an unmentioned piggy-back study on recent cocaine use and the reliability of self-reports of such use. Researchers informed patients that their urine would be tested for STDs, but neglected to inform that their urine would also be tested for cocaine metabolites. Of the 415 eligible men who agreed to participate, $39 \%$ tested positive for a major cocaine metabolite, although $72 \%$ of those with positive urinary assays denied any illicit drug use in the three days prior to sampling. Researchers concluded: "Our findings underscore the magnitude of the cocaine abuse problem for young men seeking care in inner-city, walk-in clinics. Health care providers need to be aware of the unreliability of patient self-reports of illicit drug use." 65

These researchers deceived their subjects about some aims and purposes of the research and did not disclose the means they would use. Investigators thought they faced a dilemma: On the one hand, needed accurate information about illicit drug use for health care and public policy. On the other hand, obtaining adequate informed consent would be difficult, because many potential subjects would either refuse to participate or would offer false information to researchers. The critical matter is that rules requiring informed consent have been designed to protect subjects from manipulation and abuse during the research process. Reports of the strategy used in this cocaine study could increase suspicion of medical institutions and professionals and could make patients' self-reports of illegal activities even less reliable. ${ }^{66}$ Investigators should have resolved their dilemma by developing alternative research designs, including sophisticated methods of using questions that can either reduce or eliminate response errors without violating rules of informed consent.

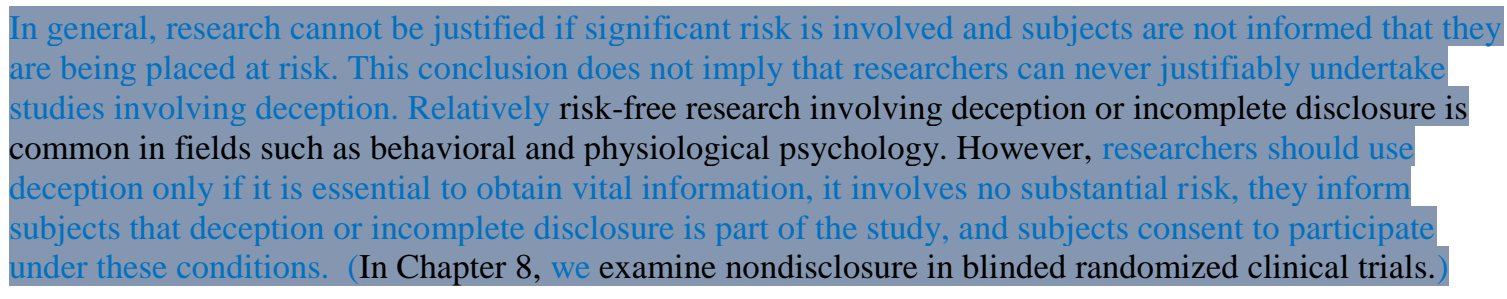

\section{UNDERSTANDING}

Understanding is the fifth element of informed consent in our earlier list. Clinical experience and empirical data indicate that patients and research subjects exhibit wide variation in their understanding of information about diagnoses, procedures, risks, probable benefits, and prognoses. ${ }^{67}$ For instance, in a study of participants in cancer clinical trials, $90 \%$ indicated they were satisfied with the informed consent process and most of them thought they were well informed. However, approximately three-fourths of them did not understand that the trials included nonstandard and unproven treatment, and approximately one-fourth did not appreciate that the primary purpose of the trials was to benefit future patients and that the benefits to them personally were uncertain. ${ }^{68}$

Many factors account for limited understanding in the informed consent process. Some patients and subjects are calm, attentive, and eager for dialogue, whereas others are nervous or distracted in ways that impair or block understanding. Other conditions that limit understanding include illness, irrationality, and immaturity. Important institutional and situational factors include pressures of time, limited or no remuneration to professionals for time spent in communication, and professional conflicts of interest.

\section{The nature of understanding}

No consensus exists about the nature and level of understanding needed for an informed consent, but an analysis sufficient for our purposes is that persons understand if they have acquired pertinent information and have relevant beliefs about the nature and consequences of their actions. Their understanding need not 
be complete, because a grasp of central facts is generally sufficient. Some facts are irrelevant or trivial; others are vital, perhaps decisive. In some cases, a person's lack of awareness of even a single risk or missing fact can deprive him or her of adequate understanding. Consider, for example, the classic case of Bang v. Miller Hospital (1958), in which patient Bang did not intend to consent to a sterilization entailed in prostate surgery ${ }^{69}$ Bang did, in fact, consent to prostate surgery, but without being told that sterilization was an inevitable outcome. (Although sterilization is not necessarily an outcome of prostate surgery, it is inevitable in the specific procedure recommended in this case.) Bang's failure to understand this one surgical consequence compromised what was otherwise an adequate understanding and invalidated what otherwise would have been a valid consent.

Patients and subjects usually should understand, at a minimum, what an attentive health care professional or researcher believes a reasonable patient or subject needs to understand to authorize an intervention. Diagnoses, prognoses, the nature and purpose of the intervention, alternatives, risks and benefits, and recommendations typically are essential. Patients or subjects also need to share an understanding with professionals about the terms of the authorization before proceeding. Unless agreement exists about the essential features of what is authorized, there can be no assurance that a patient or subject has made an autonomous decision and provided a valid consent, even if physician and patient both use a word such as stroke or hernia, their interpretations will diverge if standard medical conceptions have no meaning for the patient.

Some argue that many patients and subjects cannot comprehend enough information or sufficiently appreciate its relevance to make autonomous decisions about medical care or participation in research. Such statements overgeneralize, perhaps because of an improper ideal of full disclosure and full understanding. If we replace this unrealistic standard with a more defensible account of the understanding of material information, we can avoid this skepticism. From the fact that actions are never fully informed, voluntary, or autonomous, it does not follow that they are never adequately informed, voluntary, or autonomous. ${ }^{70}$ However, some patients have such limited knowledge bases that communication about alien or novel situations is exceedingly difficult, especially if physicians introduce new concepts and cognitive constructs. Studies indicate that these patients likely will have an impoverished and distorted understanding of scientific goals and procedures. ${ }^{71}$ Even in these difficult situations enhanced understanding and adequate decision making can often be achieved. Professionals may be able to communicate novel or specialized information to laypersons by drawing analogies between this information and more ordinary events familiar to the patient or subject. Similarly, professionals can express risks in both numeric and nonnumeric probabilities, while helping the patient or subject to assign meanings to the probabilities through comparison with more familiar risks and prior experiences, such as risks involved in driving automobiles or using power tools. ${ }^{72}$

Even with the assistance of these and other strategies, enabling a patient to both comprehend and appreciate risks and probable benefits is a formidable task. For example, patients confronted with various forms of surgery understand that they will suffer postoperative pain. Nevertheless, their projected expectations of pain are often inadequate. Many patients cannot in advance adequately appreciate the nature and severity of the pain, and many ill patients reach a point when they can no longer balance with clear judgment the threat of pain against the benefits of surgery. At this point they may not find the benefits of surgery overwhelmingly attractive, while discounting the risks. These patients correctly understand basic facts about procedures that involve pain, but their understanding is nonetheless inadequate.

Many studies focus on patients' and research participants' failures to comprehend the risks involved, but problems also arise in the understanding of expected benefits--their nature, probability, and magnitude. These problems were evident in a study of the understanding of patients with stable coronary artery disease who chose to undergo percutaneous coronary intervention (PCT). In contrast to the best available evidence and the views of their cardiologists, the overwhelming majority of these patients thought that $\mathrm{PCl}$ would reduce their risk of a heart attack (88\%) and their risk of death from a heart attack $(82 \%)$, even though PCl 's major expected benefit for such patients is only symptomatic, namely, relief from chest pain or discomfort. PCI may not be lifesaving for patients who have an acute or unstable angina, and the patients who had only stable angina may not have confused the two conditions because both involve chest pain and discomfort. According to the investigators and a commentator, direct communication about these and other 
matters, accompanied by decision aids, could have been helpful, especially when accompanied by improvements in the level of reading difficulty and the information provided in the consent form. ${ }^{73}$

\begin{abstract}
Although studies suggest that modest efforts may not significantly improve informed consent in clinical care ${ }^{74}$ special concerns about adequate understanding for valid consent arise in the context of research, which is designed to generate generalizable knowledge rather than to benefit the participant. The "therapeutic misconception" is a widely discussed problem of informed consent that must be addressed in research, where subjects may fail to distinguish between clinical care and research and may not to understand the purpose and aim of research, thereby misconceiving their participation as therapeutic in nature. ${ }^{75}$ In a stringent interpretation of the standard of adequate understanding, the therapeutic misconception invalidates a subject's consent because he or she is not truly consenting to participation in research. A partial solution is twofold: first, to recognize that the label "therapeutic misconception" is too broad, and second, to find specific interventions to address the different misunderstandings under rubric. ${ }^{76}$
\end{abstract}

Sam Horng and Christine Grady appropriately distinguish therapeutic misconception in the strict sense from therapeutic misestimation and therapeutic optimism. ${ }^{77}$ The therapeutic misconception, if uncorrected, invalidates subjects' consent because they do not have the facts straight enough to truly consent to participate in research. However, some participants who understand that they are involved in research, rather than clinical care, still overestimate the therapeutic possibilities and probabilities, that is, the odds that participants will benefit. Such a therapeutic misestimation, Horng and Grady argue, should be tolerated if "modest misestimates do not compromise a reasonable awareness of possible outcomes." By contrast, in therapeutic optimism participants accurately understand the odds that participants will benefit but are overly optimistic about their own chances of beating those odds. This therapeutic optimism usually does not compromise or invalidate the individual's informed consent because it is more like a legitimate hope than an informational bias.

\title{
Problems of Information Processing
}

With the exception of a few studies of comprehension, studies of patients' decision making pay insufficient attention to information processing. Information overload may prevent adequate understanding, and physicians exacerbate these problems when they use unfamiliar medical terms.

Some studies have uncovered difficulties in processing information about risks, indicating that risk disclosures commonly lead subjects to distort information, promote inferential errors, and create disproportionate fears of some risks. Some ways of framing information are so misleading that both health professionals and patients regularly misconstrue the content. For example, choices between risky alternatives can be influenced by whether the same risk information is presented as providing a gain or an opportunity for a patient or as constituting a loss or a reduction of opportunity. ${ }^{78}$ One study asked radiologists, outpatients with chronic medical problems, and graduate business students to make a hypothetical choice between two alternative therapies for lung cancer: surgery and radiation therapy. ${ }^{79}$ Researchers framed the information about outcomes in terms of (1) survival and (2) death. This difference of framing affected the preferences of all three groups. When faced with outcomes framed in terms of probability of survival, $25 \%$ chose radiation over surgery. However, when the identical outcomes were presented in terms of probability of death, $42 \%$ preferred radiation. The mode of presenting the risk of immediate death from surgical complications, which has no counterpart in radiation therapy, appears to have made the decisive difference.

These framing effects reduce understanding, with direct implications for autonomous choice. If a misperception prevents a person from adequately understanding the risk of death and this risk is material to the person's decision, then the person's choice of a procedure does not reflect a substantial understanding and his or her consent does not qualify as an autonomous authorization. The lesson is the need for better understanding of techniques that enable professionals to communicate both the positive and the negative sides of information--for example, both the survival and the mortality probabilities. 
Decision aids are increasingly used to prepare individuals to participate in medical decisions that involve balancing probable benefits and risks in contexts of scientific uncertainty where decisions about screening or therapeutic interventions are difficult to evaluate. Studies show that the use of decision aids can provide important information and enable patients to reflect on their own values and preferences in relation to their circumstances and options. The use of these decision aids correlates with patients' increased knowledge and more active participation in decision making. Other benefits include a reduction in patients' decisional conflict based on inadequate information or unclarity about their personal values and preferences and fewer decisions for elective procedures, such as PCI for stable coronary artery disease. ${ }^{80}$

However, caution is in order. As a result of some studies of decision aids, questions have emerged about their health effects. In a randomized controlled trial, investigators studied the impact of a decision aid to enhance informed choices and involvement in decision making about screening for bowel cancer among adults with low levels of education. The decision aid--an interactive booklet and a DVD--presented quantitative information about the relative risks of (1) testing occult fecal blood versus (2) no testing. The control group received standard information about the relative risks. The decision aid effectively enhanced informed choices, as indicated by the participants' knowledge and participation in decisions about screening. However, only $59 \%$ in the decision aid group chose to be tested in comparison with $75 \%$ in the control group. ${ }^{81}$ Some critics charge that informed choice initiatives may not be harmful in some cases, especially when solid evidence exists about a procedure's value. One critic even proposes that in efforts to reduce mortality from bowel cancer, the purpose of information interventions should be to "support uptake" rather than to "prepare or enable decision making." 82 For this critic, the presentation of information to describe the risks and benefits of screening should occur "within a framework that encourages adherence to recommendations." Defenders of improving informed choice challenge this proposal as a paternalistic manipulation of information to ensure the use of screening. ${ }^{83}$ Moreover, in many cases physicians do not agree among themselves about what, if anything, is to be recommended.

\title{
Problems of Nonacceptance and False Belief
}

\begin{abstract}
A breakdown in a person's ability to accept information as true or untainted, even if he or she adequately comprehends the information, also can compromise decision making. A single false belief can invalidate a patient's or subject's consent, even when there has been a suitable disclosure and comprehension. For example, a seriously ill patient who has been adequately informed about the nature of the illness and has been asked to make a treatment decision might refuse under the false belief that he or she is not ill. Even if the physician recognizes the patient's false belief and adduces conclusive evidence to prove to the patient that the belief is mistaken, and the patient comprehends the information provided, the patient may go on believing that what has been reported is false.
\end{abstract}

If ignorance prevents an informed choice, it may be permissible or possibly even obligatory to promote autonomy by attempting to impose unwelcome information. Consider the following case in which a false belief played a major role in a patient's refusal of treatment: ${ }^{84}$

\begin{abstract}
A 57-year-old woman was admitted to the hospital because of a fractured hip .... During the course of the hospitalization, a Papanicolaou test and biopsy revealed stage 1A carcinoma of the cervix .... Surgery was strongly recommended, since the cancer was almost certainly curable by a hysterectomy.... The patient refused the procedure. The patient's treating physicians at this point felt that she was mentally incompetent. Psychiatric and neurological consultations were requested to determine the possibility of dementia and/or mental incompetency. The psychiatric consultant felt that the patient was demented and not mentally competent to make decisions regarding her own care. This determination was based in large measure on the patient's steadfast "unreasonable" refusal to undergo surgery. The neurologist disagreed, finding no evidence of dementia. On questioning, the patient stated that she was refusing the hysterectomy because she did not believe she had cancer. "Anyone knows," she said, "that people with cancer are sick, feel bad and lose weight," while she felt quite well. The patient continued to hold this view despite the results of the biopsy and her physicians' persistent arguments to the contrary.
\end{abstract}

The physician seriously considered overriding the patient's refusal, because solid medical evidence indicated that she was unjustified in believing that she did not have cancer. As long as this patient continues to hold a false belief that is material to her decision, her refusal is not an informed refusal. The case illustrates some complexities involved in effective communication: The patient was a poor white woman 
from Appalachia with a third-grade education. The fact that her treating physician was black was the major reason for her false belief that she did not have cancer. She would not believe what a black physician told her. However, intense and sometimes difficult discussions with a white physician and with her daughter eventually corrected her belief and led her to consent to a successful hysterectomy. This example illustrates why it is sometimes necessary for clinicians to vigorously challenge patients' choices in order to further enhance the quality of their autonomous choices rather than merely accept their choices at face value.

\title{
Problems of Waivers
}

Further problems about understanding arise in waivers of informed consent. In the exercise of a waiver, a patient voluntarily relinquishes the right to an informed consent and relieves the physician of the obligation to obtain informed consent. ${ }^{85}$ The patient delegates decision-making authority to the physician or to a third party, or simply asks not to be informed. The patient makes a decision not to make an informed decision.

Some courts have held that physicians need not make disclosures of risk if a patient requests not to be informed, ${ }^{86}$ and some writers in biomedical ethics hold that rights are always waivable. ${ }^{87}$ lt is usually appropriate to recognize waivers of rights because we enjoy discretion over whether to exercise such rights, For example, if a committed Jehovah's Witness informed a doctor that he wished to have everything possible done for him, but did not want to know if the hospital utilized transfusions or similar procedures, it is difficult to imagine a moral argument sufficient to support the conclusion that he must give a specific informed consent to the transfusions. Nevertheless, a general practice of allowing waivers is dangerous. Many patients have an inordinate trust in physicians, and a widespread acceptance of waivers of consent in research and therapeutic settings could make subjects and patients more vulnerable to those who omit consent procedures for convenience, which is already a serious problem in health care.

\begin{abstract}
No solution to these problems about waivers is likely to emerge that fits all cases. Although each case or situation of waiver needs to be considered separately, there may not be appropriate procedural responses. For example, institutions can develop rules that disallow waivers except when they have been approved by deliberative bodies, such as institutional review committees and hospital ethics committees. If a committee determines that recognizing a waiver would best protect a person's interest in a particular case, then the waiver could be sustained.
\end{abstract}

\section{VOLUNTARINESS}

Voluntariness is the second element of informed consent in our list and also the third of our three conditions of autonomous action. Because it was so often neglected in the history of research, this element has come to have a prominent role in biomedical ethics. The Nuremberg Code, for example, insists on voluntariness: A research subject "should be so situated as to be able to exercise free power of choice, without the intervention of any element of force, fraud, deceit, duress, overreaching, or other ulterior form of constraint or coercion." 88

We use the term voluntariness more narrowly than some writers do. Some have analyzed voluntariness in terms of the presence of adequate knowledge, the absence of psychological compulsion, and the absence of external constraints. ${ }^{89}$ If we were to adopt such a broad meaning, we would be equating voluntariness with autonomy. We hold only that a person acts voluntarily if he or she wills the action without being under the control of another person or condition. We will consider here only the condition of control by other individuals, but we note that conditions such as debilitating disease, psychiatric disorders, and drug addiction can also diminish or destroy voluntariness, thereby precluding autonomous choice and action.

\section{Forms of Influence}

Not all influences exerted on another person are controlling. If a physician orders a reluctant patient to undergo cardiac catheterization and coerces the patient into compliance through a threat of abandonment, then the physician's influence controls the patient. If, by contrast, a physician persuades the patient to undergo the procedure when the patient is at first reluctant to do so, then the physician's actions influence, but do not control, the patient. Many influences are resistible, and some are welcomed rather than resisted. 
The broad category of influence includes acts of love, threats, education, lies, manipulative suggestions, and emotional appeals, all of which can vary dramatically both in their impact on persons and in ethical justification. Our analysis focuses on three categories of influence: coercion, persuasion, and manipulation. Coercion occurs if and only if one person intentionally uses a credible and severe threat of harm or force to control another. ${ }^{90}$ The threat of force used by some police, courts, and hospitals in acts of involuntary commitment for psychiatric treatment is coercive. Some threats will coerce virtually all persons (e.g., a credible threat to kill the person), whereas others will coerce only a few persons (e.g employee's threat to an employer to quit a job unless a raise is offered). Whether coercion occurs depends on the subjective responses of the coercion's intended target. However, a subjective response in which persons comply because they feel threatened even though no threat has actually been issued does not qualify as coercion. Coercion occurs only if an intended and credible threat displaces

directed course of action, thereby rendering even intentional and well-informed behavior nonautonomous. We reject a common tendency in biomedical ethics to use "coercion" as a broad term of ethical criticism that obscures relevant and distinctive ethical concerns. For instance, coercion is not identical to taking advantage of a person in dire circumstances. Both are wrong in many contexts, often for different reasons. ${ }^{9 !}$

In persuasion a person must come to believe in something through the merit of reasons another person advances. Appeal to reason--that is, attempted persuasion--is distinguishable from influence by appeal to emotion. In health care, the problem is how to distinguish emotional responses from cognitive responses and to determine which are likely to be evoked. Disclosures or approaches that might rationally persuade one patient might overwhelm another whose fear or panic undercuts reason.

Manipulation is a generic term for several forms of influence that are neither persuasive nor coercive. The essence of manipulation is swaying people to do what the manipulator wants by means other than coercion or persuasion. In health care, the most likely form of manipulation is informational manipulation, a deliberate act of managing information that alters a person's understanding of a situation and motivates hi or her to do what the agent of influence intends. Many forms of informational manipulation are incompatible with autonomous decision making. For example, lying, withholding information, and misleading by exaggeration with the intent to lead persons to believe what is false all compromise autonomous choice. The manner in which a health care professional presents information--by tone of voice, by forceful gesture, and by framing information positively ("we succeed most of the time with therapy") rather than negatively ("we fail with this therapy in $35 \%$ of the cases")--can also manipulate

Nevertheless, it is easy to inflate control by manipulation beyond its actual significance in health care. We typically make decisions in a context of competing influences, such as personal desires, familial constraints, legal obligations, and institutional pressures. These influences usually do not control decisions to a morally worrisome degree. In biomedical ethics we need only establish general criteria for the point at which influence threatens autonomous choice.

\section{The Obligation to Abstain from Controlling Influence}

Coercion and controlling manipulation are occasionally justified--infrequently in medicine, more often in public health, and even more often in law enforcement. If a physician taking care of a disruptive and noncompliant patient threatens to discontinue treatment unless the patient alters certain behaviors, the physician's mandate may be justified even if it is coercive. The most difficult problems about manipulation do not involve threat and punishment, which are almost always unjustified in health care and research. Rather, they involve the effect of rewards, offers, and encouragement.

A classic example of an unjustified offer occurred during the Tuskegee syphilis study. Researchers used various offers to stimulate and sustain the subjects' interest in continued participation; these offers included free burial assistance and insurance, free transportation to and from the examinations, and a free stop in town on the return trip. Subjects also received free medicines and free hot meals on the days of the examination. The subjects' socioeconomic deprivation made them vulnerable to these overt and unjustified forms of manipulation..$^{92}$ 
The conditions under which an influence both controls persons and lacks moral justification may be clear in theory, but they are often unclear in concrete situations. For example, many patients report feeling severe pressure to enroll in clinical trials, even though their enrollment is voluntary. ${ }^{93}$ Some difficult cases in health care involve manipulation-like situations in which patients or subjects are in desperate need of a given medication or a source of income. Attractive offers such as free medication or extra money can leave a person without a meaningful choice. A threatening situation can constrain a person even in the absence of another's intentional manipulation. Influences that persons ordinarily find resistible can control abnormally weak, dependent, and surrender-prone patients. ${ }^{94}$ In short, people's vulnerabilities differ, thereby producing variations in what constitutes an "undue" influence. ${ }^{95}$

The threat of exploitation for research and other purposes is substantial in institutions where populations are confined involuntarily, but even if persons voluntarily admit themselves to institutions, rules, policies, and practices can work to compromise autonomous choice. This compromise is often evident in long-term care. The elderly in nursing homes can experience constricted choices in everyday matters. Many suffer a decline in their ability to carry out personal choices because of physical impairments, but this decline in executional autonomy need not be accompanied by a decline in decisional autonomy. ${ }^{96}$ On the one hand, the problem is that caregivers in nursing homes may neglect, misunderstand, or override residents' autonomous decisions in everyday decisions that range over food, roommates, possessions, exercise, sleep, and clothes, along with baths, medications, and restraints. On the other hand, institutional needs for structure, order, safety, and efficiency are sometimes legitimately invoked to override residents' autonomous choices.

\section{CONCLUSION}

The intimate connection between autonomy and decision making in health care and research, especially in circumstances of consent and refusal, unifies this chapter's several sections. Although we have justified the obligation to solicit decisions from patients and potential research subjects by the principle of respect for autonomy, we have also acknowledged that the principle's precise demands remain unsettled and open to legitimate interpretation and specification.

We have criticized various approaches that have been taken to obtaining consents, but we should be mindful that the history of informed consent and the place of autonomy in biomedical ethics are still under development. Current deficiencies may be no less apparent to future generations than the past failures we have occasionally pointed to in this chapter.

Finally, we again stress that construing respect for autonomy as a principle with priority over all other moral principles, rather than as one principle in a framework of prima facie principles, is indefensible. The human moral community--indeed, morality itself--is rooted no less deeply in the three clusters of principles to be discussed in the next three chapters.

\section{NOTES}

1. Generally we refer to those who enroll in research as subjects, but occasionally as participants. See the discussion of this distinction in National Bioethics Advisory Commission (NBAC), Ethical and Policy Issues in Research involving Human Participants, Vol. I: Report and Recommendations (Bethesda, MD: NBAC, August 2001), pp. 32-33.

2. The core idea of autonomy is treated by Joel Feinberg, Harm to Self vol. Ill in The Moral Limits of Criminal Law (New York: Oxford University Press, 1986), chaps. 18-19; various essays in Franklin G. Miller and Alan Werlheimer, eds., The Ethics of Consent: Theory and Practice (New York: Oxford University Press, 2010); and several essays in James Stacey Taylor, ed., Personal Autonomy: New Essays on Personal Autonomy and its Role in Contemporary Moral Philosophy (Cambridge: Cambridge University Press, 2005). 
3. For a theory that points to the importance of a broader theory of the autonomous person than we provide, see Rebecca Kukla, "Conscientious Autonomy: Displacing Decisions in Health Care," Hastings Center Report 35 (March-April 2005): 34-44.

4. Gerald Dworkin, The Theory and Practice of Autonomy (New York: Cambridge University Press, 1988), chaps. 1-4; Harry G. Frankfurt, "Freedom of the Will and the Concept of a Person," Journal of Philosophv 68 (1971): 5-20, as reprinted in The Importance of What We Care About (Cambridge: Cambridge University Press, 1988), pp. 11-25. Frankfurt may not be primarily focused on a theory of freedom rather a theory of autonomy; but see his uses of the language of "autonomy" in his Necessity, Volition, and Love (Cambridge: Cambridge University Press, 1999), chaps. 9, 11, especially pp. 95-110, 137.

5. Dworkin, The Theory and Practice of Autonomy, p. 20.

6. Agnieszka Jaworska, "Caring, Minimal Autonomy, and the Limits of Liberalism," in Naturalized Bioethics: Toward Responsible Knowing and Practice, ed. Hilde Lindemann, Marian Verkerk, and Margaret Urban Walker (New York: Cambridge University Press, 2009), pp. 80-105, esp. 82.

7. For a "planning theory" and its relation to theories of autonomy, see Michael Bratman, "Planning Agency, Autonomous Agency," in Personal Autonomy, ed. Taylor, pp. 33-57.

8. See Arthur Kuflik, "The Inalienability of Autonomy," Philosophy and Public Affairs 13 (1984): 271-98; Joseph Raz, "Authority and Justification," Philosophy and Public Affairs 14 (1985): 3-29; and Christopher McMahon, "Autonomy and Authority," Philosophy and Public Affairs 16 (1987): 303-28.

9. See several essays in Relational Autonomy: Feminist Perspectives on Autonomy, Agency, and the Social Self, ed. Catriona Mackenzie and Natalie Stoljar (New York: Oxford University Press, 2000); Marilyn Friedman, Autonomy, Gender, and Politics (New York: Oxford University Press, 2003); John Christman, "Feminism and Autonomy," in Nagging Questions: Feminist Ethics in Everyday Life, ed. Dana Bushnell (Lanham, MD: Rowman \& Littlefield, 1995); and Alasdair Maclean on "relational consent" in his Autonomy, Informed Consent and Medical Law: A Relational Challenge (Cambridge: Cambridge University Press, 2009).

10. See, further, Carolyn Ells, "Shifting the Autonomy Debate to Theory as Ideology," Journal of Medicine and Philosophy 26 (2001): 417-30; Stoljar, "Informed Consent and Relational Conceptions of Autonomy," Journal of Medicine and Philosophy 36 (2011): 375-84; Susan Sherwin, "A Relational Approach to Autonomy in Health-Care," in The Politics of "Women's Health: Exploring Agency and Autonomy, The Feminist Health Care Ethics Research Network (Philadelphia: Temple University Press, 1998); and Anne Donchin, "Understanding Autonomy Relationally," Journal of Medicine and Philosophy 23, no. 4 (1998).

11. See Barbara Herman, "Mutual Aid and Respect for Persons," Ethics 94 (July 1984): 577-602, esp. 6002; and Onora O'Neill, "Universal Laws and Ends-in-Themselves," Monist 72 (1989): 341-61.

12. This misunderstanding of our claim is seen in M. Therese Lysaught, "Respect: or, How Respect for Persons Became Respect for Autonomy," Journal of Medicine and Philosophy 29 (2004): 665-80, esp. 676.

13. Carl E. Schneider, The Practice of Autonomy: Patients, Doctors, and Medical Decisions (New York: Oxford University Press, 1998), esp. p. xi. See also Paul Root Wolpe, "The Triumph of Autonomy in American Bioethics: A Sociological View," in Bioethics and Society: Constructing the Ethical Enterprise, ed. Raymond DeVries and Janardan Subedi (Upper Saddle River, NJ: Prentice Hall, 1998), pp. 38-59; Daniel Callahan, "Autonomy: A Moral Good, Not a Moral Obsession," Hastings Center Report 14 (October 1984): 40-42; Robert M. Veatch, "Autonomy’s Temporary Triumph," Hastings Center Report 14 (October 1984): 38-40; James F. Childress, "The Place of Autonomy in Bioethics," Hastings Center Report 20 (January-February 1990): 12-16: and Thomas May, "The Concept of Autonomy in Bioethics: An Unwarranted Fall from Grace." in Personal Autonomy, ed. Taylor, pp. 299-309. 
14. Leslie J. Blackhall, Sheila T. Murphy, Gelya Frank, et al., "Ethnicity and Attitudes toward Patient Autonomy," JAMA: Journal of the American Medical Association 274 (September 13, 1995): 820-25.

15. Joseph A. Carrese and Lorna A. Rhodes, "Western Bioethics on the Navajo Reservation: Benefit or Harm?" JAMA: Journal of the American Medical Association 274 (September 13, 1995): 826-29.

16. We make these points to forestall misunderstanding. Some critics of theories that connect respect for autonomy to informed consent mistakenly presume that defenders of these views, including us, view them as necessary and sufficient. See Neil C. Manson and Onora O'Neill, Rethinking Informed Consent in Bioethics (Cambridge: Cambridge University Press, 2007), pp. 19, $185 f f$.

17. For a fuller discussion of the relation between autonomy and consent, see Tom L. Beauchamp, "Autonomy and Consent," in The Ethics of Consent, ed. Miller and Wertheimer, chap. 3.

18. See Avram Goldstein, "Practice vs. Privacy on Pelvic Exams: Med Students' Training Intrusive and Needs Patient Consent, Activists Say," Washington Post, May 10, 2003, p. Al.

19. Britt-lngjerd Nesheim, "Commentary: Respecting the Patient's Integrity ls the Key," BMJ: British Medical Journal 326 (January 11, 2003): 100.

20. Peter A. Ubel, Christopher Jepson, and Ari Silver-Isenstadt. "Don't Ask, Don't Tell: A Change in Medical Student Attitudes after Obstetrics/Gynecology Clerkships toward Seeking Consent for Pelvic Examinations on an Anesthetized Patient," American Journal of Obstetrics and Gynecology 188 (February 2003): 575-79.

21. Bernard M. Branson, H. Hunter Handsfield, Margaret A. Lampe, et al., "Revised Recommendations for HIV Testing of Adults, Adolescents, and Pregnant Women in Health-Care Settings," Morbidity and Mortality Weekly Report, Recommendations and Report 55 (RR-14) (September 22, 2006: 1-17. Under these recommendations, specific, explicit informed consent is still expected in nonclinical settings.

22. See Ronald Bayer and Amy L. Fairchild, "Changing the Paradigm for HIV Testing-The End of Exceptionalism," New England Journal of Medicine 355 (August 17, 2006): 647-49; Lawrence O. Gostin, "HIV Screening in Health Care Setting: Public Health and Civil Liberties in Conflict?" JAMA: Journal of the American Medical Association 296 (October 25, 2006): 2023-25: and Thomas R. Frieden el al., "Applying Public Health principles to the HIV Epidemic," New England Journal of Medicine 353 (December 1, 2005): 2397-402. For a cost-effectiveness analysis, see Gillian D. Sanders et al., "CostEffectiveness of Screening for HIV in the Era of Highly Active Antiretroviral Therapy," New England Journal of Medicine 352 (February 10, 2005): 570-85.

23. Sec Carl W. Dieffenbach and Anthony S. Fauci, "Thirty Years of HIV and AIDS: Future Challenges and Opportunities," Annals of Internal Medicine 154, no. 11 (June 2011): 766-72.

24. Quoted in Bayer and Fairchild. "Changing the Paradigm for HIV Testing," p. 649.

25. For a fuller discussion of the issues raised by "opt-out" policies to increase the supply of transplantable organs, see Institute of Medicine, Committee on Increasing Rates of Organ Donation, Organ Donation: Opportunities for Action, ed. James F. Childress and Catharyn Liverman (Washington, DC: National Academies Press, 2006), chap. 7. See also Richard H. Thaler and Cass R. Sunstein, Nudge: Improving Decisions About Health, Wealth, and Happiness (New Haven, CT: Yale University Press, 2008), chap. 11, "How to Increase Organ Donations."

26. This case was developed by Gail Povar, M.D.

27. See Thomas Grisso and Paul S. Appelbaum, Assessing Competence to Consent to Treatment: A Guide for Physicians and Other Health Professionals (New York: Oxford University Press, 1998), p. 11. 
28. The analysis in this section has profited from discussions with Ruth R. Faden, Nancy M. P. King, and Dan Brock.

29. See the analysis of the core meaning in Charles M. Culver and Bernard Gert, Philosophy in Medicine (New York: Oxford University Press, 1982), pp. 123-26.

30. Pratt v. Davis, 118 Ill. App. 161 (1905), aff'd, 224 Ill. 300, 79 N.E. 562 (1906).

31. See Daniel Wikler, "Paternalism and the Mildly Retarded," Philosophy and Public Affairs 8 (1979): 377-92; and Kenneth F. Schaffner, "Competency: A Triaxial Concept," in Competency, ed. M. A.G. Cutter and E. E. Shelp (Dordrecht, Netherlands: Kluwer Academic, 1991), pp. 253-81.

32. This case was prepared by P. Browning Hoffman, M.D., for presentation in the series of "Medicine and Society" conferences at the University of Virginia.

33. Laura L. Sessums, Hanna Zembrzuska, and Jeffrey I. Jackson, "Does this Patient Have Medical Decision-Making Capacity?" JAMA: Journal of the American Medical Association 306 (July 27, 2011): 420. See also J. B. Jourdan and L. Glickman, "Reasons for Requests for Evaluation of Competency in a Municipal General Hospital," Psycomatics 32 (1991): 413-16.

34. This schema is indebted to Paul S. Appelbaum and Thomas Grisso, "Assessing Patients' Capacities to Consent to Treatment," New England Journal of Medicine 319 (December 22, 1988): 1635-38: and Jessica W. Berg, Paul S. Appelbaum, Charles W. Lidz, and Lisa S. Parker, Informed Consent: Legal Theory and Clinical Practice, 2nd ed. (New York: Oxford University Press, 2001).

35. For additional ways in which values are incorporated, see Loretta M. Kopelman, "On the Evaluative Nature of Competency and Capacity Judgments," International Journal of Law and Psychiatry 13 (1990): 309-29. For conceptual and epistemic problems in available tests, see E. Haavi Morreim, "Competence: At the Intersection of Law, Medicine, and Philosophy," in Competency, ed. Cutter and Shelp, pp. 93-125 esp. pp. $105-8$.

36. See Sander P. K. Welie, "Criteria for Patient Decision Making (In)competence: A Review of and Commentary on Some Empirical Approaches," Medicine, Health Care and Philosophy 4 (2001): 139-51; Jennifer Moye, Ronald J. Guerrera, Michele J. Karel, et al., "Empirical Advances in the Assessment of the Capacity to Consent to Medical Treatment: Clinical Implications and Medical Needs," Clinical Psychology Review 26 (2006): 1054-77; Laura B. Dunn, Milap A. Nowrangi, Barton W. Palmer, et al., "Assessing Decisional Capacity for Clinical Research or Treatment: A Review of Instruments," American Journal of Psychiatry 163 (2006): 1323-34: and Sessums, Zembrzuska, and Jackson, "Does this Patient Have Medical Decision-Making Capacity?" Various factors enter into the assessment of these instruments; for example, the last article listed stresses their suitability for use in an office visit, robust likelihood ratios, moderate to strong levels of evidence, and consistency with U.S. or Canadian law.

37. See Sessums, Zembzuska, and Jackson, "Does this Patient Have Medical Decision-Making Capacity?" which shows that physicians count as competent many persons who lack capacity but usually count as incompetent only those who lack capacity.

38. Grisso and Appelbaum, Assessing Competence to Consent to Treatment, p. 139.

39. See Willard Gaylin, "The Competence of Children: No Longer All or None," Hastings Center Report 12 (April 1982): 33-38, esp. 35; Allen Buchanan and Dan Brock, Deciding for Others (Cambridge:

Cambridge University Press, 1989), pp. 51-70; and Eric Kodish, "Children's Competence for Assent and Consent: A Review of Empirical Findings," Ethics \& Behavior 14 (2004): 255-95.

40. Buchanan and Brock, Deciding for Others, pp. 52-55. For elaboration and defense, see Brock, "Decisionmaking Competence and Risk," Bioethics 5 (1991): 105-12. 
41. Report and Recommendations of the National Bioethics Advisory Commission, Research Involving Persons with Mental Disorders That May Affect Decision Making Capacity, vol. I (Rockville, MD: National Bioethics Advisory Commission, December 1998), p. 58.

42. Onora O'Neill, Autonomy and Trust in Bioethics (Cambridge: Cambridge University Press, 2002); O'Neill, "Autonomy: The Emperor's New Clothes," Proceedings of the Aristotelian Society, supp. vol. 77 (2003): 1-21; O'Neill, "Some Limits of Informed Consent," Journal of Medical Ethics 29 (2003): 4-7; and Manson and O'Neill, Rethinking Informed Consent in Bioethics.

43. O'Neill, "Some Limits of Informed Consent," p. 5.

44. See Jay Katz, The Silent World of Doctor and Patient (New York: Free Press, 1984), pp. 86-87 [Reprint ed. (Baltimore, MD: The Johns Hopkins University Press, 2002)]; and President's Commission for the Study of Ethical Problems in Medicine and Biomedical and Behavioral Research, Making Health Care Decisions, vol. I (Washington, DC: U.S. Government Printing Office, 1982), p. 15.

45. For extensions of this thesis, see Simon Whitney, Amy McGuire, and Laurence McCullough, "A Typology of Shared Decision Making, Informed Consent, and Simple Consent," Annals of Internal Medicine 140 (2003): 54-59.

46. The analysis in this subsection is based in part on Faden and Beauchamp, A History and Theory of Informed Consent, chap. 8 .

47. Mohr v. Williams, 95 Minn. 261,265; 104 N.W. 12, 15 (1905).

48. Franklin G. Miller and Alan Wertheimer, "The Fair Transaction Model of Informed Consent: An Alternative to Autonomuus Authorization," Kennedy Institute of Ethics Journal 21 (2011): 201-18. At pp. 210-12 these authors recognize the importance of our second sense of "informed consent" and the qualifications it allows, but they seem not to appreciate the critical importance of maintaining the first sense as the primary model of an informed consent. See also their "Preface to a Theory of Consent Transactions: Beyond Valid Consent," in The Ethics of Consent, ed. Miller and Wertheimer, pp. 79-105.

49. See, for example, Alan Meisel and Loren Roth, "What We Do and Do Not Know about Informed Consent," JAMA: Journal of the American Medical Association 246 (1981): 2473-77; President's Commission, Making Health Care Decisions, vol. II, pp. 317-410, esp. p. 318, and vol. I, chap. I, esp. pp. 38-39; National Commission for the Protection of Human Subjects of Biomedical and Behavioral Research, The Belmont Report (Washington. DC: DHEW Publication OS 78-0012, 1978), p. 10.

50. A classic case is Planned Parenthood of Central Missouri v. Danforth, 428 U.S. 52 at 67 n.8 (1976) (U.S. Supreme Court).

51. Moore v. Regents of the University of California, 793 P.2d 479 (Cal. 1990) al 483.

52. See, for example, Clarence H. Braddock et al., "How Doctors and Patients Discuss Routine Clinical Decisions: Informed Decision Making in the Outpatient Setting," Journal of General Internal Medicine 12 (1997): 339-45; and John Briguglio et al., "Development of a Model Angiography Informed Consent Form Based on a Multiinstitutional Survey of Current Forms," Journal of Vascular and Interventional Radiology 6 (1995): 971-978.

53. The Oklahoma Supreme Court supported this standard in Scott v. Bradford, 606 P.2d 554 (Okla. 1979) at 559 and Masquat v. Maguire, 638 P.2d 1105, Okla. 1981.

54. Canterbury v. Spence. 464 F.2d 772 (1977), at 785-89: and see Nathan A. Bostick, Robert Sade, John W. McMahon, and Regina Benjamin, "Report of the American Medical Association Council on Ethical and Judicial Affairs: Withholding Information from Patients: Rethinking the Propriety of 'Therapeutic Privilege,"' Journal of Clinical Ethics 17 (Winter 2006): 302-6. For studies of levels of anxiety and stress 
produced by informed consent disclosures, see Jeffrey Goldberger el al., "Effect of Informed Consent on Anxiety in Patients Undergoing Diagnostic Electrophysiology Studies," American Heart Journal 134 (1997): 119-26; and Kenneth D. Hupper et al., "The Effect of Informed Consent on the Level of Anxiety in Patients Given IV Contrast Material," American Journal of Roentgenology 162 (1994): 531-35.

55. Thornburgh v. American College of Obstetricians, 476 U.S. 747 (1986) (White, J., dissenting).

56. Howard Brody, Placebos and the Philosophy of Medicine: Clinical, Conceptual, and Ethical Issues (Chicago: University of Chicago Press, 1980), pp. 10-11.

57. Ted J. Kaptchuk, Elizabeth Friedlander, John M. Kelley, et al, "Placebos without Deception: A Randomized Controlled Trial in Irritable Bowel Syndrome," PloS one 5 (2010), available at http://www.plosone.org/article/info:doi/10.1371/journal.pone.OO15591 (accessed October 11, 2011).

58. Jon C. Tilhurt, Ezekiel J. Emanuel, Ted J. Kaptchuk, el al., "Prescribing 'Placebo Treatments': Results of National Survey of US Internists and Rheumatologists," BMJ: British Medical Journal 337 (2008): a1938. Similar results have been reported in studies in other countries.

59. On the merit of these arguments, see Anne Barnhill, "What it Takes to Defend Deceptive Placebo Use," Kennedy Institute of Ethics Journal 21 (2011): 219-50.

60. For a similar proposal, see Armand Lione, "Ethics of Placebo Use in Clinical Care" (Correspondence), Lancet 362 (September 20, 2003): 999. For cases involving the different appeals to "consent," along with analysis and assessment, see P. Lichtenberg, U. Heresco-Levy, and U. Nitzan, "The Ethics of the Placebo in Clinical Practice," Journal of Medical Ethics 30 (2004): 551-54; "Case Vignette: Placebos and Informed Consent," Ethics and Behavior 8 (1998): 89-90, with commentaries by Jeffrey Blustein, Walter Robinson, and Gregory S. Loeben and Benjamin S. Wilfond; and Philip Levendusky and Loren Pankratz, "SelfControl Techniques as an Alternative to Pain Medication," Journal of Abnormal Psychology 84 (1975): $165-68$.

61. Nathan A. Bostick, Robert Sade, Mark A. Levine, and Dudley M. Steward. Jr., "Placebo Use in Clinical Practice: Report of the American Medical Association Council on Ethical and Judicial Affairs," Journal of Clinical Ethics 19, no. 1 (Spring 2008): 58-61. for a criticism of this policy, see both Bennett Foddy, "A Duty to Deceive: Placebos in Clinical Practice," American Journal of Bioethics 9, no. 12 (2009): 4-12 (and his response to commentaries in the same issue, Wl-2); and Adam Kolber, "A Limited Defense of Clinical Placebo Deception," Yale Law \& Policy Review 26 (2007-08): 75-134. For a defense of the American Medical Association policy, see Kavita R. Shah and Susan Door Goold, "The Primacy of Autonomy, Honest, and Disclosure-Council on Ethical and Judicial Affairs' Placebo Opinions," American Journal of Bioethics 9, no. 12 (2009): 15-17; and for an analysis of the science and ethics of placebo treatment, see Franklin G. Miller and Luana Colloca, "The Legitimacy of Placebo Treatments in Clinical Practice: Evidence and Ethics," American Journal of Bioethics 9, no. 12 (2009): 39-47.

62. Kaptchuk, Friedlander, Kelley, et al., "Placebos without Deception"; Brody, Placebos and the Philosophy of Medicine, pp. 110, 113, et passim; Brody, "The Placebo Response: Recent Research and Implications for Family Medicine," Journal of Family Practice 49 (July 2000): 649-54. For a broader defense of placebos, see Howard Spiro, Doctors, Patients, and Placebos (New Haven, CT: Yale University Press, 1986).

63. See Fabrizio Benedetti, "Mechanisms of Placebo and Placebo-Related Effects across Diseases and Treatments," Annual Review of Pharmocology and Toxicology 48 (2008): 33-60, more fully developed in his Placebo Effects: Understanding the Mechanisms of Health and Disease (New York: Oxford University Press, 2009). Benedetti focuses on the "psychosocial-induced biochemical changes in a person's brain and body."

64. See Yael Schenker, Alicia Fernandez, and Bernard Lo, "Placebo Prescriptions Are Missed Opportunities for Doctor-Patient Communication," and Howard Brody, "Medicine“s Continuing Quest for 
an Excuse to Avoid Relationships with Patients," both in American Journal of Bioethics 9, no. 12 (2009): 48-54 and 13-15, respectively.

65. Sally E. McNagy and Ruth M. Parker, "High Prevalence of Recent Cocaine Use and the Unreliability of Patient Self-Report in an Inner-City Walk-in Clinic," JAMA: Journal of the American Medical Association 267 (February 26, 1992): 1106-8.

66. Sisscela Bok, "Informed Consent in Tests of Patient Reliability," JAMA: Journal of the American Medical Association 267 (February 26, 1992): 1118-19.

67. Barbara A. Bernhardt et al., "Educating Patients about Cystic Fibrosis Carrier Screening in a Primary Care Setting," Archives of Family Medicine 5 (1996): 336-40.

68. Steven Joffe et al., "Quality of Informed Consent in Cancer Clinical Trials: A Cross-Sectional Survey," Lancet 358 (November 24, 2001): 1772-77.

69. Bang v. Charles T. Miller Hospital, 251 Minn. 427, 88 N.W. 2d 186 (1958).

70. Sec also Gopal Sreenivasan, "Does Informed Consent to Research Require Comprehension?" Lancet 362 (December 13, 2003): 2016-18.

71. C. K. Dougherty et al., "Perceptions of Cancer Patients and their Physicians Involved in Phase I Clinical Trials," Journal of Clinical Oncology 13 (1995): 1062-72; Paul R. Benson et al., "Information Disclosure, Subject Understanding, and Informed Consent in Psychiatric Research," Law and Human Behavior 12 (1988): 455-75.

72. See further Edmund G. Howe, "Approaches (and Possible Contraindications) to Enhancing Patients" Autonomy," Journal of Clinical Ethics 5 (1994): 179-88.

73. See Michael B. Rothberg, Senthil K. Sivalingam, Javed Ashraf, et al., "Patients' and Cardiologists Perceptions of the Benefits of Percutaneous Coronary Intervention for Stable Coronary Disease," Annals of Internal Medicine 153 (2010): 307-13. See also the commentary by Alicia Fernandez, "Improving the Quality of Informed Consent: it Is Not All about the Risks," Annals of Internal Medicine 153 (2010): 34243.

74. Yael Schenker, Alica Fernandez, Rebecca Sudore, and Dean Schillinger, "Intervention to Improve Patient Comprehension in Informed Consent for Medical and Surgical Procedures: A Systematic Review." Medical Decision Making 31 (2011): 151-73.

75. This label was apparently coined by Paul S. Appelbaum, Loren Roth, and Charles W. Lidz in "The Therapeutic Misconception: Informed Consent in Psychiatric Research," International Journal of Law and Psychiatry 5 (1982):319-29. See also Applebaum, Lidz, and Thomas Grisso, "Therapeutic Misconception in Clinical Research: Frequency and Risk Factors," IRB: Ethics and Human Research 26 (2004): 1-8; Walter Glannon, "Phase I Oncology Trials: Why the Therapeutic Misconception Will Not Go Away," Journal of Medical Ethics 32 (2006): 252-55; Appelbaum and Lidz, "The Therapeutic Misconception," in The Oxford Textbook of Clinical Research Ethics, ed. Ezekiel Emanuel, Christine Grady, Robert Crouch, et al (New York: Oxford University Press, 2008); and Franklin G. Miller, "Consent to Clinical Research," in The Ethics of Consent: Theory and Practice, ed. Miller and Wertheimer, chap. 15.

76. A broader problem and one more difficult to address is that the frame of discourse in interactions between researchers and potential subjects may not incorporate the therapeutic misconception. See Philip J. Candilis and Charles W. Lidz, "Advances in Informed Consent Research." in The Ethics of Consent, ed. Miller and Wertheimer, p. 334; David E. Ness, Scott Kiesling, and Charles W. Lidz, "Why Does lnformed Consent Fail? A Discourse Analytic Approach," Journal of the American Academy of Psychiatry and the Law 37, no. 3 (2009): 349-62. 
77. Sam Horng and Christine Grady, "Misunderstanding in Clinical Research: Distinguishing Therapeutic Misconception, Therapeutic Misestimation, \& Therapeutic Optimism," IRB: Ethics and Human Research 25 (January-February 2003): 11-16.

78. The pioneering work was done by Amos Tversky and Daniel Kahneman. See "Choices, Values and Frames," American Psychologist 39 (1984): 341-50; and "The Framing of Decisions and the Psychology of Choice," Science 211 (1981): 453-58. See also Daniel Kahneman and Amos Tversky, eds., Choices, Values, and Frames (Cambridge: Cambridge University Press, 2000). On informed consent specifically, see Dennis J. Mazur and Jon F. Merz, "How Age, Outcome Severity, and Scale Influence General Medicine Clinic Patients' Interpretations of Verbal Probability Terms," Journal of General Internal Medicine 9 (1994): 268-71.

79. S. E. Erikar and H. C. Sox. "Assessment of Patients' Preferences for Therapeutic Outcome," Medical Decision Making 1 (1981): 29-39; Barbara McNeil et al., "On the Elicitation of Preferences for Alternative Therapies," New England Journal of Medicine 306 (May 27, 1982): 1259-62.

80. See A. M. O'Connor, C. L. Bennett, D. Stacey, et al., "Decision Aids for People Facing Health Treatment or Screening Decisions," Cochrane Database of Systematic Reviews, no. 3 (2009), Art. No. CD001431.

81. Sian K. Smith, Lyndal Trevena, Judy M. Simpson, el al., "A Decision Aid to Support Informed Choices about Bowel Cancer Screening among Adults with Low Education: Randomised Controlled Trial," BMJ: British Medical Journal 341 (2010): c5370. By contrast with this Australian study, a study in Germany found that evidence-based risk information on colorectal cancer screening (along with two optional Internet modules on risk and diagnostic tests) did not affect planned and actual uptake of screening even though it, too, increased informed choices and improved knowledge. See Anke Steckelberg, Christian Hulfenhaus, Burkhard Haastert, and Ingrid Muhlhauser, "Effect of Evidence Based Risk Information on 'Informed Choice' in Colorectal Cancer Screening: Randomised Controlled Trial," BMJ: British Medical Journal 342 (2011): d3193. The authors conclude that those "designing and implementing screening programmes should respect the ethical right of consumers for evidence based information and informed choices."

82. Hilary L. Bekker, "Decision Aids and Uptake of Screening," BMJ: British Medical Journal 341 (2010), c5407.

83. For criticisms of the editorial by Bekker, see C. B. Dalton, "Decision Aids and Screening. Editorial Was Amoral," BMJ: British Medical Journal 341 (2010): c6648; and Ben Hudson, "Decision Aids and Screening. Information v Promotion," BMJ: British Medical Journal 341 (2010): c6650.

84. Ruth Faden and Alan Faden, "False Belief and the Refusal of Medical Treatment," Journal of Medical Ethics 3 (1977): 133-36.

85. Neil Manson and Onora O'Neill interpret all consent as a waiver of rights. Although this interpretation is not incorrect, it is often more illuminating to describe informed consent as an exercise of rights rather than a waiver of rights. See Manson and O'Neill, Rethinking Informed Consent in Bioethics, esp. pp. 72-77, $187-89$.

86. Cobbs v. Grant, 502 P.2d 1, 12 (1972).

87. Baruch Brody, Life and Death Decision Making (New York: Oxford University Press, 1988), p. 22.

88. The Nuremberg Code, in Trials of War Criminals Before the Nuremberg Military Tribunals under Control Council Law no. 10. (Washington, DC: U.S. Government Printing Office, 1949).

89. See Joel Feinberg, Social Philosophy (Englewood Cliffs, NJ: Prentice Hall, 1973), p. 48; Harm to Self, pp. 112-18. For a notably different view of the concept of voluntariness and its connection to consent--one heavily influenced by law--see Paul S. Appelbaum, Charles W. Lidz, and Robert Klitzman, "Voluntariness 
of Consent to Research: A Conceptual Model," Hastings Center Report 39 (January-February 2009): 30-39, esp. 30-31, 33; and a criticism of Appelbaum, Lidz, and Klitzman in Robert M. Nelson, Tom Beauchamp, Victoria A. Miller, et al. "The Concept of Voluntary Consent," American Journal of Bioethics 11 (2011): 616, esp. 12-13.

90. Our formulation is indebted to Robert Nozick, "Coercion," in Philosophy, Science and Method: Essays in Honor of Ernest Nagel, ed. Sidney Morgenbesser, Patrick Suppes, and Morton White (New York: St. Martin's, 1969), pp. 440-72; and Bernard Gert, "Coercion and Freedom," in Coercion: Nomos XIV, ed. J. Roland Pennock and John W. Chapman (Chicago: Aldine, Atherton, 1972), pp. 36-37. See also Alan Wertheimer, Coercion (Princeton, NJ: Princeton University Press, 1987).

91. Cf. Jennifer S. Hawkins and Ezekiel J. Emanuel, "Clarifying Confusions about Coercion," Hastings Center Report 35 (September-October 2005): 16-19.

92. See James H. Jones, Bad Blood, rev. ed. (New York: Free Press, 1993); David J. Rothman, "Were Tuskegee \& Willowbrook 'Studies in Nature'?" Hastings Center Report 12 (April 1982): 5-7; Susan M. Reverby, ed., Tuskegee's Truths: Rethinking the Tuskegee Syphilis Study (Chapel Hill, NC: University of North Carolina Press, 2000); Reverby, Examining Tuskegee: The Infamous Syphilis Study and its Legacy (Chapel Hill, NC: University of North Carolina Press, 2009); and Ralph V. Katz and Rueben Warren, eds., The Search for the Legacy of the USPHS Syphilis Study at Tuskegee: Reflective Essays Based Upon Findings from the Tuskegee Legacy Project (Lanham, MD: Lexington Books, 2011).

93. See Sarah E. Hewlett, "ls Consent to Participate in Research Voluntary," Arthritis Core and Research 9 (1996): 400-4; Virginia Miller et al., "Challenges in Measuring a New Construct: Perception of Voluntariness for Research and Treatment Decision Making," Journal of Empirical Research on Human Research Ethics 4 (2009): 21-31; and Nancy E. Kass et al., "Trust: The Fragile Foundation of Contemporary Biomedical Research," Hastings Center Report 25 (September-October 1996): 25-29.

94. See Charles W. Lidz et al., Informed Consent: A Study of Decision Making in Psychiatry (New York: Guilford, 1984), chap. 7, esp. pp. 110-11, 117-23.

95. Although the U.S. federal regulations for research involving human subjects require additional "safeguards" to protect groups-prisoners, children, pregnant women, mentally disabled persons, and persons who are economically or educationally disadvantaged--all of whom are deemed "likely to be vulnerable to coercion or undue influence," the key concepts are inadequately analyzed and the list of groups is controversial. For examinations of possible types of vulnerability in research involving human subjects, see Kenneth Kipnis, "Vulnerability in Research Subjects: A Bioethical Taxonomy," in National Bioethics Advisory Commission, Ethical and Policy Issues in Research Involving Human Participants, vol. 2 (Bethesda, MD: National Bioethics Advisory Commission, 2001): G1-13; and James DuBois, "Vulnerability in Research," in Institutional Review Board: Management and Function, 2nd ed., ed. Robert Amdur and Elizabeth Bankert (Boston: Jones \& Bartlett, 2005), pp, 337-40.

96. For the distinction between decisional autonomy and executional autonomy, see Bart J. Collopy, "Autonomy in Long Term Care," Gerontologist 28, Supplementary Issue (June 1988): 10-17. On failures to appreciate both capacity and incapacity, see C. Dennis Barton et al., "Clinicians' Judgement of Capacity of Nursing Home Patients to Give Informed Consent," Psychiatric Services 47 (1996): 956-60; and Meghan B. Gerety et al., "Medical Treatment Preferences of Nursing Home Residents," Journal of the American Geriatrics Society 41 (1993): 953-60. 
VITA

David Elliott was born in Maryville, Tennessee, but spent most of his boyhood in Murray, Kentucky, where he graduated from Murray High School in 1975. He graduated from Murray State University in 1991 with a Bachelor of Arts in Business with a double area in accounting and computer information systems. He continued at Murray State for his M.B.A. and graduated in 1993.

He then spent a year as a doctoral student in accounting at the University of Memphis, but he withdrew from the program to be near his children while recovering from a divorce. While at Memphis, he took his first two courses in sociology and fell in love. He decided that once he could manage to return to grad school, it would be in sociology. A year after arriving at the University of Missouri, he gained physical custody of his children and continued his graduate studies as a single parent. Mr. Elliott came to Missouri to study with symbolic interactionist Peter M. Hall. Eventually, he found that his interest in pragmatism and symbolic interactionism fit very well with the social network approach to relational sociology. 